CAROLINE ANTUNES LINO

\title{
O SISTEMA UBIQUITINA-PROTEASSOMA \\ NO MODELO DE HIPERTROFIA CARDÍACA INDUZIDA POR \\ HORMÔNIO TIREOIDIANO
}

\begin{abstract}
Dissertação apresentada ao Programa de PósGraduação em Ciências Morfofuncionais do Instituto de Ciências Biomédicas da Universidade de São Paulo, para a obtenção do Título de Mestre em Ciências.
\end{abstract}


CAROLINE ANTUNES LINO

\title{
O SISTEMA UBIQUITINA-PROTEASSOMA \\ NO MODELO DE HIPERTROFIA CARDÍACA INDUZIDA \\ POR HORMÔNIO TIREOIDIANO
}

\begin{abstract}
Dissertação apresentada ao Programa de PósGraduação em Ciências Morfofuncionais do Instituto de Ciências Biomédicas da Universidade de São Paulo, para a obtenção do Título de Mestre em Ciências.

Área de concentração: Ciências Morfofuncionais

Orientadora: Profa. Dra. Maria Luiza Morais Barreto de Chaves

Versão original
\end{abstract}




\section{DADOS DE CATALOGAÇÃO NA PUBLICAÇÃO (CIP)}

Serviço de Biblioteca e Informação Biomédica do Instituto de Ciências Biomédicas da Universidade de São Paulo

reprodução não autorizada pelo autor

Lino, Caroline Antunes.

O sistema ubiquitina-proteassoma no modelo de hipertrofia cardíaca induzida por hormônio tireoidiano / Caroline Antunes Lino. -- São Paulo, 2013.

Orientador: Profa. Dra. Maria Luiza Morais Barreto de Chaves.

Dissertação (Mestrado) - Universidade de São Paulo. Instituto de Ciências Biomédicas. Departamento de Anatomia. Área de concentração: Ciências Morfofuncionais. Linha de pesquisa: Ação endócrina na fisiologia cardiovascular.

Versão do título para o inglês: The ubiquitin proteasome system in thyroid hormone-induced cardiac hypertrophy model.

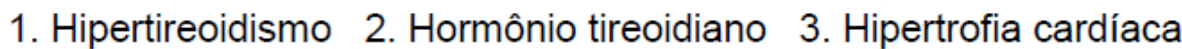
4. Proteólise 5. Sistema ubiquitina proteassoma I. Chaves, Profa. Dra. Maria Luiza Morais Barreto de II. Universidade de São Paulo. Instituto de Ciências Biomédicas. Programa de Pós-Graduação em Ciências Morfofuncionais III. Título. 
Candidato(a):

Título da Dissertação:

Orientador(a):
Caroline Antunes Lino.

O sistema ubiquitina-proteassoma no modelo de hipertrofia cardíaca induzida por hormônio tireoidiano.

A Comissão Julgadora dos trabalhos de Defesa da Dissertação de Mestrado, em sessão pública realizada a considerou
( ) Aprovado(a)
( ) Reprovado(a)

\section{Examinador(a): Assinatura: Nome: \\ Instituição: \\ Examinador(a): Assinatura: \\ Nome: \\ Instituição: \\ Presidente: Assinatura: \\ Nome: \\ Instituição:}




\section{Certificado}

Certificamos que o protocolo registrado sob $n^{0} 053$ nas fls. 103 do livro 02 para uso de animais em experimentaçà, sob a responsabilidade do Profia) Dr(a)) Maria Luiza Morais Barreto de Chaves, Coordenadorlal da Linha de pesquisa ${ }^{\circ} \mathrm{O}$ sistema ubiquitina-proteassoma no modelo de hiperfrofia cardiaca induzida por hombonio tiroideano" do qual participam o(s) alunos Caroline Antunes Lino, está de acordo com os Princípios Éticos de Experimentaçào Animal adotado pela Sociedade Brasileira de Ciencia de Animais de Laboratório (SBCAL) e foi aprowado pela COMISSÄO DE ETICA NO USO DE ANIMAIS (CEUA) em 17,05.2011, com validade de 3 anos.

Sào Paulo, 23 de maio de 2011.

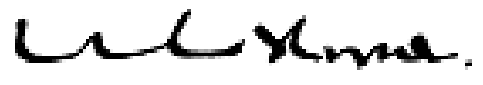

Prof.Dr.Wothan Tavares de Lise Coordenador CEUA - ICB/USP

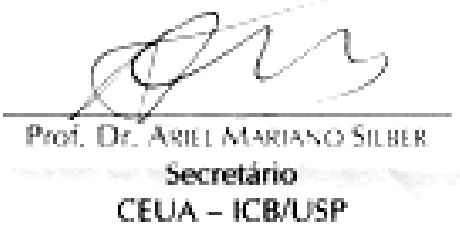


À minha família. Por tudo. 


\section{AGRADECIMENTOS}

À minha orientadora querida, Maria Luiza M.B. de Chaves. Obrigada por acreditar no meu trabalho. Parte do que somos hoje, professora, deve ser creditado a você. Registro meu respeito e admiração pela profissional que é. O convívio do dia-a-dia nos esclarece que nós é que fazemos a nossa própria sorte.

Aos meus queridos amigos, equipe do Laboratório de Biologia Celular e Anatomia Funcional (LBACF). Obrigada por terem contribuído para a realização de mais um trabalho. Obrigada por se empenharem em compreender comigo o Sistema Ubiquitina Proteassoma. A exemplo do nosso querido amigo Felix agradeço, em destaque, cada um dos que fazem ou fizeram parte dessa equipe. Ao Ivson. Especial. De Deus. Não tenho palavras para expressar a imensidão que você ocupa. À Cristina Ribas Fürstenau. Obrigada por discutir ciência comigo. À Ana Paula Takano. Seu trabalho é admirável. À Ana Paula Taniguti. Pela simplicidade da sua pessoa. À Maria Brito. Pelo sorriso de todas as manhãs. Obrigada pelo carinho incondicional dispensado a mim. Você é rara. À Ana Cláudia Barbosa, guerreira. O reconhecimento do nosso trabalho é dado por Deus, minha querida. E isso nos basta. À Nathália Senger, recém-chegada. Ao Luiz Bozi, nosso querido agregado. À Mary. Obrigada pelos cafezinhos e, é claro, pelos momentos de descontração. À Gabriela Placoná Diniz, Dayane Gomes, Caroline Emy Rodrigues Shibata, Priscilla Monteiro, Felix Meira Tavares e Vanessa Lima, que deixaram saudade.

À Dra. Marilene Demasi, colaboradora deste projeto. Obrigada pelas ricas discussões.

Aos técnicos Marina Fevereiro (LBCAF) e Adrian (Instituto Butantan), pela dedicação.

Aos Professores Maria Teresa Nunes, Anselmo Moriscot e Julio Batista Ferreira pela participação no meu exame de qualificação e pelas valiosas sugestões.

Ao Ismael Neto, meu amigo e amor. 
Aos funcionários, professores e alunos de pós-graduação do Departamento de Anatomia/ICB/USP. Aos funcionários da biblioteca do ICB, que contribuíram com as diretrizes para a normalização técnica.

Às instituições de fomento, CAPES, CNPq, e especialmente à FAPESP, que concederam auxílio financeiro para a realização deste projeto e de outros desenvolvidos em nosso laboratório.

A todos aqueles cujos nomes não foram citados, mas que direta ou indiretamente colaboraram para realização deste trabalho. 
"O importante é não parar de questionar." 


\section{RESUMO}

LINO, C. A. O Sistema Ubiquitina Proteassoma na hipertrofia cardíaca induzida por hormônio tireoidiano. 2013. 82 f. Dissertação (Mestrado em Ciências Morfofuncionais) Instituto de Ciências Biomédicas, Universidade de São Paulo, São Paulo, 2013.

Disfunções da glândula tireóide são, frequentemente, associadas a manifestações cardiovasculares e, em situações de hipertireoidismo, o coração hipertrofia. A hipertrofia cardíaca $(\mathrm{HC})$ consiste em uma resposta adaptativa caracterizada pelo aumento de síntese de proteínas estruturais. O Sistema Ubiquitina Proteassoma (UPS) corresponde ao principal mecanismo de proteólise intracelular e crescentes evidências sugerem seu envolvimento no desenvolvimento da HC. O objetivo do presente estudo foi avaliar a modulação do UPS no tecido cardíaco de animais submetidos ao hipertireoidismo. Os resultados referentes ao aumento da atividade e expressão do proteassoma (PT) cardíaco apresenta-se mais contundente no grupo tratado por 7 dias, período em que a HC já encontra-se estável. Ao término de 14 e 21 dias, a modulação desse sistema tende à normalização. Os resultados obtidos atestam evidências da literatura que sugerem o aumento da atividade do PT cardíaco como resposta compensatória ao aumento de síntese proteica.

Palavras-chave: Hipertireoidismo. Hormônio Tireoidiano. Hipertrofia Cardíaca. Proteólise. Sistema Ubiquitina Proteassoma. 


\begin{abstract}
LINO, C. A. The Ubiquitin Proteasome System in cardiac hypertrophy induced by hormone tireodiano. 2013. 82 p. Masters thesis (Morphological Sciences) - Instituto de Ciências Biomédicas, Universidade de São Paulo, São Paulo, 2013.

Thyroid gland disorders are often associated with cardiovascular events and hyperthyroidism state promotes cardiac hypertrophy $(\mathrm{CH})$. $\mathrm{CH}$ consists in adaptive response characterized by increased synthesis of structural proteins. The Ubiquitin Proteasome System (UPS) is the major mechanism of intracellular proteolysis and increased evidences suggest its involvement in the development of $\mathrm{CH}$. The aim of this study was to evaluate the modulation of UPS in cardiac tissue of animals subjected to hyperthyroidism. The results related to the increased proteasome (PT) activity and expression in the heart was more accentuated in the group treated for 7 days, when the $\mathrm{CH}$ process finds stable. At the end of 14 and 21 days of hyperthyroidism, the modulation of cardiac UPS achieves standard values. These results suggest an increased activity of cardiac PT as a compensatory response to protein synthesis induced by thyroid hormones.
\end{abstract}

Keywords: Hyperthyroidism. Thyroid hormone. Cardiac Hypertrophy. Proteolysis. Ubiquitin Proteasome System. 


\section{LISTA DE FIGURAS}

Figura 1 - Representação esquemática da poliubiquitinação de substratos proteicos

Figura 2 - $\quad$ Representação esquemática da estrutura do proteassoma..................... 24

Figura 3 - Representação esquemática da degradação proteica mediada pelo Sistema Ubiquitina Proteassoma......

Figura 4 - $\quad$ Representação esquemática do modelo experimental de indução ao hipertireoidismo

Figura 5 - Representação esquemática da constituição dos grupos experimentais

Figura 6 - Análise da massa corporal dos animais durante tratamento

Figura 7 - $\quad$ Análise da massa corporal dos animais ao término do tratamento

Figura 8 - $\quad$ Análise dos parâmetros hemodinâmicos ao término do tratamento......

Figura 9 - $\quad$ Análise do trofismo cardíaco ao término do tratamento.

Figura 10 - Análise dos níveis de mRNA que codificam marcadores moleculares de hipertrofia cardíaca.

Figura 11 - Análise dos níveis de mRNA que codificam as subunidades catalíticas constitutivas do PT 20S.

Figura 12 - Análise dos níveis de mRNA que codificam as subunidades catalíticas constitutivas do PT 20S

Figura 13 - Análise dos níveis de mRNA que codificam POMP 53

Figura 14 - Análise da atividade do tipo quimiotripsina do proteassoma. 54

Figura 15 - Expressão de proteínas poliubiquitinadas. 56 58

Figura 17 - $\quad$ Análise dos níveis de mRNA que codificam MuRF1............................... 59

Figura 18 - Expressão proteica de MuRF1 ............................................................ 60

Figura 19 - Análise dos níveis de mRNA que codificam Atrogin/MAFbx................... 61

Figura 20 - Expressão proteica de Atrogin/MAFbx................................................. 62

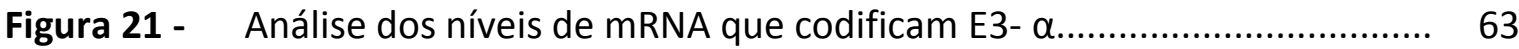




\section{LISTA DE TABELAS}

Tabela 1 - Relação de anticorpos utilizados nos ensaios de Western Blotting........... 36

Tabela 2 - Sequência dos primers utilizados nos ensaios de PCR em tempo real....... 37

Tabela 3 - $\quad$ Níveis séricos de T3 e T4 Total, dosados por RIE....................................... 40 


$\begin{array}{ll}\text { 19SRP } & \text { Partícula regulatória 19S } \\ \text { ATP } & \text { Adenosine Triphosphate } \\ \text { CQP } & \text { Controle de Qualidade de Proteínas } \\ \text { E1 } & \text { Enzima Ativadora de Ubiquitina } \\ \text { E2 } & \text { Enzima Conjugadora de Ubiquitina } \\ \text { E3 } & \text { Enzima Ubiquitina-Ligase } \\ \text { HC } & \text { Hipertrofia Cardíaca } \\ \text { HT } & \text { Hormônios Tireoidianos } \\ \text { PCR } & \text { Polymerase Chain Reaction } \\ \text { PT20S } & \text { Proteassoma 20S (partícula catalítica) } \\ \text { PT26S } & \text { Proteassoma 26S (partícula catalítica + partícula regulatória) } \\ \text { Rpn } & \text { Proteasome Regulatory Particle Non-ATPase-like family member } \\ \text { Rpt } & \text { Proteasome Regulatory Particle ATPase-like family member } \\ \text { T3 } & \text { Triiodotironina } \\ \text { T4 } & \text { Tiroxina } \\ \text { TR } & \text { Thyroid Receptor } \\ \text { TRE } & \text { Thyroid Receptor Elements } \\ \text { TRH } & \text { Thyroid Releasing Hormone } \\ \text { TSH } & \text { Thyroid Stimulating Hormone } \\ \text { Ub } & \text { Ubiquitina } \\ \text { UBP } & \text { Ubiquitin-specific processing proteases } \\ \text { UPS } & \text { Ubiquitin Proteasome System } \\ \text { WB } & \text { Western Blotting } \\ \text { RT } & \text { Reve Transcriptase } \\ & \end{array}$




\section{LISTA DE SÍMBOLOS}

Bases nitrogenadas dos nucleotídeos

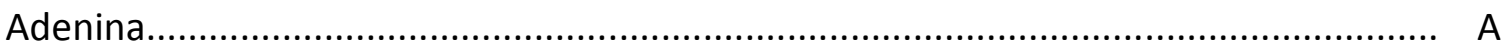

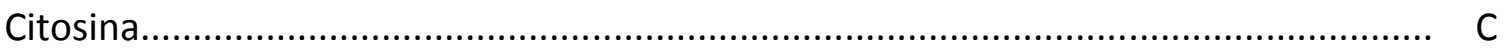

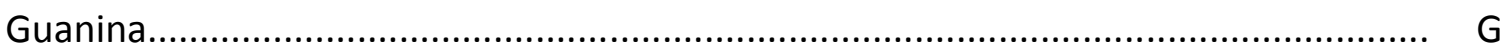

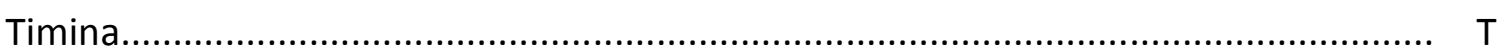

\section{Aminoácidos}

Lisina

\section{Símbolos}

Alfa

Beta

Gama. 


\section{SUMÁRIO}

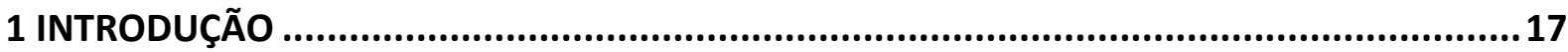

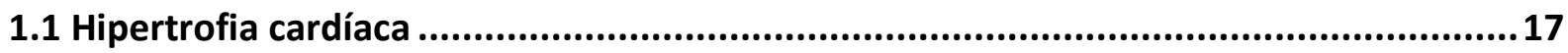

1.2 Hormônios tireoidianos e hipertrofia cardíaca...................................................................19

1.3 Sistema Ubiquitina Proteassoma..................................................................................22

1.4 Sistema Ubiquitina Proteassoma e hipertrofia cardíaca ................................................27

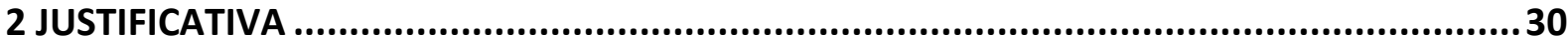

3 OBJETIVOS.........................................................................................................

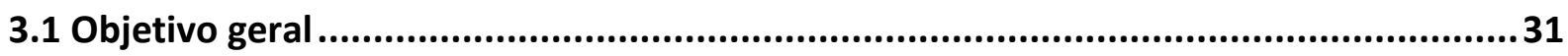

3.2 Objetivos específicos ..............................................................................................31

3.2.1 Modulação do proteassoma cardíaco no miocárdio de animais submetidos ao

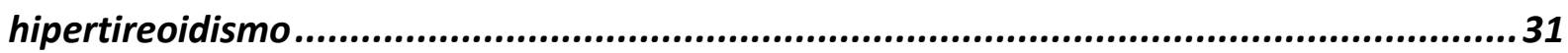

3.2.2 Modulação de E3-ligases no miocárdio de animais submetidos ao hipertireoidismo. 31

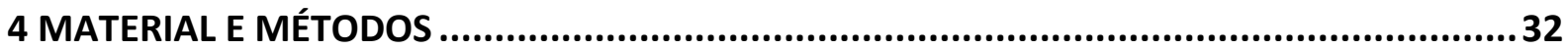

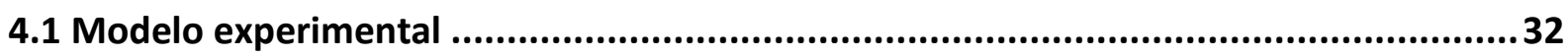

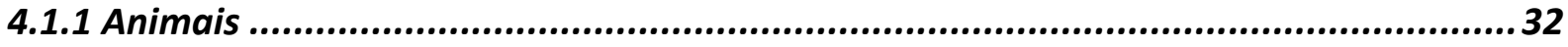

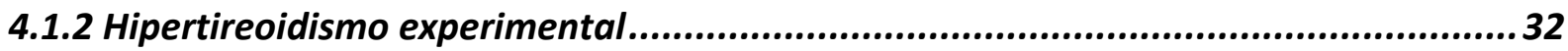

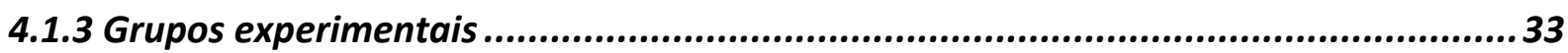

4.2 Dosagem dos níveis séricos de hormônios tireoidianos ..................................................34

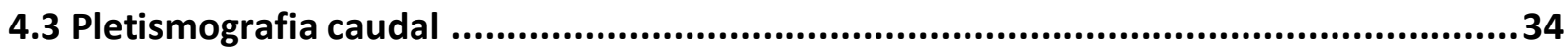

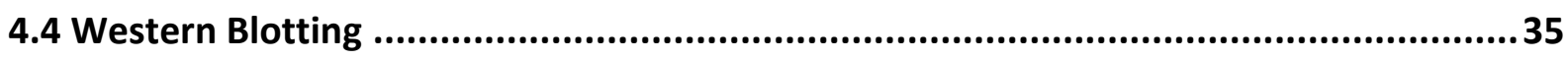

4.5 RT-PCR em tempo real ..............................................................................................36

4.5.1 Extração de RNA total e reação de transcrição reversa ..............................................36

4.5.2 Reação de RT-PCR em tempo real.............................................................................

4.6 Ensaio de atividade do PT20S tipo quimiotripsina ..........................................................38

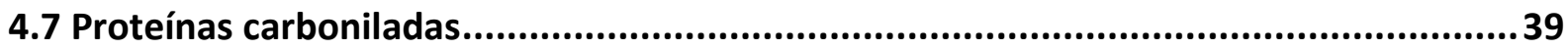

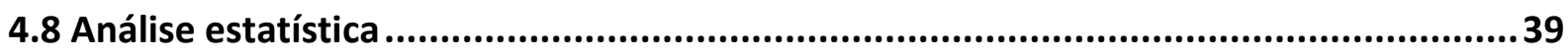

5 RESULTADOS ................................................................................................................. 40

5.1 Caracterização do modelo experimental .................................................................40

5.1.1 Dosagens dos niveis séricos de T3 e T4 Total por RIE ...............................................40

5.1.2 Efeitos do hipertireoidismo sobre a massa corporal .................................................. 41 
5.1.3 Efeitos do hipertireoidismo sobre a modulação de parâmetros hemodinâmicos 42

5.1.4 Efeitos do hipertireoidismo sobre a modulação do trofismo cardíaco.

5.1.5 Efeitos do hipertireoidismo sobre a modulação da expressão de genes marcadores de hipertrofia cardiaca. 46

5.2 Efeitos do hipertireoidismo sobre o proteassoma cardíaco. 48

5.2.1 Análise da expressão gênica das subunidades catalíticas do PT20S 48

5.2.2 Análise da expressão gênica das subunidades da partícula regulatória 195 50

5.2.3 Análise da expressão de POMP no tecido cardíaco 52

5.2.4 Atividade do PT20S e PT26S no tecido cardíaco 53

5.2.5 Efeitos do hipertireoidismo sobre a expressão de proteínas poliubiquitinadas no tecido cardíaco. 55

5.2.6 Efeitos do hipertireoidismo sobre o estado oxidativo do tecido cardíaco - proteínas carboniladas. 57

5.3 Efeitos do hipertireoidismo sobre a expressão de E3 ligases no tecido cardíaco 59

5.3.1 Efeitos do hipertireoidismo sobre a expressão de MuRF1 no tecido cardíaco. 59

5.3.2 Efeitos do hipertireoidismo sobre a expressão de Atrogin/MAFbx no tecido cardíaco 61

5.3.3 Efeitos do hipertireoidismo sobre a expressão de E3- $\alpha /$ UBR1 no tecido cardíaco...... 63

6 DISCUSSÃO. 64

6.1 Modelo de hipertrofia cardíaca promovida pelo hormônio tireoidiano. 64

6.2 Efeitos do hormônio tireoidiano sobre modulação do proteassoma cardíaco. 67

6.3 Efeitos do hormônio tireoidiano sobre a expressão de E3-ligases no tecido cardíaco ..69

7 CONCLUSÃO 73

REFERÊNCIAS 74 


\section{INTRODUÇÃO}

\subsection{Hipertrofia cardíaca}

O coração é constantemente submetido a uma variedade de estímulos capazes de alterar a homeostasia tecidual. Dependendo da intensidade e duração, esses estímulos podem promover modificações estruturais e funcionais ao miocárdio. Neste sentido, a hipertrofia cardíaca (HC) consiste num dos principais mecanismos de adaptação do coração à sobrecarga de trabalho. Trata-se de um mecanismo desenvolvido no sentido de compensar o aumento da demanda metabólica através do aumento da massa que, temporariamente, proporciona o aumento da força de ejeção do coração (SUGDEN; CLERK, 1998). A HC corresponde ao principal fator que contribui para a disfunção diastólica e insuficiência cardíaca congestiva sintomática em humanos e, assim, consiste em importante indicador do prognóstico e mortalidade cardiovascular (VAKILI; OKIN; DEVEREUX, 2001).

As células musculares cardíacas representam cerca de $80 \%$ do volume celular total presente no miocárdio, sendo o restante representado na maioria por fibroblastos e algumas células endoteliais e musculares lisas. Essas células, devido ao seu extremo grau de diferenciação, são consideradas pós-mitóticas, tendo desenvolvido a regulação do tamanho celular como principal mecanismo de citoproteção (HEDHLI; PELAT; DEPRE, 2005; POPESCU, 2006; SUGDEN; CLERK, 1998). Em nível celular, a HC corresponde ao aumento do volume dos cardiomiócitos, associado ao aumento e reorganização das proteínas contráteis, pertencentes à unidade sarcomérica, modulação de fontes de energia celular e alteração no padrão de expressão gênico e proteico (LI et al., 2007; SUGDEN; CLERK, 1998). Os mecanismos moleculares envolvidos com o desenvolvimento da HC não são completamente esclarecidos, no entanto, sabe-se que tanto fatores mecânicos (sobrecarga de pressão e volume) quanto neuro-humorais (catecolaminas, peptídeos vasoativos e outros hormônios) são capazes de deflagrar vias de sinalização, as quais promovem o aumento de síntese proteica pelos miócitos cardíacos (BOHELER; SCHWARTZ, 1992; MORGAN; BAKER, 1991; WEBER; BRILLA, 1991).

Estímulos hipertróficos de diferentes etiologias resultam em fenótipos hipertróficos distintos, que apresentam diferenças estruturais, funcionais, metabólicas e moleculares. Morfologicamente, a HC pode ser classificada em concêntrica ou excêntrica. A HC 
concêntrica, geralmente associada à sobrecarga de pressão, caracteriza-se pelo aumento da espessura da parede ventricular em detrimento da câmara ventricular. Esse aumento resulta da deposição dos sarcômeros em paralelo, o que contribui para o aumento da área de secção transversa dos cardiomiócitos. A HC excêntrica, por outro lado, é geralmente associada à sobrecarga de volume e caracteriza-se pela diminuição da espessura da parede e dilatação da câmara ventricular. Os sarcômeros são depositados em série e promovem o aumento dos cardiomiócitos em comprimento (MILL; VASSALO, 2001; RUSSEL; MOTLAGH; ASHLEY, 2000; SPONITZ; SONNENBLICK, 1973).

Ainda que controverso na literatura, a HC tem sido classificada em fisiológica ou patológica, o que depende da natureza do estímulo hipertrófico (BERNARDO et al., 2010; DORN, 2007). O crescimento fisiológico do coração, caracterizado pela conservação das proporções da morfologia cardíaca normal e, ainda, manutenção ou aumento da função contrátil do coração, pode ser observado, por exemplo, em gestantes e em atletas, decorrente do treinamento físico. Há estudos que sugerem a distinção das vias sinalizadoras relacionadas à regulação do tamanho celular moduladas na HC fisiológica e na patológica. Assim, as vias de sinalização comumente associadas à hipertrofia fisiológica são mediadas por IGF-I (insulin-like growth factor), que ao se ligarem aos seus respectivos receptores, promovem a ativação da via Akt/PKB (protein kinase B), PI3K (phosphatidylinositol-3 kinase) e mTOR (mammalian target of rapamycin). Por outro lado, a HC patológica, associada às características mal adaptativas, como fibrose intersticial, morte celular e disfunção cardíaca, relaciona-se à ativação da via das MAPK (mitogen activated protein kinase), mediadas por ERK (extracellular signal-regulated kinases), p38 e JNK (c-Jun NH2 terminal kinase), além da ativação da via da calcineurina (DILLMANN, 2010; LI et al., 2007).

Como exposto anteriormente, os mecanismos moleculares envolvidos com o desenvolvimento da $\mathrm{HC}$ não são completamente esclarecidos. O entendimento de como estas diferentes vias de sinalização interagem, promovendo distintos fenótipos hipertróficos e, possivelmente, distintos prognósticos, são de grande importância pública. 


\subsection{Hormônios tireoidianos e hipertrofia cardíaca}

Os hormônios tireoidianos (HT), triiodotironina e tiroxina (T3 e T4, respectivamente), são sintetizados e secretados pela glândula tireóide, a qual se encontra localizada na região cervical junto à traquéia. A glândula tireóide apresenta o folículo tireoidiano como unidade funcional. Esse é delimitado por células foliculares, responsáveis por sintetizar o principal constituinte do colóide tireoidiano, a tireoglobulina. A tireoglobulina apresenta resíduos de tirosina em sua estrutura, os quais são iodados para a síntese de HT. A regulação da síntese e secreção de T3 e T4 envolve um mecanismo de retroalimentação negativa, cujos níveis circulantes de HT estimulam ou inibem a secreção de TRH (Thyroid Releasing Hormone) pelo hipotálamo e de TSH (Thyroid Stimulating Hormone) pela adenohipófise. O TRH estimula a secreção de TSH que, por sua vez, estimula a secreção de HT pela tireóide. Cerca de $90 \%$ dos HT secretados pela glândula tireóide apresenta-se como T4 e os 10\% restantes como T3, o qual é considerado o hormônio tireoidiano biologicamente ativo. O T4 é convertido a T3 através de enzimas denominadas deiodinases ou desiodases, localizadas nos tecidos.

Os hormônios tireoidianos, classicamente, exercem seus efeitos mediante a interação com receptores nucleares. Os receptores de hormônios tireoidianos (TR) são codificados por dois genes distintos, TR $\alpha$ e TR $\beta$, localizados nos cromossomos 17 e 3, respectivamente. Múltiplas isoformas de TR, no entanto, podem ser sintetizadas a partir de splicing alternativo. O transcrito primário de TR $\alpha$ é precursor das isoformas TR 1 1, TR $\alpha 2$ e TR $\alpha 3$, enquanto o gene que codifica TR $\beta$ apresenta dois promotores, permitindo a transcrição de dois polipeptídeos, TRß1 e TRß2 (ZHANG; LAZAR, 2000). No miocárdio, as isoformas predominantes de TR são TR $\alpha 1$ e TRß1 (OJAMAA, 2010). Os TR apresentam-se associados às sequências específicas do DNA, denominadas de elementos responsivos aos HT (TRE ou thyroid receptor elements), as quais se encontram próximas às regiões promotoras dos genes alvo dos HT (ZHANG; LAZAR, 2000). Embora os TR possam interagir com os TRE na forma de monômeros ou homodímeros, predominantemente, interagem na forma de heterodímeros, associados aos receptores de ácido retinóico, RXR. O acoplamento do ligante ao seu receptor (T3/TR) promove alterações estruturais do receptor que, ao recrutar proteínas co-ativadoras, promovem a ativação da maquinaria de transcrição.

Os TR, comparados aos demais receptores nucleares, apresentam a peculiaridade de exercer seus efeitos independentemente da interação do ligante, apresentando ações 
semelhantes às de fatores de transcrição. No entanto, essas ações correspondem, geralmente, à inibição da transcrição basal de determinados genes (DILLMAN, 2010). Recentemente, foi demostrado que, além dos efeitos relacionados à ativação da transcrição gênica, os HT também podem desencadear efeitos muito rápidos, que ocorrem na ordem de segundos a minutos, e que, portanto, independem da formação desses complexos intranucleares. Esses efeitos são denominados não-genômicos e podem ser desencadeados em nível citoplasmático ou, até mesmo, na membrana plasmática, após interação com proteínas nelas presentes (BERGH et al., 2005; DAVIS; DAVIS, 2002; DAVIS; LEONARD; DAVIS, 2008; HIROI et al., 2006).

As disfunções tireoidianas representam as doenças endócrinas de maior incidência e estima-se que atinjam mais de $10 \%$ da população mundial (CANARIS et al., 2000). Em sua maioria, consistem em alterações reversíveis, que podem ser facilmente tratadas através da normalização dos níveis circulantes de HT. As alterações cardiovasculares são, frequentemente, consideradas evidências primárias das disfunções da glândula tireóide. Neste sentido, o coração, tem sido considerado um dos principais órgãos-alvo de ação dos HT (KAHALY; DILLMANN, 2005; KLEIN; OJAMAA, 2001). O estado de hipertireoidismo crônico, especificamente, caracteriza-se pelo aumento da força e da velocidade de contração sistólica, paralelamente ao aumento da velocidade de relaxamento diastólico. Esses efeitos cardiovasculares são considerados benéficos ao promoverem o aumento generalizado da função cardíaca. Por outro lado, os HT também apresentam efeitos eletrofisiológicos associados ao aumento da frequência cardíaca. Assim, o estado de hipertireoidismo também pode estar relacionado a eventos de taquicardia e maior propensão à fibrilação atrial e arritmias (DILLMAN, 2009; KENESSEY, 2006).

Em resposta à elevação dos níveis circulantes de $\mathrm{HT}$, o coração hipertrofia. Os efeitos hemodinâmicos periféricos promovidos pelos $\mathrm{HT}$, como o aumento do retorno venoso e do volume sanguíneo, secundários ao aumento da resistência vascular sistêmica, são fatores que, indiretamente, estimulam o aumento da função contrátil cardíaca e, portanto, contribuem para o desenvolvimento da hipertrofia. No entanto, além desses efeitos indiretos, os HT também agem diretamente sobre as células cardíacas, aumentando a síntese de proteínas e, como citado anteriormente, a frequência cardíaca. Estudos demostraram que o aumento da síntese proteica ocorre independentemente das alterações hemodinâmicas promovidas pelos HT (DIEKMAN et al., 2001). Assim, a exposição dos 
miócitos cardíacos ao T3 resulta no aumento da expressão de proteínas envolvidas, principalmente, com o mecanismo de contração. Neste sentido, os HT estimulam a expressão de $\alpha-M H C$ (myosin heavy chain), SERCA2 (sarcoendoplasmic reticulum calcium ATPase) e inibem a expressão de $\beta$-MHC e phospholamban (DILLMANN, 2010; OJAMAA; KLEIN, 1993).

A hipertrofia cardíaca promovida pelos HT tem sido descrita, por muitos autores, como fisiológica (DILLMANN, 2010; OJAMAA, 2010). Trata-se de uma hipertrofia concêntrica, na qual o aumento dos cardiomiócitos é acompanhado de um arranjo miofibrilar e vascularização adequada (OJAMAA, 2010). Além disso, este tipo de hipertrofia cardíaca é considerado reversível, uma vez demostrado que o retorno do estado hipertireoideo para eutireoideo resulta no retorno da hipertrofia cardíaca à sua configuração normal, à semelhança do observado nos exemplos clássicos de hipertrofia cardíaca fisiológica, decorrentes da gestação e do exercício físico.

Embora, o fenótipo da hipertrofia cardíaca associada ao hipertireoidismo seja, a princípio, considerada compensatória ou fisiológica, dependendo do tempo e intensidade da doença, esse fenótipo pode ser totalmente alterado. Desta forma, um estudo realizado com pacientes hipertireoideos de causa primária demonstrou que, embora incomum (cerca de $6 \%$ ), o hipertireoidismo pode também promover o desenvolvimento de insuficiência cardíaca e disfunção sistólica do ventrículo esquerdo. Embora os sintomas decorrentes do quadro de agravamento da função cardíaca sejam melhorados com o tratamento para o hipertireoidismo, 1/3 desses pacientes desenvolvem cardiomiopatia dilatada persistente agravando, consideravelmente, o estado dos pacientes, os quais com frequência acabam indo a óbito (BOCCALANDRO et al., 2003; SIU et al., 2007).

Embora os mecanismos envolvidos com o aumento de síntese proteica na hipertrofia cardíaca induzida pelo hipertireoidismo tenham sido intensamente estudados, relativamente pouco se sabe a respeito dos mecanismos que regulam negativamente 0 fenótipo hipertrófico. 


\subsection{Sistema Ubiquitina Proteassoma}

A disponibilidade e estabilidade proteica apresentam relação direta com sua função no meio intracelular. Neste sentido, proteínas estruturais são altamente estáveis e, portanto, apresentam uma meia vida longa, comparativamente às proteínas regulatórias. As proteínas são mediadoras efetivas de processos biológicos e o controle de sua disponibilidade consiste em um importante mecanismo de regulação da manutenção da homeostasia e resposta celular adaptativa. Assim, após o desempenho de suas funções, as proteínas são destinadas a sistemas de degradação intracelular. Proteínas associadas à membrana e endocitadas são, geralmente, degradadas em organelas denominadas lisossomos. Outra via proteolítica, mais específica que a anterior, corresponde ao Sistema Ubiquitina Proteassoma (SOROKIN; KIM; OVCHINNIKOV, 2009). Em células eucariontes, o Sistema Ubiquitina Proteassoma (UPS) corresponde ao principal mecanismo de proteólise intracelular, sendo responsável pela degradação de $80 \%$ a $90 \%$ das proteínas nucleares e citoplasmáticas (SOROKIN; KIM; OVCHINNIKOV 2009).

O UPS apresenta duas principais funções biológicas, a ubiquitinação dos substratos proteicos destinados à degradação e a proteólise propriamente dita (COUX; TANAKA; GOLDBERG, 1996; GLICKMAN; CIECHANOVER, 2002; HEDHLI; DEPRE, 2010). O UPS foi inicialmente descrito por seu envolvimento com o Controle de Qualidade de Proteínas (CQP), responsável pela degradação de proteínas inativadas que apresentam alterações estruturais. No entanto, a proteólise mediada pelo UPS pode ser altamente seletiva, promovendo a degradação de proteínas específicas, previamente marcadas. Desta forma, este sistema é atualmente considerado como um importante mecanismo de regulação negativa da disponibilidade de proteínas intracelulares.

A proteólise seletiva requer a marcação, ou mais especificamente, a ubiquitinação dos substratos proteicos destinados à degradação. A ubiquitinação consiste, basicamente, na interação covalente entre a proteína a ser degradada e um peptídeo de aproximadamente 76 aminoácidos, denominado Ubiquitina (Ub). A Ub apresenta 7 resíduos de lisina em sua estrutura (Lys6, Lys11, Lys27, Lys29, Lys33, Lys48 e Lys63) e todos esses resíduos podem ser utilizados para a formação de cadeias de Ub. Assim, a estrutura das cadeias de poliubiquitinas apresenta alta diversidade. O padrão de ubiquitinação, ou seja, o resíduo no qual ocorre a interação com a Ub e a cadeia de poliubiquitina pode ser 
interpretado diferentemente pela célula. Neste sentido, a monoubiquitinação, ou seja, o acoplamento de apenas uma Ub ao substrato proteico está relacionado à regulação de histonas, enquanto a multiubiquitinação, acoplamento de mais de uma Ub, está relacionado a mecanismos de endocitose. A poliubiquitinação na Lys63 apresenta relação com os mecanismos de reparo do DNA e a poliubiquitinação na Lys48 com a degradação mediada pelo proteassoma 26S (PT26S). A ubiquitinação é produto de reações químicas em série, as quais requerem a ação coordenada de três enzimas: a enzima Ativadora de Ubiquitina (E1), a enzima Conjugadora de Ubiquitina (E2) e a enzima Ubiquitina-Ligase (E3), também conhecida simplesmente por E3-Ligase. A Ub é ativada através de uma reação dependente de energia mediada pela E1. A E2 substitui a E1 que, ao interagir com a E3 promove a transferência da Ub às proteínas específicas destinadas à degradação (JENTSCH, 1992).

Figura 1 - Representação esquemática da poliubiquitinação de substratos proteicos.

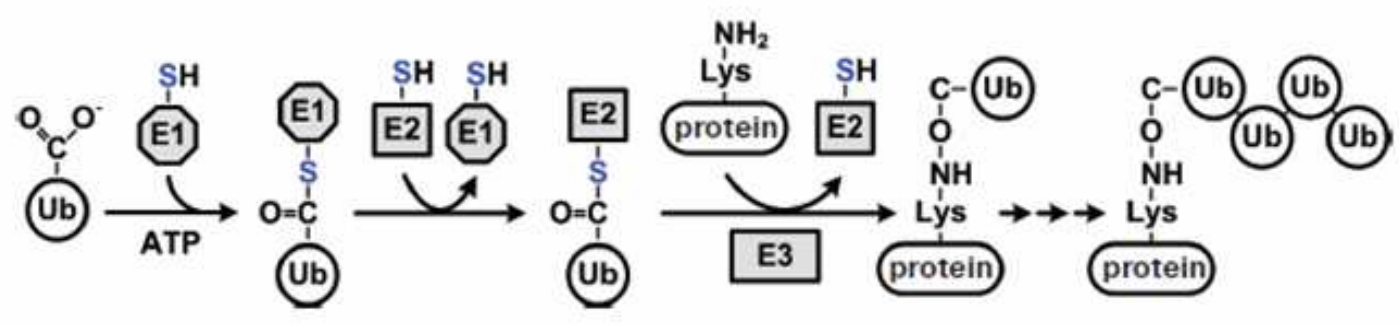

Estágios da poliubiquitinação de proteínas. Ativação da ubiquitina (Ub) pela enzima E1. Translocação da Ub, associada à E1, para E2. Acoplamento da Ub ao substrato proteico alvo.

Fonte: Modificado de Sorokin; Kim; Ovchinnikov, 2009.

Após a ubiquitinação, como representado na figura acima (Figura 1), o substrato proteico já apresentando a molécula de Ub é destinado à degradação mediada pelo PT26S. A ubiquitinação consiste em um processo reversível, uma vez que existem enzimas responsáveis pela remoção das Ub associadas à proteína alvo. Este mecanismo de deubiquitinação ocorre logo após o reconhecimento da cadeia de poliubiquitinas por subunidades presentes na partícula regulatória do proteassoma. Essas enzimas, denominadas de deubiquitinas, podem ser classificadas em duas famílias: a das UBP (Ubiquitin-specific processing proteases) e a das UCH (Ubiquitin C-terminal hydrolases) (WILKINSON, 2000). 
A estrutura do PT26S é constituída por dois subcomplexos, o centro catalítico, ou proteassoma 20S (PT20S), e a partícula reguladora 19S (19SRP) (Figura 2). O 19SRP é um componente-chave na regulação do PT26S, uma vez que apresenta em sua constituição subunidades capazes de reconhecer proteínas poliubiquitinadas e, através de mudanças conformacionais, permite a entrada do substrato proteico ao centro catalítico. A estrutura molecular do 19SRP é formada por um total de 17 subunidades regulatórias, classificadas como dependentes e independentes de ATP, Rpt e Rpn, respectivamente (ETLINGER; GOLDBERG, 1977; HERSHKO, 1996). A estrutura do PT20S, comumente descrita como semelhante a um barril, é constituída por quatro anéis, sendo cada anel formado por sete subunidades de proteases. Trata-se, portanto, de um heptâmero. Como demonstrado a seguir, os dois anéis mais externos são formados, exclusivamente, por subunidades do tipo $\alpha$, enquanto que os dois anéis mais internos por subunidades do tipo $\beta$.

Figura 2 - Representação esquemática da estrutura do proteassoma.

a

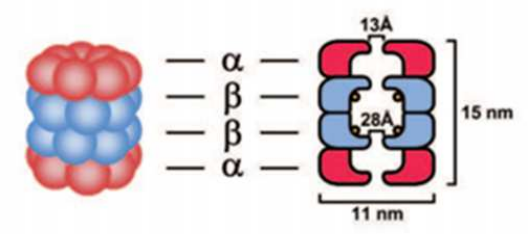

b

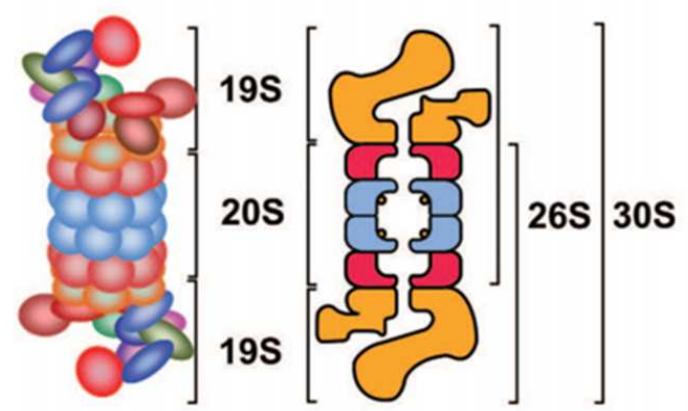

c

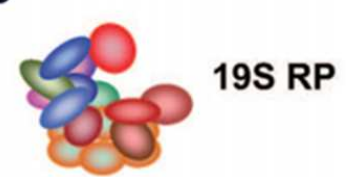

(a) Estrutura do protessoma 20S, em forma de barril. Os dois anéis localizados nas extremidades do proteassoma são constituídos por subunidades $\alpha$, as quais interagem com partículas regulatórias, permitindo a abertura do centro catalítico do proteassoma. Os dois anéis internos são constituídos por subunidades $\beta$, algumas das quais são responsáveis pela atividade conferida ao proteassoma (b) Estrutura dos proteassomas $26 \mathrm{~S}$ e $30 \mathrm{~S}$, os quais são formados por uma partícula catalítica associada a uma ou a duas partículas regulatórias, respectivamente. (c) Estrutura da partícula regulatória (19S $\mathrm{RP}$ ). Apresenta subunidades responsáveis pelo reconhecimento da cadeia de poliubiquitinas que marca o substrato proteico alvo para a degradação mediada pelo proteassoma.

Fonte: Modificado de Sorokin; Kim; Ovchinnikov, 2009. 
O PT20S, portanto, é constituído por um total de 28 subunidades. Os mecanismos relacionados com a regulação da expressão das subunidades que constituem o proteassoma são desconhecidos e insuficientemente estudados. Sabe-se, no entanto, que suas subunidades são sintetizadas em um padrão estequiométrico, o que evidencia o rígido e coordenado controle de sua expressão.

O proteassoma apresenta, em seu complexo central, subunidades que apresentam sítios ativos de degradação. São três as subunidades com esta especialidade, $\beta 1, \beta 2$, e $\beta 5$, as quais exercem atividade do tipo caspase (degradação de aminoácidos ácidos), tripsina (degradação de aminoácidos básicos) e quimiotripsina (degradação de aminoácidos hidrofóbicos), respectivamente (WANG et al., 2011). A variação tecidual que pode existir entre as subunidades constituintes do proteassoma confere especificidade e seletividade à atividade proteolítica. Essas modificações dão origem aos denominados proteassomas heterogêneos e acredita-se que essas modificações alterem de alguma forma sua eficiência proteolítica (DREWS et al., 2007). Os proteassomas são constantemente montados e desmontados no meio intracelular, além disso, suas subunidades, assim como qualquer outra proteína, são suscetíveis às modificações co-traducionais e pós-traducionais, tais como oxidação, fosforilação, acetilação, glicosilação, nitrosilação, glutatiolação. O significado biológico dessas modificações não é completamente compreendido.

O PT26S é responsável pela regulação da proteólise de inúmeras proteínas intracelulares e, inclusive, é responsável pela regulação de sua própria disponibilidade. 0 conteúdo relativo de proteassoma e sua localização na célula variam dinamicamente e se adaptam às necessidades e condições de estresse às quais as células são submetidas. Além disso, o proteassoma interage continuamente com uma variedade de proteínas que regulam a sua atividade e assistem ao reconhecimento de seus substratos (SOROKIN; KIM; OVCHINNIKOV, 2009). A seguir, encontra-se ilustrado (Figura 3), uma representação esquemática das principais etapas constituintes do mecanismo de degradação proteica mediada pelo UPS. 
Figura 3 - Representação esquemática da degradação proteica mediada pelo Sistema Ubiquitina Proteassoma.

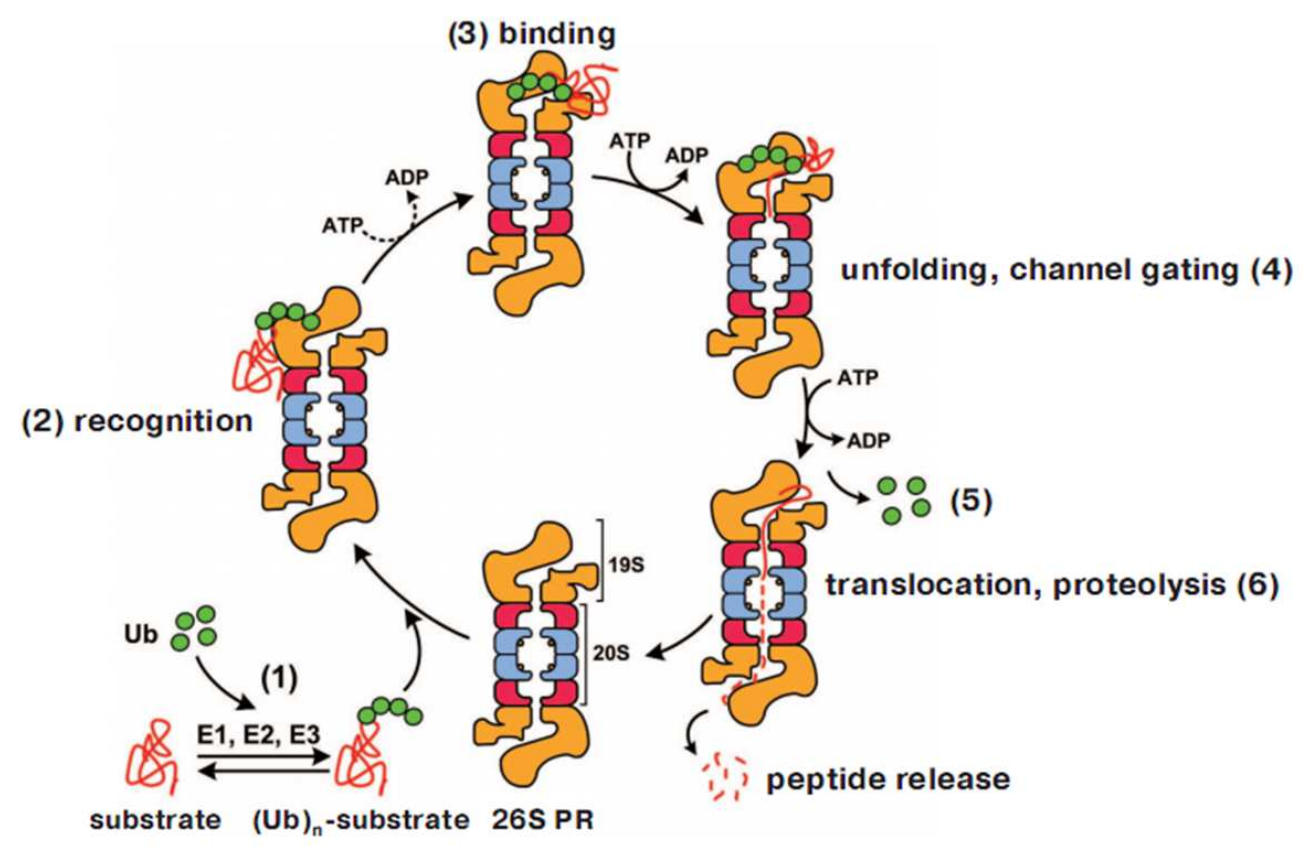

Modelo convencional simplificado da degradação proteica dependente de ubiquitinação mediada pelo proteassoma 26S/30S. (1) Formação da cadeia de poliubiquitinas no substrato proteico alvo. Reação mediada pelas enzimas E1, E2 e E3. (2) Reconhecimento da estrutura quaternária da cadeia de poliubiquitinas pela subunidade Rpn10 da partícula regulatória. (3) Ligação do substrato proteico às subunidades da partícula regulatória, Rpn 1 e Rpn 2. (4) Subunidades ATP dependentes desdobram o substrato proteico alvo para a entrada no centro catalítico. (5) Deubiquitinação do substrato proteico (6) Translocação do polipeptídeo no interior partícula catalítica, degradação e liberação dos peptídeos contendo, aproximadamente, 25 aminoácidos.

Fonte: Sorokin; Kim; Ovchinnikov, 2009. 


\subsection{Sistema Ubiquitina Proteassoma e hipertrofia cardíaca}

A hipertrofia cardíaca requer, a princípio, o aumento de síntese proteica pelos cardiomiócitos. Dados da literatura atestam que cerca de $50 \%$ das proteínas nascentes são degradadas concomitantemente à sua tradução (DEPRE et al., 2006; SCHUBERT et al., 2000). Neste sentido, o aumento de síntese proteica deve ser acompanhado, invariavelmente, do aumento de degradação. Estudos consistentes da literatura demonstram evidências da necessidade da ativação do proteassoma (PT) cardíaco para o desenvolvimento de uma resposta hipertrófica adequada. O aumento dos transcritos que codificam as subunidades proteassomais, paralelamente ao aumento de sua atividade, sugerem maior assembly do PT. Corroborando com essas evidências, estudos demostraram que a inibição do PT cardíaco é capaz de prevenir o desenvolvimento e reverter a hipertrofia cardíaca pré-estabelecida (DEPRE et al., 2006; HEDHLI et al., 2008; HEDHLI; DEPRE, 2010).

Recentemente, tem sido proposto que quando ocorre a diminuição da proteólise, ou quando a síntese de proteínas simplesmente excede a capacidade de degradação, os cardiomiócitos apresentam aumento na deposição de agregados proteicos, os quais comprometem o desempenho celular devido à sua toxicidade. Pacientes portadores de hipertrofia cardíaca descompensada apresentam acúmulo de proteínas poliubiquitinadas e de agregados proteicos nos cardiomiócitos, acompanhado de considerada diminuição da expressão gênica das subunidades proteassomais (TSUKAMOTO; MINAMINO; KITAKAZE, 2010). Neste sentido, o aumento de proteínas pró-apoptóticas, como p53 e Bax, em função da depressão da atividade proteolítica, indica o possível envolvimento desta via proteolítica na transição da hipertrofia compensada para descompensada (MEARINI et al., 2008).

A modulação de vias de sinalização associadas à regulação do tamanho, sobrevivência e morte celular é controlada por um nível basal de proteínas, que resulta do balanço existente entre síntese e degradação (HEDHLI; PELAT; DEPRE, 2005; WILLIS; ZUNG; PATTERSON, 2010). O Sistema Ubiquitina Proteassoma desempenha um papel central na degradação de proteínas. Neste sentido, diversos estudos têm evidenciado o envolvimento deste sistema proteolítico na patogênese de doenças, dentre as quais, a hipertrofia cardíaca (YU; PATTERSON; KEM, 2009). A proteólise mediada pelo UPS é altamente seletiva e como citado anteriormente, requer a marcação prévia dos substratos proteicos mediante ubiquitinação. Estudos sugerem que a especificidade e seletividade, conferida à degradação 
mediada pelo PT, permitem a regulação negativa da concentração basal de proteínas e modulação de vias de sinalização.

As E3-ligases são responsáveis por catalisar a transferência da cadeia de ubiquitinas à proteína-alvo, a qual é subsequentemente degradada pelo PT. O reconhecimento do substrato proteico pela E3 depende de sua sequência e dos domínios de interação proteínaproteína presentes em sua estrutura (FOLETTA et al., 2011). Estima-se que aproximadamente 500 ubiquitinas-ligases sejam codificadas pelo genoma humano, sendo apenas 9 descritas no miocárdio (WILLIS; ZUNG; PATTERSON, 2010). A expressão e atividade dessas enzimas têm sido avaliadas em resposta a diferentes condições patológicas e há evidências de seu envolvimento na modulação do trofismo cardíaco (CLAVEL et al. 2006; LECKER et al., 2004). Dentre as ubiquitina-ligases descritas no tecido cardíaco, três merecem destaque e, portanto, serão brevemente descritas a seguir.

Atrogin-1 ou MAFbx (Muscle-atrophy F-box) consiste em uma E3-ligase músculo estriado específica, inicialmente descrita em modelos de atrofia do músculo esquelético. Apresenta um domínio F-box em sua estrutura, através da qual interage com outras proteínas que constituem um complexo enzimático denominado SCF (skp1, cullin, F-box protein). O complexo SCF funciona como um adaptador que permite sua ligação com proteínas específicas. Os domínios de interação proteína-proteína, presentes na estrutura dessas enzimas, permite a ubiquitinação dos substratos proteicos destinados à degradação. Estudos recentes demostraram que Atrogin/MAFbx está envolvida com vias de apoptose, inflamação e hipertrofia de cardiomiócitos (ZENG, 2013). De fato, inúmeros trabalhos na literatura evidenciaram o envolvimento desta enzima na modulação do trofismo do músculo cardíaco e esquelético.

MuRF1, por sua vez, pertence à família Muscle-specific Ring Finger. Assim como Atrogin/MAFbx, também contribui para controle do tamanho dos cardiomiócitos. Este controle se dá através da facilitação da degradação de proteínas sarcoméricas e da inibição de fatores de transcrição envolvidos com a sinalização pró-hipertrófica. Estudos demonstram que MuRF1 é necessário para que a resposta hipertrófica a determinado estímulo seja adequada, ou seja, na sua ausência a resposta é exacerbada (WILLIS, 2007). De maneira geral, as proteínas apresentam, em sua estrutura, modificações características que sinalizam sua degradação. Esses sinais de degradação são denominados de dégrons. A E3ligase E3- $\alpha /$ UBR1 promove a ubiquitinação de proteínas devido ao reconhecimento de 
alterações presentes no resíduo $\mathrm{N}$-terminal das mesmas. Esta forma de reconhecimento dos sinais de degradação é denominada de via de degradação $N$-end rule e parece ser particularmente importante para a degradação de proteínas do músculo esquelético (GOLDBERG, 2011).

Embora os mecanismos envolvidos com a modulação do UPS não sejam completamente compreendidos, muitos esforços têm sido empregados para o entendimento desse complexo sistema proteolítico. Em se tratando de um mecanismo de degradação de proteínas, o UPS foi considerado inicialmente como possível alvo terapêutico para a reversão da hipertrofia cardíaca, por isso a grande quantidade de estudos voltados para a inibição do PT cardíaco. Considerando a ausência de uma resposta padrão do UPS frente às distintas respostas hipertróficas, faz-se necessário o empreendimento de diferentes abordagens para a melhor caracterização desse importante sistema no estabelecimento das diversas patologias que culminam com o desenvolvimento de diferentes modelos de hipertrofia cardíaca. 


\section{JUSTIFICATIVA}

O entendimento dos mecanismos relacionados à patogenia e a busca de possíveis intervenções terapêuticas das doenças cardiovasculares são considerados de grande relevância científica e importância pública, dados os elevados índices de morbidade e mortalidade que apresentam. A hipertrofia cardíaca consiste, basicamente, em uma resposta adaptativa do coração às variações na homeostasia tecidual e, neste sentido, manifesta-se em patologias de diferentes etiologias. O Sistema Ubiquitina Proteassoma (UPS), por sua vez, corresponde ao principal sistema de proteólise intracelular. Através da degradação seletiva de proteínas, o UPS promove a regulação negativa da concentração basal de proteínas específicas, modulando vias de sinalização intracelulares envolvidas com eventos biológicos importantes, como o crescimento celular. Recentemente, estudos têm demonstrado fortes evidências do possível envolvimento do UPS com o desenvolvimento de doenças cardiovasculares, tais como a hipertrofia cardíaca. Embora o estudo deste sistema proteolítico já tenha sido abordado em diferentes modelos, a complexa relação entre UPS e hipertrofia cardíaca permanece desconhecida. Desta forma, o objetivo do presente estudo consiste em avaliar o UPS no modelo de hipertrofia cardíaca induzida por hormônio tireoidiano, em diferentes tempos de tratamento. 


\section{OBJETIVOS}

\subsection{Objetivo geral}

Avaliar a possível modulação do Sistema Ubiquitina Proteassoma no miocárdio de ratos submetidos ao hipertireoidismo.

\subsection{Objetivos específicos}

O presente estudo contempla dois principais objetivos específicos, os quais consistem em avaliar a expressão e atividade do proteassoma cardíaco e em avaliar a expressão de E3-ligases, relacionadas ao remodelamento cardíaco, no miocárdio de animais submetidos à administração crônica de hormônios tireoidianos. Neste sentido, encontramse descritas a seguir as abordagens utilizadas neste estudo, no intuito de responder a esses objetivos propostos.

3.2.1 Modulação do proteassoma cardíaco no miocárdio de animais submetidos ao hipertireoidismo

- Avaliar os níveis de mRNA que codificam as subunidades catalíticas $\beta 1, \beta 2$ e $\beta 5$ do proteassoma.

- Avaliar os níveis de mRNA que codificam as subunidades da partícula regulatória (19S RP), Rpt1, Rpt6 e Rpn6, do proteassoma

- Avaliar a expressão de proteínas poliubiquitinadas

- Avaliar a atividade tipo quimiotripsina do proteassoma 205 e 265

\subsubsection{Modulação de E3-ligases no miocárdio de animais submetidos ao hipertireoidismo}

- Avaliar os níveis de mRNA que codificam Atrogin/MAFbx, MuRF1 e E3- $\alpha /$ UBR1

- Avaliar a expressão proteica de Atrogin/MAFbx e MuRF1 


\section{MATERIAL E MÉTODOS}

Os procedimentos realizados no presente estudo foram previamente aprovados pela Comissão de Ética em Experimentação Animal (CEEA), segundo protocolo registrado na fl.103 do livro 02, n053, no dia 17 de maio de 2011, e encontra-se de acordo com os Princípios Éticos de Experimentação Animal adotado pela Sociedade Brasileira de Ciência de Animais de Laboratório (SBCAL/COBEA - www.cobea.org.br).

\subsection{Modelo experimental}

\subsubsection{Animais}

Para o desenvolvimento do modelo experimental in vivo foram utilizados ratos ( $\underline{\text { Rattus }}$ norvegicus) adultos (12 semanas de idade) da linhagem Wistar, provenientes do Biotério Central do Instituto de Ciências Biomédicas da Universidade de São Paulo (ICB-USP) e mantidos no Biotério do Departamento de Anatomia (ICB III-USP). Os animais foram acondicionados em gaiolas plásticas, mantidos com água e ração (Nuvital Nutrientes, Curitiba, PR Brazil) ad libitum, em sala climatizada $\left(22^{\circ} \mathrm{C}\right)$, com ciclo claro/escuro não invertido de 12 horas.

\subsubsection{Hipertireoidismo experimental}

Conforme demostrado a seguir (Figura 4), os animais foram randomizados em dois grupos experimentais: Controle e Hiper. Os animais do grupo Hiper receberam injeções intraperitoneais diárias de triiodotironina/T3 (Sigma Aldrich, Steinhein, Alemanha) em doses que correspondem a 20 vezes a fisiológica ( $7 \mu \mathrm{g} / 100 \mathrm{~g}$ de massa corporal). Os animais do grupo Controle receberam, sob as mesmas condições, apenas solução veículo (solução salina $+\mathrm{NaOH} 0,34 \mathrm{M})$. 
Figura 4 - Representação esquemática do modelo experimental de indução ao hipertireoidismo.

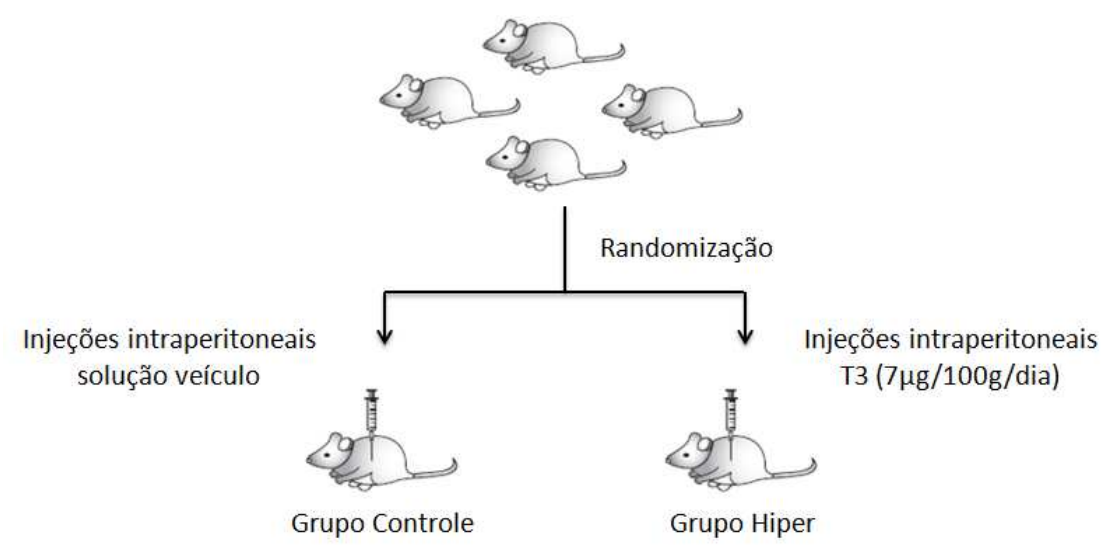

Os animais foram randomizados em dois grupos experimentais, Controle e Hiper. O grupo Controle recebeu injeções intraperitoneais diárias de solução veículo, enquanto o grupo Hiper recebeu T3 (dose:7 $\mu \mathrm{g} / 100 \mathrm{~g} / \mathrm{dia}$ ), sob as mesmas condições.

\subsubsection{Grupos experimentais}

O protocolo experimental padrão utilizado em nosso laboratório para indução ao hipertireoidismo consiste no tratamento dos animais com T3 por 14 dias. No intuito de melhor compreender os efeitos do hipertireoidismo sobre a modulação do Sistema Ubiquitina Proteassoma cardíaco dos animais, foram constituídos diferentes grupos experimentais, submetidos a diferentes períodos de tratamento: 7, 14 e 21 dias (Figura 5).

Figura 5 - Representação esquemática da constituição dos grupos experimentais.

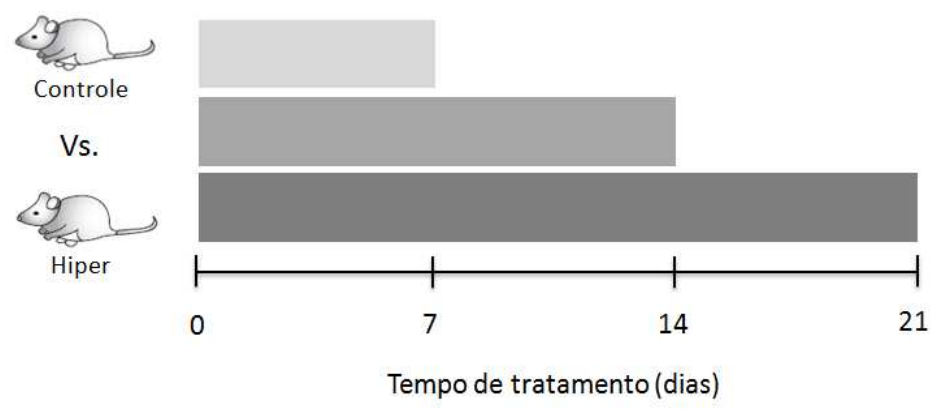

Animais dos grupos Controle e Hiper foram submetidos a diferentes períodos de tratamento, sendo subdividos nos grupos tratados por 7, 14 e 21 dias. 


\subsection{Dosagem dos níveis séricos de hormônios tireoidianos}

Os níveis séricos de hormônios tireoidianos (T3 e T4 Total) foram quantificados por radioimunoensaio (RIE). O RIE consiste em um ensaio de competição, no qual o hormônio previamente marcado com radioativo $\left({ }^{125}\right)$ compete por um sítio de ligação (o anticorpo contido no fundo do tubo) com o hormônio não marcado da amostra. Desta forma, trata-se de uma relação inversa, ou seja, quanto menor a concentração de hormônio contido na amostra, maior a radioatividade detectada pelo aparelho (valor obtido em CPM). Para a obtenção do soro dos animais analisados, o sangue proveniente do tronco dos animais foi rapidamente coletado após a decapitação e submetido à centrifugação (5.000 RPM, 30 min, $4{ }^{\circ} \mathrm{C}$ ). A fração sérica, correspondente ao sobrenadante, foi coletada e armazenada em freezer a $-80{ }^{\circ} \mathrm{C}$ para posterior análise. Todos os procedimentos foram realizados de acordo com as instruções do fabricante do kit de RIE (Coat-a-Count, Siemens, Munich, Germany). O conteúdo radioativo das amostras foi mensurado em Contador Gama (170 Wizard Automatic Gamma Counter, PerkinEImer Inc., Walthan, Massachusetts, United States of America).

\subsection{Pletismografia caudal}

Os parâmetros hemodinâmicos dos animais foram avaliados por pletismografia caudal (RTBP2000 Rat Tail Blood Pressure System for Rats and Mice, Kent Scientific Corporation, Torrington, Connecticut). A pletismografia caudal consiste em um método indireto que permite a avaliação da pressão arterial sistólica (PAS) e da frequência cardíaca (FC) dos animais. Para que se acostumassem à manipulação e os dados obtidos não apresentassem o fator estresse como interferente, os animais foram previamente treinados (por 14 dias antes de qualquer registro). Antes de serem iniciadas as análises, os animais permaneceram por certo período de tempo em uma caixa com luz incandescente, com o intuito de realizar pequenas dilatações da artéria caudal, possibilitando a obtenção do pulso. Posteriormente, os animais foram acondicionados em um tubo de contenção (tubo cilíndrico de acrílico com abertura para cauda). O tamanho do tubo de contenção foi ajustado para cada animal, de modo que permanecessem confortáveis, mas imóveis durante todo o experimento. Um sensor pizoelétrico, altamente sensível, capaz de detectar a distensão causada pelos pulsos da artéria caudal, foi colocado na região proximal da cauda do animal. 
O pulso detectado pelo sensor foi amplificado e transmitido para um conversor analógico digital (DI-720-USB, DATAQ Instruments, Akron, Ohio, United States of America). Os dados de FC foram quantificados a partir da média de um mínimo de 5 medidas para cada animal e os dados de PAS a partir da média de um mínimo de 3 medidas para cada animal.

\subsection{Western Blotting}

Amostras do tecido cardíaco foram submetidas à homogeneização (Polytron) em tampão específico contendo inibidores de proteases. Após centrifugação (10.000 rpm, 20 min., $4{ }^{\circ} \mathrm{C}$ ), o sobrenadante foi coletado e armazenado em freezer $-80^{\circ} \mathrm{C}$. A concentração proteica das amostras foi determinada por espectrometria, segundo método descrito por Bradford (1976), e calculada segundo a equação da reta obtida a partir de uma curva de concentração padrão (Albumina Sérica Bovina - BSA). Todas as amostras foram dosadas em duplicata. Amostras com volumes correspondentes a $30 \mu \mathrm{g}$ de proteína foram incubadas com tampão de amostra contendo $\beta$-Mercaptoetanol e aquecidas em banho-maria $\left(100{ }^{\circ} \mathrm{C}\right.$ por $5 \mathrm{~min}$ ) para denaturação. Em seguida, as amostras foram submetidas à eletroforese em gel denaturante de poliacrilamida ( $8 \%$ ou 10\%, dependendo do peso molecular da proteína avaliada) a $140 \mathrm{~V}$ por $1 \mathrm{~h}$ e transferidas para membranas de nitrocelulose (Bio-Rad, Hercules, California, United States of America) a $20 \mathrm{~V}$ por $1 \mathrm{~h}$. Para a confirmação da homogeneidade entre as amostras quanto à concentração proteica, as membranas foram coradas com solução Ponceau. As membranas foram lavadas com solução de TBST (Tris 50 mM, NaCL 150 mM e Tween-20 a 0,2\%, pH 7,5) e incubadas com anticorpos primários, sob agitação constante, durante aproximadamente 18 horas, a $4{ }^{\circ} \mathrm{C}$. Após lavagem com solução de TBST, as membranas foram incubadas com anticorpo secundário, conjugado à peroxidase, sob agitação constante durante 1 hora, em temperatura ambiente. Após lavagem com solução de TBST, as membranas foram incubadas com solução de ECL (Thermo Scientific, Rockford, Illinois, United States of America), a qual promove uma reação de luminescência, cujo produto final é capaz de impressionar filmes de raios-X. A banda correspondente à proteína de interesse foi quantificada pelo programa Image J. Os valores são expressos em porcentagem em relação à expressão do normalizador/controle interno, GAPDH. A relação dos anticorpos utilizados, seus respectivos fabricantes e diluições utilizadas encontram-se descritos na tabela a seguir (Tabela 1): 
Tabela 1 - Relação de anticorpos utilizados nos ensaios de Western Blotting

\begin{tabular}{|c|c|c|c|}
\hline & Anticorpo & Fabricante & Diluição \\
\hline \multirow{5}{*}{ Primários } & Anti-Ubiquitina & Boston Biochem & $1: 500$ \\
\hline & Anti-MuRF1 & ECM Biosciences & $1: 500$ \\
\hline & Anti-Atrogin & ECM Biosciences & $1: 500$ \\
\hline & Anti-GAPDH & Santa-Cruz & 1:1.000 \\
\hline & Anti-DNP & Sigma & $1: 1.000$ \\
\hline \multirow{3}{*}{ Secundários } & Anti-Rabbit & Santa-Cruz & 1:10.000 \\
\hline & Anti-Goat & Santa-Cruz & $1: 10.000$ \\
\hline & Anti-Mouse & Santa-Cruz & 1:10.000 \\
\hline
\end{tabular}

\subsection{RT-PCR em tempo real}

\subsubsection{Extração de RNA total e reação de transcrição reversa}

O RNA total foi extraído de amostras de tecido cardíaco, de acordo com as especificações do fabricante do reagente Trizol (Invitrogen, Carlsbad, California, United States of America). Após as diferentes etapas do processo de extração, a qualidade da extração foi avaliada através da análise da razão das absorbâncias obtidas em $\lambda=260 \mathrm{~nm}$ e $\lambda=280 \mathrm{~nm}$ e a concentração de RNA total determinada em espectrofotômetro de alta sensibilidade (Gen5 Data Analysis Software, BioTek, Winooski, Vermont, United States of America). A integridade do RNA extraído foi confirmada através da verificação de RNA ribossomal (18S e 28S) sob luz UV, após separação por eletroforese em gel de agarose (1\%) contendo Brometo de Etídio. A reação de transcrição reversa para síntese da fita complementar ao mRNA (cDNA) foi realizada utilizando-se $2 \mu \mathrm{g}$ de RNA total, segundo as especificações fornecidas pelo fabricante da enzima transcriptase reversa (M-MLV Reverse Transcriptase, Invitrogen/Life Technologies, Carlsbad, California, United States of America) em termociclador (PTC 200 Termocycler, MJ Research, Walthan, Massachusetts, United States of America). 


\subsubsection{Reação de RT-PCR em tempo real}

As reações de RT-PCR em tempo real foram realizadas segundo protocolo modificado do fabricante do coquetel de reagentes (Platinum SYBR Green qPCR UPSer Mix-UDG, Invitrogen/Life Technologies, Carlsbad, California, United States of America). As amostras foram avaliadas em duplicata, em um volume final de $12 \mu \mathrm{L}$. Os níveis de cDNA foram determinados através do cálculo $2^{\Delta \Delta \mathrm{Ct}}$, sendo $\Delta \Delta \mathrm{Ct}=(\Delta \mathrm{Ct}$ Tratado $-\Delta \mathrm{Ct}$ Controle $)$ e $\Delta \mathrm{Ct}=(\mathrm{Ct}$ gene interesse - $\mathrm{Ct}$ controle interno). $\mathrm{O}$ valor do $\mathrm{Ct}$ representa a linha de base para detecção da fluorescência emitida, correspondente à fase exponencial, conforme a amplificação do material genético analisado. Os níveis de GAPDH foram utilizados como controle interno, uma vez verificado que sua expressão não é alterada no tecido cardíaco de animais tratados com HT (CARNEIRO-RAMOS et al., 2010). As sequências dos primers utilizados encontram-se descritas na tabela a seguir (Tabela 2):

Tabela 2 - Sequência dos primers utilizados nos ensaios de PCR em tempo real

\begin{tabular}{|c|c|c|}
\hline Genes & Sequência sense & Sequência anti-sense \\
\hline$\beta 1 / P S M B 1$ & 5'-TTG CTT CAG ACA CTC GGT TG-3' & 5'-AGC CAC TGC AGC CAA TTA CT-3' \\
\hline$\beta 2 / P S M B 2$ & 5'-GGA GTC GGA CCC CTT ATC AT-3' & 5'-CAT AGC CAT GAG CTG CAA AA-3' \\
\hline$\beta 5 / P S M B 5$ & 5'-TGC TTG CCA ACA TGG TGT AT-3' & 5'-TCC ATG ACT CCA AAC GCA TA-3' \\
\hline Rpt1/PSMC2 & 5'-GGC CAC TAA CCG ACC TGA TA-3' & 5'-CAC ACT CAT TGA GCG AGC AT-3' \\
\hline Rpt6/PSMC5 & 5'-CTG GGA GGA TTG ACA GGA AA-3' & 5'-GAA GCT CCT GGC ATC AAC TC-3' \\
\hline Rpn6/PSMD1 & 5'-TAG AAT GTG CTT CCC CCT AC-3' & 5'-ATT CCA TCA TCG GAC AGA GC-3' \\
\hline Atrogin/MAFbx & 5'-TAC TAA GGA GCG CCA TGG ATA CT-3' & 5'-GTT GAA TCT TCT GGA ATC CAG GAT-3' \\
\hline MuRF1 & 5'-TGA CCA AGG AAA ACA GCC ACC AG-3' & 5'-TCA CTC CTT CTT CTC GTC CAG GAT GG-3' \\
\hline E3- $\alpha /$ UBR1 & 5'-AGC ACA GTG CAG CAT TTC AGT T-3' & 5'-TTG CAC AAT CCC TAC AGG AAT ATGT-3' \\
\hline POMP & 5'-TTC TCC GGA AAG GGT TTT CT-3' & 5'-AAG AAA CGG AAG ACG CTG AA-3' \\
\hline$\alpha-\mathrm{MHC}$ & 5'-ACA GAG TGC TTC GTG CCT GAT -3' & 5'-CGA ATT TCG GAG GGT TCT GC-3' \\
\hline$\beta-\mathrm{MHC}$ & 5'-AGC GAG GCT CCA CCC CAC AT-3' & 5'-CAA GGT GCC CTT GCC TGG GG-3' \\
\hline GAPDH & $5^{\prime}$-TGG TGG ACC TCA TGG CCT AC-3' & 5'-CAG CAA CTG AGG GCC TCT CT-3' \\
\hline
\end{tabular}


Os valores foram descritos como variação em relação ao Controle. Os primers foram desenhados e sintetizados de acordo com os programas PrimerQuest ${ }^{\mathrm{SM}}$ e OligoAnalyser 3.1 (Integrated DNA Technologies-IDT, Coralville, lowa, United States of America).

\subsection{Ensaio de atividade do PT20S tipo-quimiotripsina}

A atividade do proteassoma foi avaliada mediante ensaio fluorimétrico. O coração dos animais, submetidos ao protocolo experimental já descrito, foram previamente perfundidos com PBS para a retirada do excesso de sangue do tecido. Amostras de tecido cardíaco foram homogeneizadas com tampão de extração de proteína total, modificado (10 $\mathrm{mM} \mathrm{KCl}, 3 \mathrm{mM} \mathrm{MgCl}$ e $10 \mathrm{mM}$ Hepes, $\mathrm{pH}$ 7,4). Os homogenatos foram centrifugados (10.000 rpm, $40 \mathrm{~min}, 4{ }^{\circ} \mathrm{C}$ ) e o sobrenadante coletado. A concentração de proteína total foi determinada pelo método de Bradford (1976). O ensaio foi realizado em microplacas de 96 poços. O volume correspondente a $50 \mu \mathrm{g}$ de proteína total foi adicionado a um tampão Tris$\mathrm{HCl}(\mathrm{pH} 7,4)$, seguido do substrato, para avaliação da atividade tipo quimiotripsina, Suc-LeuLeu-Val-Try-7-amido-4-methylcoumarin (25 $\mu \mathrm{M}$ Suc-LLVY-MCA). As amostras foram avaliadas em espectrofotômetro de fluorescência (Molecular Devices, Sunnyvale, California, United States of America) nos seguintes comprimentos de onda, $\lambda=350 \mathrm{~nm}$ e $\lambda=440 \mathrm{~nm}$, para excitação e emissão, respectivamente. A fluorescência detectada, resultante da clivagem do substrato proteico pela peptidase e consequente liberação do grupo AMC (amido-4methylcoumarin) foi acompanhada durante 45 minutos, a $37^{\circ} \mathrm{C}$. Para avaliação da atividade do proteassoma $20 \mathrm{~S}$ foram realizados ensaios paralelos na presença de um inibidor farmacológico do proteassoma, o Bortezomibe $(0,1 \mathrm{mM})$. Os resultados apresentados correspondem à diferença de atividade obtida para as mesmas amostras, na presença e ausência de inibidor. Para avaliação da atividade do proteassoma 265 foram adicionados, ao longo do experimento, volumes de ATP $(10 \mathrm{mM})$. Os resultados são expressos em porcentagem. 


\subsection{Proteínas carboniladas}

A avaliação de proteínas carboniladas corresponde ao principal indicador de estresse oxidativo, devido à estabilidade da reação química (DALLE-DONNE et al., 2003). Amostras de tecido cardíaco foram submetidas à extração de proteína total, seguida de centrifugação (10.000 rpm, $40 \mathrm{~min}, 4^{\circ} \mathrm{C}$ ). A concentração de proteína total foi determinada pelo método de Bradford (1976). O volume correspondente a $70 \mu \mathrm{g}$ de proteína total foi incubado com Solução A (20 mM DNPH, 10\% TFA) e SDS a 24\%, em temperatura ambiente, ao abrigo de luz, por 30 min. Em seguida, foi adicionada Solução B (Tris 2 M, 30\% Glicerol, 19\% $\beta$ mercaptoetanol) às amostras, as quais, posteriormente, foram separadas por eletroforese em gel de poliacrilamida (10\%), seguido de Western Blotting. As membranas foram incubadas com anticorpos anti-DNP.

\subsection{Análise estatística}

A análise estatística foi realizada mediante análise de variância multifatorial (TwoWay ANOVA), seguida do pós-teste de Fisher para comparação entre médias (controle e hiper) do mesmo período de tratamento. Os resultados foram descritos como média \pm erro padrão e expressos na unidade de medida convencional, em porcentagem ou expressão relativa. Valores de $p<0,05$ foram considerados estatisticamente significativos, uma vez estabelecido $\alpha=5 \%$. O valor de " $n$ " corresponde à quantidade de animais utilizada em cada ensaio. A análise estatística e representação gráfica foram realizadas no programa GraphPad Prism (GraphPad Software, La Jolla, California, United States of America). 


\section{RESULTADOS}

\subsection{Caracterização do modelo experimental}

\subsubsection{Dosagens dos níveis séricos de T3 e T4 Total por RIE}

Para a caracterização do protocolo experimental utilizado de indução ao hipertireoidismo, os níveis de T3 e T4 Total foram dosados no soro dos animais controles e nos tratados com hormônio tireoidiano. Conforme exposto a seguir (Tabela 3), apenas os animais do grupo Hiper, tratados por 7 dias, apresentaram aumento significativo dos níveis séricos de T3 Total, não sendo observada a modulação desta fração nos demais períodos avaliados. Por outro lado, os níveis séricos de T4 Total foram indetectáveis em todos os períodos de tratamento.

Tabela 3 - Níveis séricos de T3 e T4 Total, dosados por RIE

\begin{tabular}{llcc}
\hline Grupo & Controle & Hiper \\
\hline & 7 dias $(n=5)$ & $59,49 \pm 4,49$ & $127,8 \pm 13,71$ * \\
T3 total (ng/dL) & 14 dias $(n=5)$ & $57,35 \pm 3,22$ & $54,26 \pm 7,33$ \\
& 21 dias $(n=3)$ & $54,65 \pm 5,62$ & $55,34 \pm 2,37$ \\
T4 total (ug/dL) & 7 dias $(n=5)$ & $6,17 \pm 0,51$ & - \\
& 14 dias $(n=5)$ & $5,98 \pm 0,70$ & - \\
\hline
\end{tabular}

Os níveis séricos de T4 total apresentaram-se abaixo da concentração mínima de deteç̧ão. Para que fosse possível quantificar e comparar os grupos experimentais, os valores foram analisados na unidade dada pelo aparelho (CPM - Contagens Por Minuto). Assim, a intensidade da radiação obtida apresentou-se significativamente elevada no grupo Hiper, indicando que o tratamento com HT promoveu a diminuição significativa na concentração sérica de T4 Total (dados não mostrados). Embora não tenha sido possível observar o aumento dos níveis séricos de T3, a diminuição de T4 Total indica a ocorrência de 
um mecanismo de retroalimentação negativa e, consequente, inibição do eixo hipotálamohipófise-tireóide, em resposta à administração de T3. Este resultado confirma o estado hipertireoideo dos animais do grupo Hiper, nos diferentes tempos de tratamento.

\subsubsection{Efeitos do hipertireoidismo sobre a massa corporal}

A hiperatividade da glândula tireóide apresenta relação direta com a perda de massa em humanos e o menor ganho de massa corporal em animais (BYERS et al., 1952; LEVINE et al., 2003). Os dados apresentados a seguir resultam da avaliação da massa corporal diária dos animais tratados com hormônio tireoidiano por 21 dias (Figura 6). Observa-se que o grupo Hiper apresentou menor ganho de massa corporal durante o tratamento comparado ao grupo Controle, sendo esta diferença considerada estatisticamente significativa nos períodos correspondentes ao $19^{\circ}$ e $20^{\circ}$ dia de tratamento $(253,56 \pm 18,02$ vs. $282,63 \pm 15,07)$.

Figura 6 - Análise da massa corporal dos animais durante tratamento

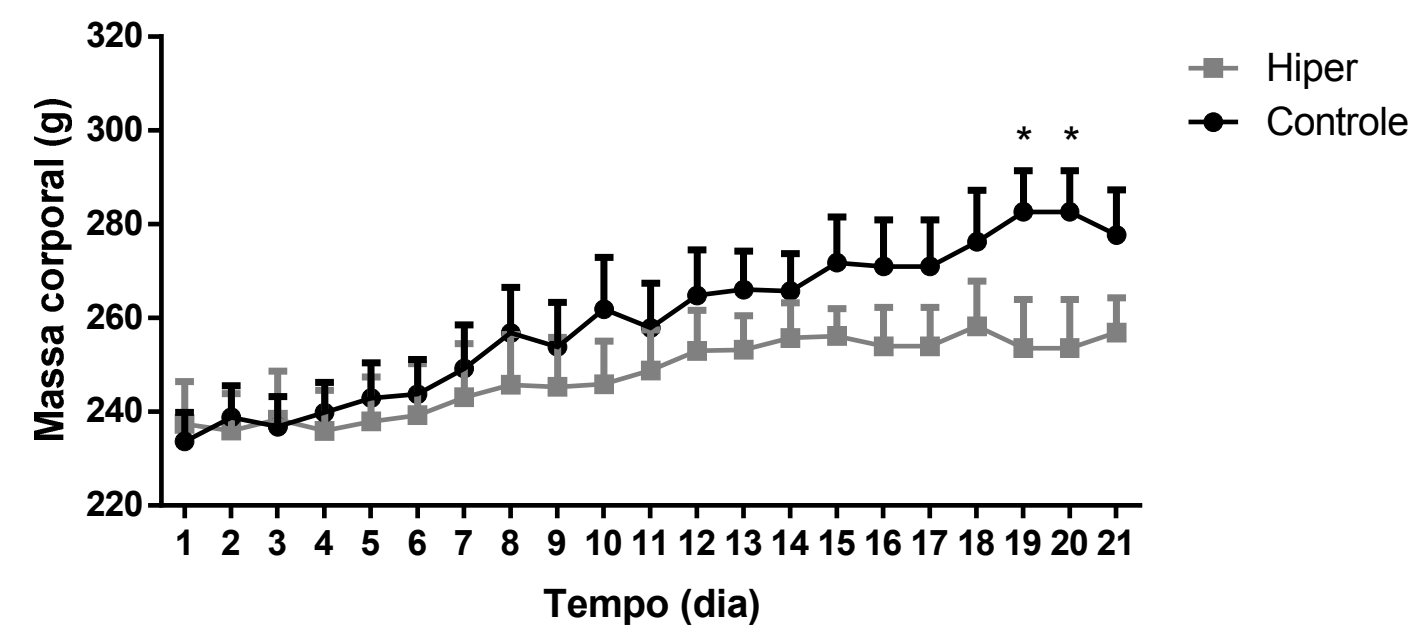

Análise do ganho de massa corporal (g) dos animais controle e tratados com hormônio tireoidiano por 21 dias. Os valores são representados como média \pm erro-padrão da massa corporal diária dos animais ( $n=3$ para ambos os grupos, controle e tratados). ${ }^{*}$ vs. controle, sendo $p<0,05$.

O menor ganho de massa corporal diária (Figura 6) resultou, ao término do tratamento, na redução significativa da massa corporal dos animais do grupo Hiper, comparado aos seus respectivos Controle (Figura 7). Esta diminuição significativa observada na massa corporal dos animais do grupo Hiper (7dias: 263,8 $\pm 12,39$ vs. $293,8 \pm 14,49 / 14$ dias: 
$295,9 \pm 18,2$ vs. $314,6 \pm 12,65 / 21$ dias: $246,2 \pm 17,51$ vs. $279,8 \pm 18,72$ ) pode estar relacionada ao aumento do metabolismo basal promovido pelos hormônios tireoidianos. Desta forma, os resultados obtidos apresentaram-se de acordo com o esperado e confirmam, dentre outros parâmetros avaliados, o modelo experimental utilizado de indução ao hipertireoidismo.

Figura 7 - Análise da massa corporal dos animais ao término do tratamento

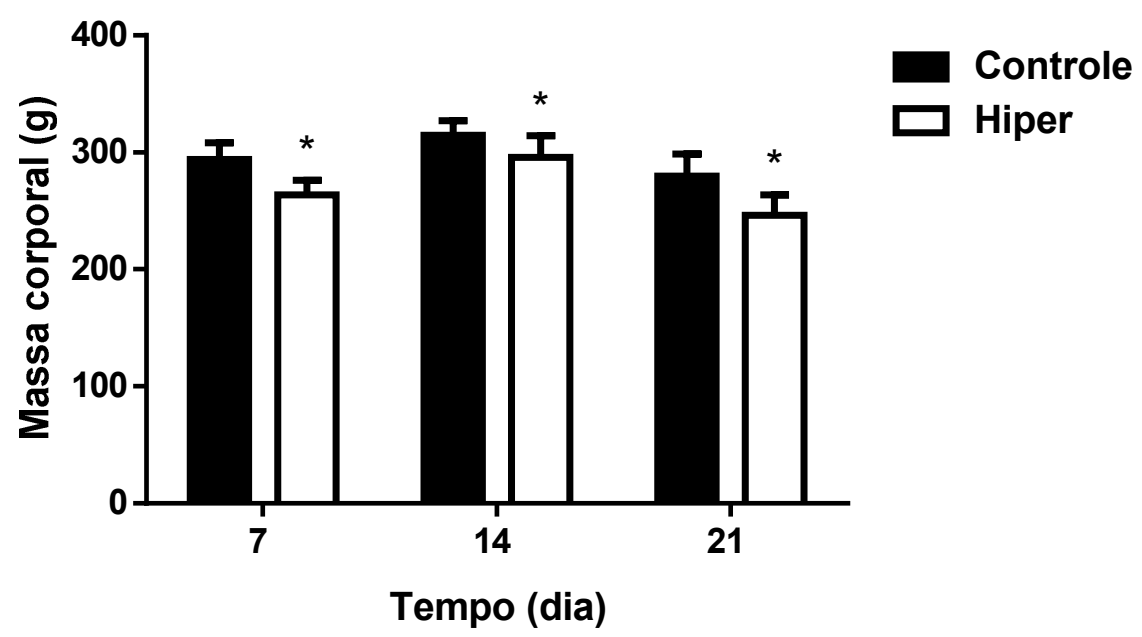

Análise da massa corporal ( $\mathrm{g}$ ) dos animais controles e tratados com hormônio tireoidiano ao término do tratamento por 7, 14 e 21 dias. Os valores são representados como média \pm erro padrão ( $n=6$ para os grupos Controle e Hiper tratados por 7 e 14 dias e $n=3$ para os grupos Controle e Hiper tratados por 21 dias). *vs. controle, sendo $p<0,05$.

\subsubsection{Efeitos do hipertireoidismo sobre a modulação de parâmetros hemodinâmicos}

Os HT apresentam ações clássicas sobre o sistema cardiovascular, sendo a modulação dos parâmetros hemodinâmicos observada em pacientes com alterações de função da glândula tireóide. Os resultados descritos a seguir evidenciam os efeitos do HT sobre a modulação da frequência cardíaca (Figura 8A) e pressão arterial sistólica (Figura 8B). O aumento significativo da FC, observado a partir da primeira semana de tratamento no grupo Hiper, manteve-se até o término do tratamento ( 7 dias: $463,8 \pm 8,05$ vs. $348,5 \pm 15,31$ / 14 dias: $465,4 \pm 17,15$ vs. $326,7 \pm 15,86 / 21$ dias: $510,7 \pm 33,54$ vs. $330,9 \pm 4,95)$. Com relação à análise da pressão arterial sistólica, esse parâmetro mostrou-se significativamente aumentado aos 7 $(163,1 \pm 11,38$ vs. $137,6 \pm 13,78)$ e $14(188,4 \pm 12,72$ vs. $129,2 \pm 10,91)$ dias de tratamento. Ao 
término de 21 dias, no entanto, não foi possível a detecção do pulso correspondente à pressão arterial, uma vez que os animais mostraram-se intensamente agitados, impossibilitando a realização precisa da análise.

Figura 8 - Análise dos parâmetros hemodinâmicos ao término do tratamento

A)

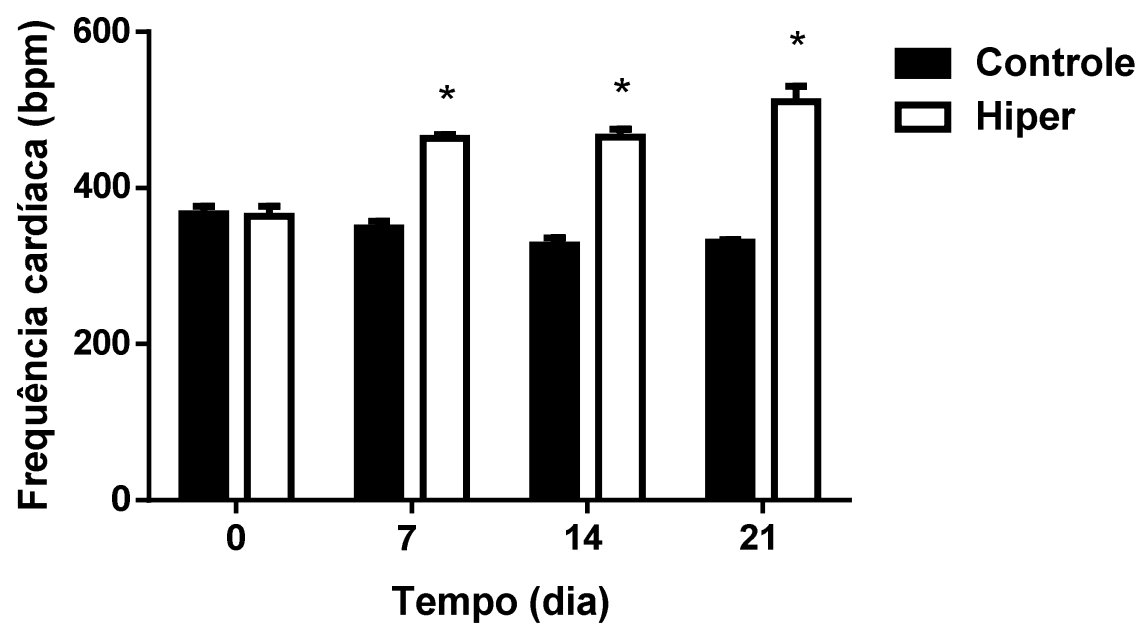

B)

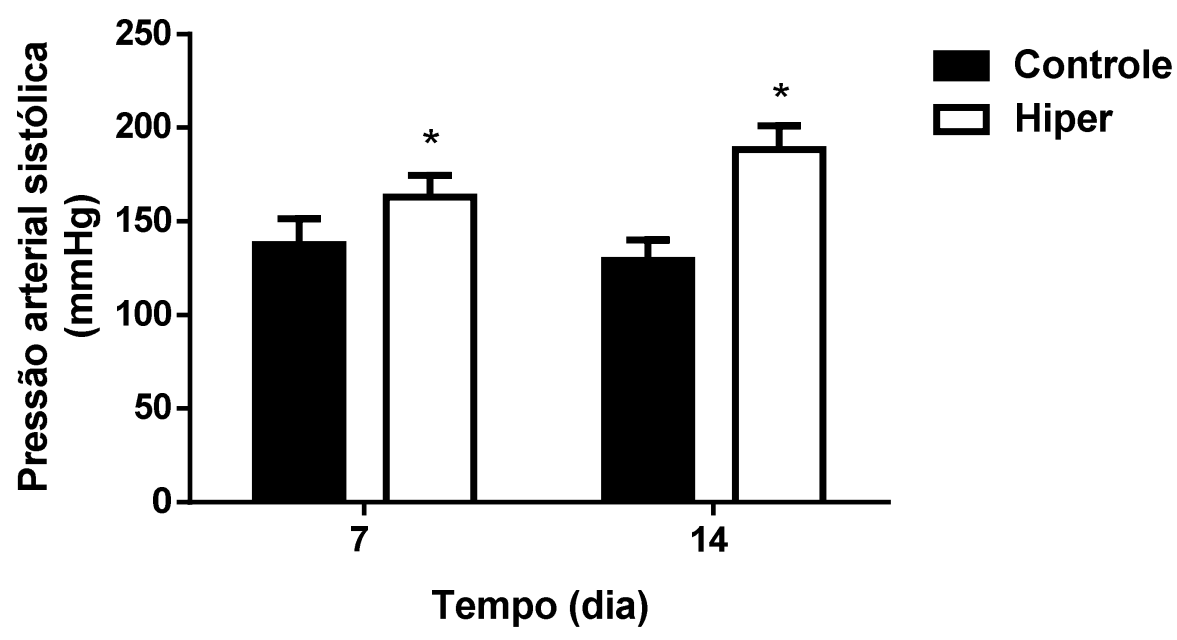

Análise dos parâmetros hemodinâmicos indiretos, obtidos por pletismografia caudal, ao término do tratamento. A) Análise da frequência cardíaca (bpm) dos animais controles e tratados com hormônio tireoidiano por 7, 14 e 21 dias. B) Análise da pressão arterial sistólica $(\mathrm{mmHg})$ dos animais controles e tratados com hormônio tireoidiano por 7 e 14 dias. Os valores são representados como média \pm erro padrão ( $n=3$ para ambos os grupos experimentais). A média representada corresponde à média de cinco medidas para FC e três medidas para PAS. *vs. Controle, sendo $p<0,05$. 


\subsubsection{Efeitos do hipertireoidismo sobre a modulação do trofismo cardíaco}

Os efeitos tróficos promovidos pelos hormônios tireoidianos foram avaliados mediante a análise da razão entre massa cardíaca e comprimento da tíbia dos animais, o qual consiste em um parâmetro bem estabelecido na literatura. O tratamento com hormônio tireoidiano promoveu aumento significativo da massa cardíaca (em g) dos animais do grupo Hiper nos diferentes períodos experimentais (Figura 9A) (7 dias: 1,16 $\pm 0,14$

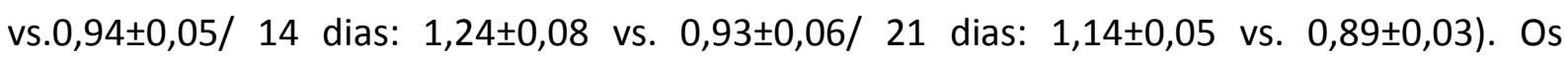
resultados referentes à análise do comprimento da tíbia (Figura 9B) asseguram o uso do comprimento da tíbia como normalizador, uma vez que o tratamento não promoveu alteração dessa variável (7 dias: $37,64 \pm 0,73$ vs. $38,07 \pm 0,56 / 14$ dias: $38,15 \pm 0,79$ vs. $38,87 \pm 0,46 / 21$ dias: $37,61 \pm 1,58$ vs. $38,36 \pm 1,26)$. Os animais submetidos ao hipertireoidismo apresentaram um aumento correspondente a $28 \%$ da razão massa cardíaca/comprimento da

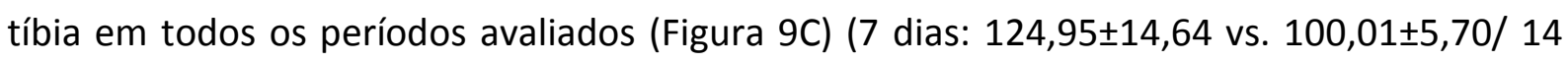
dias: $131,72 \pm 6,39$ vs. $100,08 \pm 6,60 / 21$ dias: $131,96 \pm 11,44$ vs. 100,04 11,58$)$. Os resultados obtidos estão de acordo com dados previamente descritos por nosso grupo (CARNEIRORAMOS et al., 2010; HU et al., 2003) e outros, confirmando a ação trófica do hormônio tireoidiano sobre o músculo cardíaco. Outro parâmetro utilizado com o propósito de avaliação do trofismo cardíaco consiste na análise da razão entre a massa cardíaca e a massa corporal. No entanto, conforme demonstrado anteriormente, (Figura 7), o tratamento com HT induz a uma diminuição na massa corporal dos animais, o que torna este parâmetro pouco fidedigno como meio de comparação. 
Figura 9 - Análise do trofismo cardíaco ao término do tratamento

A)

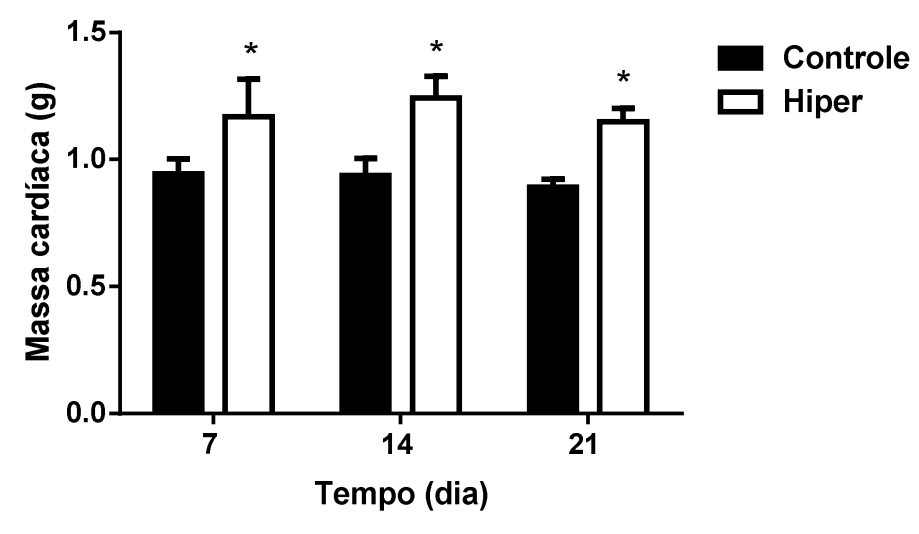

B)

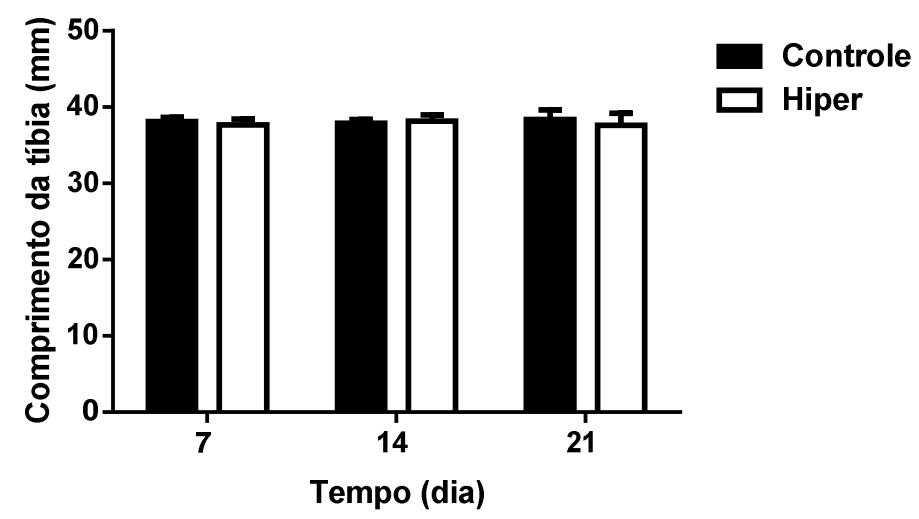

C)

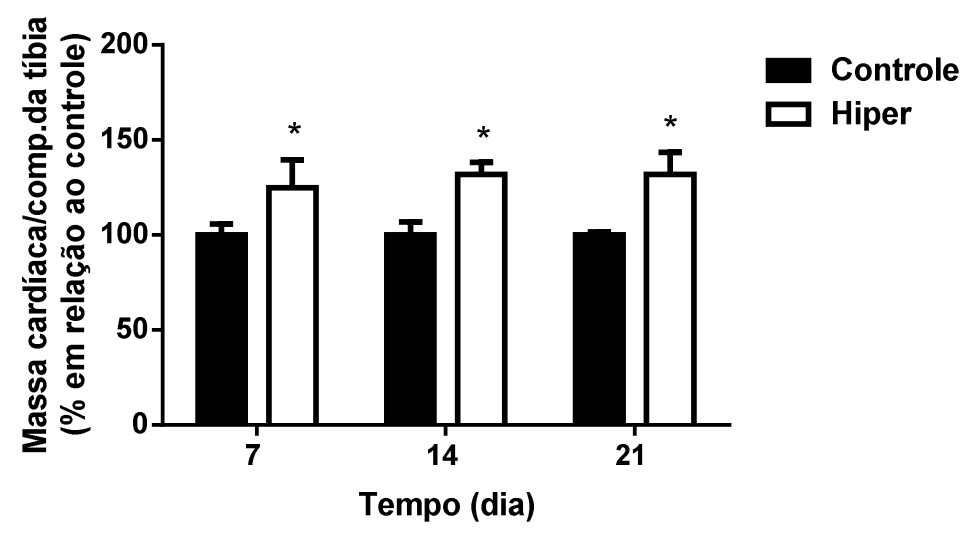

Análise do trofismo cardíaco dos animais controle e tratados com hormônios tireoidianos ao término do tratamento por 7, 14 e 21 dias. A) Análise da massa cardíaca (g); B) Análise do comprimento da tíbia (mm); C) Análise da razão massa cardíaca/comprimento da tíbia (\% em relação ao Controle). Os valores são representados como média \pm erro padrão ( $n=6$ para os grupos Controle e Hiper tratados por 7 e 14 dias e $n=3$ para os grupos Controle e Hiper tratados por 21 dias). *vs. Controle, sendo $p<0,05$. 
5.1.5 Efeitos do hipertireoidismo sobre a modulação da expressão de genes marcadores de hipertrofia cardíaca

Para a caracterização molecular da hipertrofia cardíaca no modelo experimental utilizado foi avaliada a expressão de $\alpha-\mathrm{MHC}$ e $\beta$-MHC no coração dos animais. De acordo com o descrito na literatura, o tratamento com hormônio tireoidiano promove aumento da expressão gênica da miosina de cadeia leve do tipo alpha ( $\alpha-M H C)$, que corresponde à miosina caracterizada por contração rápida, e por outro lado, promove diminuição da miosina de cadeia leve do tipo beta ( $\beta-M H C)$, de contração lenta (DILLMANN, 2010). A expressão de $\alpha-M H C$ (Figura 10A) não foi modulada em função do tratamento. No entanto, a expressão de $\beta$-MHC (Figura 10B) apresentou diminuição significativa em todos os períodos de tratamento analisados. 
Figura 10 - Análise dos níveis de mRNA que codificam marcadores moleculares de hipertrofia cardíaca

A)

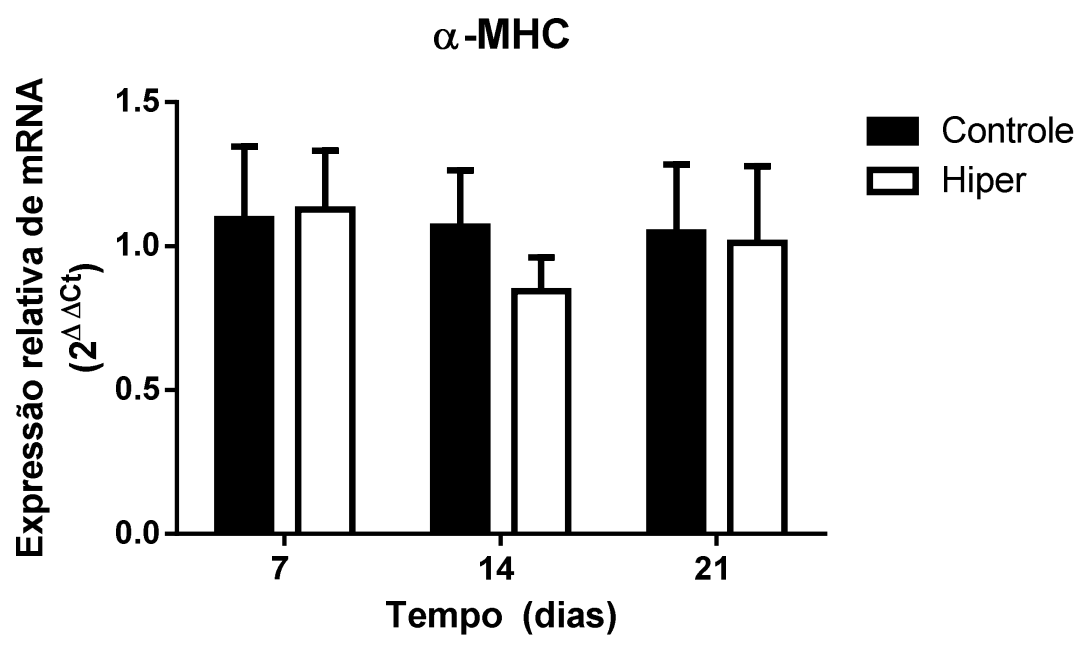

B)

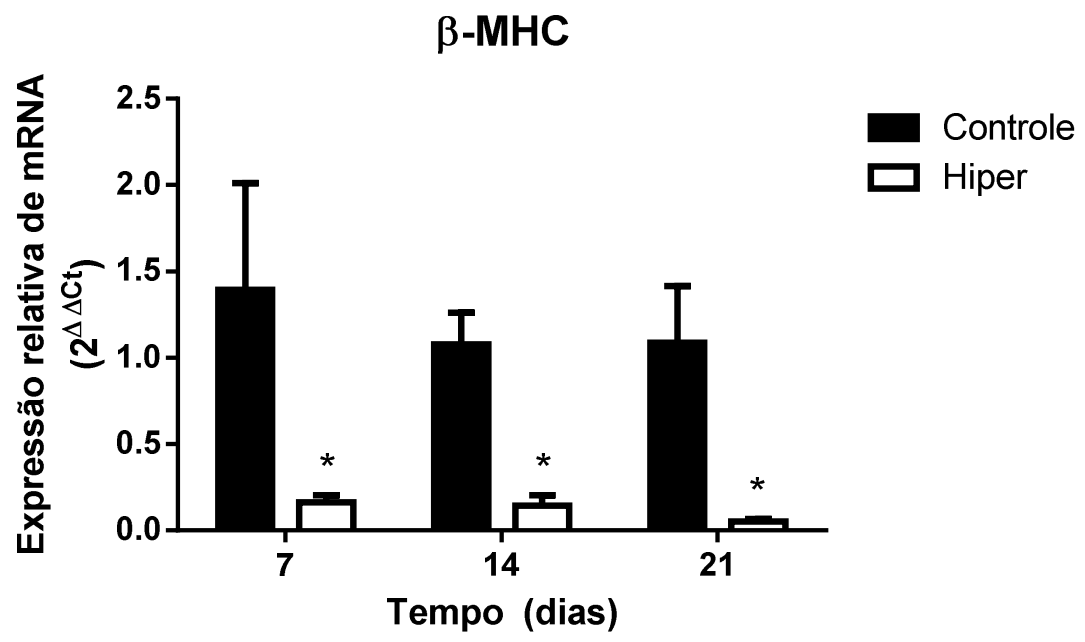

Análise dos níveis de mRNA que codificam $\alpha-\mathrm{MHC}$ e $\beta-\mathrm{MHC}$ no miocárdio normal e hipertrofiado de animais controles e tratados com hormônios tireoidianos por 714 e 21 dias, respectivamente, por RT-PCR em tempo real. A) Análise de $\alpha$-MHC B) Análise de $\beta$-MHC. Os valores são representados como média \pm erro padrão e expressos em vezes de variação em relação ao Controle $\left(2^{\Delta \Delta c t}\right),(n=5$ para os grupos Controle e Hiper tratados por 7 e 14 dias e $n=3$ para os grupos Controle e Hiper tratados por 21 dias). As amostras foram avaliadas em duplicata, na presença de controle negativo. A expressão de GAPDH foi utilizada como controle interno. *vs. Controle, sendo $p<0,05$. 


\subsection{Efeitos do hipertireoidismo sobre o proteassoma cardíaco}

A avaliação do proteassoma cardíaco foi realizada através da análise dos níveis de mRNA que codificam subunidades constituintes do proteassoma (PT20S) e da partícula regulatória $19 S$.

\subsubsection{Análise da expressão gênica das subunidades catalíticas do PT20S}

As subunidades do PT20S avaliadas no presente estudo correspondem às subunidades que apresentam atividade de peptidase, as do tipo $\beta$. Os resultados obtidos sugerem que os HT regulam positivamente a expressão gênica das três subunidades proteassomais. A comparação do nível dos transcritos obtido para cada uma das subunidades evidencia que os HT exercem um efeito padrão sobre sua expressão. $A$ análise dos níveis de mRNA para a subunidade $\beta 2$ foi significativa aos 7 dias de tratamento $(2,10 \pm 0,96$ vs. $1,03 \pm 0,29)$ (Figura 11B). Conforme demostrado (Figura 11C), o tratamento com HT induziu ao aumento dos níveis de mRNA que codificam a subunidade $\beta 5$, no entanto, este aumento não foi considerado estatisticamente significativo, embora o valor seja muito próximo do $\alpha$ pré-determinado (7 dias: $1,78 \pm 0,58$ vs. $1,01 \pm 0,17 ; p=0,0505 / 14$ dias: $1,73 \pm 1,09$ vs. $1,06 \pm 0,35 ; p=0,0866 / 21$ dias: $1,11 \pm 0,06$ vs. $1,00 \pm 0,14)$. 
Figura 11 - Análise dos níveis de mRNA que codificam as subunidades catalíticas constitutivas do PT20S

A)

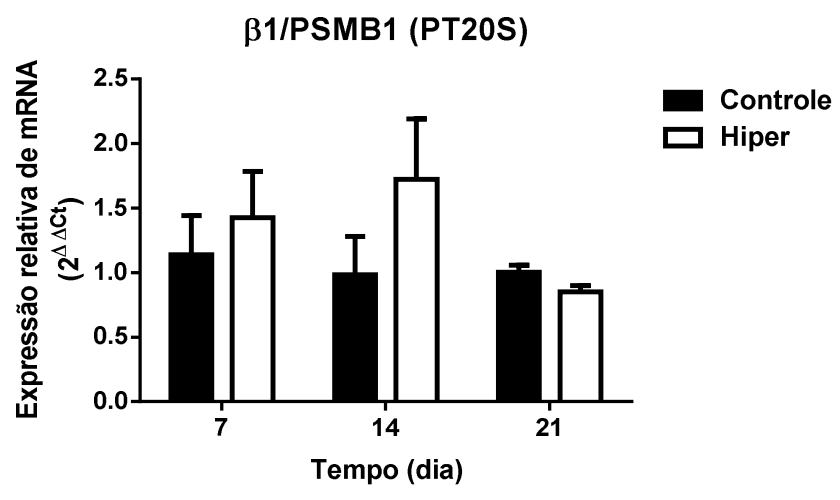

B)

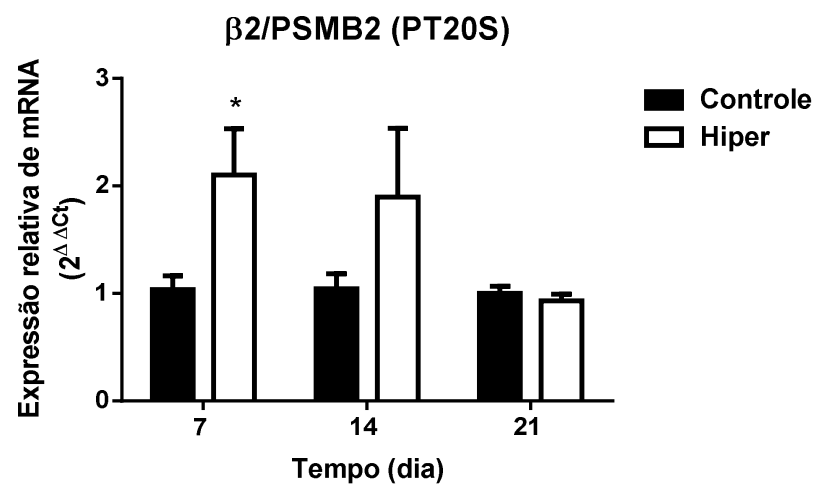

C)

35/PSMB5 (PT20S)

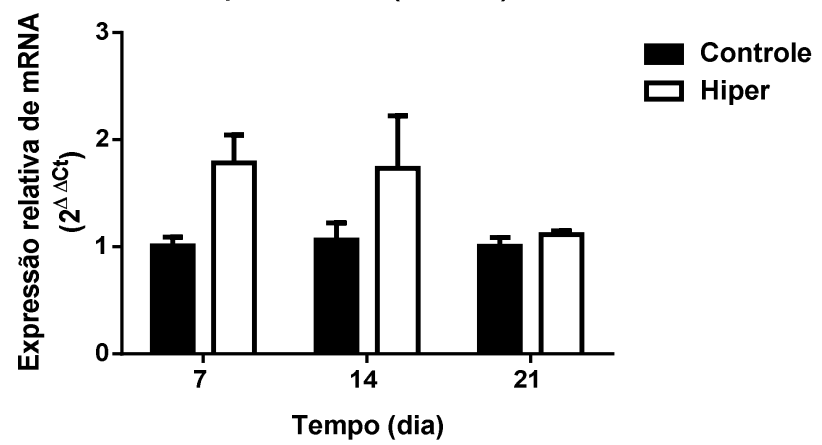

Análise dos níveis de mRNA que codificam as subunidades catalíticas do PT20S no miocárdio normal e hipertrofiado de animais controles e tratados com hormônios tireoidianos por 714 e 21 dias, respectivamente, por RT-PCR em tempo real. A) Análise da subunidade $\beta 1$; B) Análise da subunidade $\beta 2$; C) Análise da subunidade $\beta 5$. Os valores são representados como média \pm erro padrão e expressos em vezes de variação em relação ao Controle $\left(2^{\Delta \Delta c t}\right)$, ( $n=5$ para os grupos Controle e Hiper tratados por 7 e 14 dias e $n=3$ para os grupos Controle e Hiper tratados por 21 dias). As amostras foram avaliadas em duplicata, na presença de um controle negativo. A expressão de GAPDH foi utilizada como controle interno. *vs. Controle, sendo $p<0,05$. 


\subsubsection{Análise da expressão gênica das subunidades da partícula regulatória 195}

Para avaliação das subunidades da partícula regulatória 195 foram analisados os níveis de mRNA de duas subunidades consideradas ATPases (Rpt1 e Rpt6) e uma não-ATPase (Rpn6), as quais constituem a base e a tampa desta partícula, respectivamente. As subunidades da base têm contato direto com a partícula catalítica do proteassoma e estão envolvidas com a abertura do centro catalítico. Já as subunidades da tampa estão envolvidas com o reconhecimento da cadeia de poliubiquitinas que marcam o substrato proteico alvo para a degradação. Conforme demonstrado (Figura 12A) o tratamento com HT promoveu aumento significativo da expressão de Rpt1 aos 7 dias $(2,12 \pm 0,34$ vs. 1,16 $\pm 0,31)$. O mesmo foi observado quanto à subunidade Rpn6 (Figura 12C), também aos 7 dias de tratamento $(3,39 \pm 0,57$ vs. $1,44 \pm 0,72)$. 
Figura 12 - Análise dos níveis de mRNA que codificam as subunidades constitutivas da partícula regulatória PT19S

A)

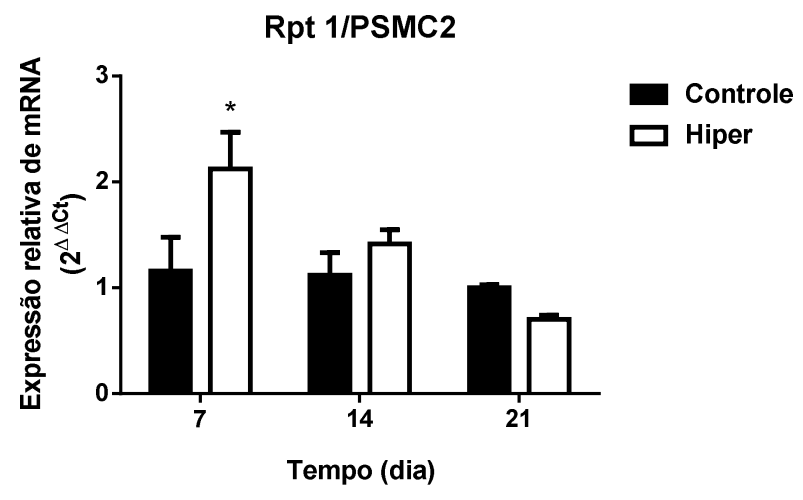

B)

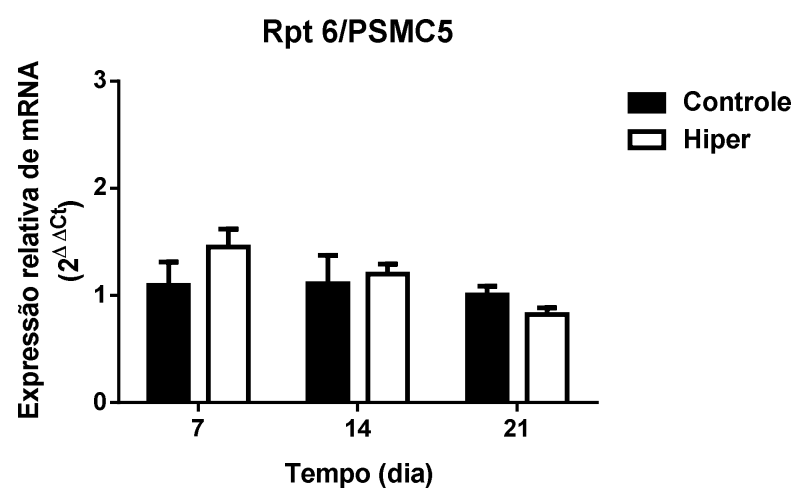

C)

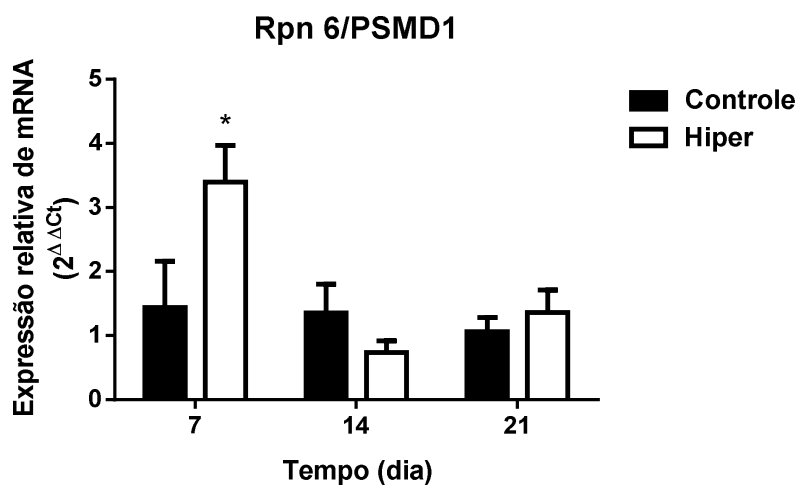

Análise dos níveis de mRNA que codificam as subunidades da partícula regulatória 195 no miocárdio normal e hipertrofiado de animais controles e tratados com hormônios tireoidianos por 7, 14 e 21 dias, respectivamente, por RT-PCR em tempo real. A) Análise da subunidade Rpt1; B) Análise da subunidade Rpt6; C) Análise da subunidade Rpn6. Os valores são representados como média \pm erro padrão e expressos em vezes de variação em relação ao Controle $\left(2^{\Delta \Delta C t}\right)$, ( $n=5$ para os grupos Controle e Hiper tratados por 7 e 14 dias e $n=3$ para os grupos Controle e Hiper tratados por 21 dias). As amostras foram avaliadas em duplicata, na presença de um controle negativo. A expressão de GAPDH foi utilizada como controle interno. *vs. Controle, sendo $p<0,05$. 


\subsubsection{Análise da expressão de POMP no tecido cardíaco}

POMP (Proteasome Maturation Protein, ou ainda, proteassemblin) corresponde a uma proteína acessória de mamíferos, homóloga à Ump1 (Ubiquitin-Mediated Proteolysis), identificada em Saccharomyces cerevisia (BURRI et al., 2000). Estudos de caracterização de POMP demostraram que a biogênese do PT20S, em mamíferos, é mediada por precursores complexos, que apresentam subunidades $\alpha$ e $\beta$ não processadas, e que POMP assessora o assembly desses hemiproteassomas (WITT et al., 2000; RAMOS et al., 1998).

Assim, na tentativa de entender melhor os resultados referentes à expressão das subunidades correspondentes à partícula regulatória e catalítica do proteassoma, foram avaliados os níveis de mRNA que codificam POMP no miocárdio dos animais controles e tratados com hormônio tireoidiano. Embora não seja estatisticamente significativo, foi observada uma tendência ao aumento da expressão gênica de POMP nos períodos de 7 e 14 dias de tratamento (Figura 13). Ao comparar a modulação deste gene entre os diferentes grupos, é possível observar que este, aparentemente, é regulado negativamente conforme o tempo de tratamento. Este resultado nos indica que, nos períodos mais precoces da hipertrofia cardíaca, parece ocorrer aumento do assembly do proteassoma e, embora este estímulo hipertrófico persista (14 e 21 dias de tratamento), a expressão de POMP diminui. Considerando que não há diferença quanto ao grau de hipertrofia cardíaca entre os tempos de tratamento contemplados no presente estudo, é possível sugerir que aumento do proteassoma seja importante em um período inicial do estímulo hipertrófico. 
Figura 13 - Análise dos níveis de mRNA que codificam POMP

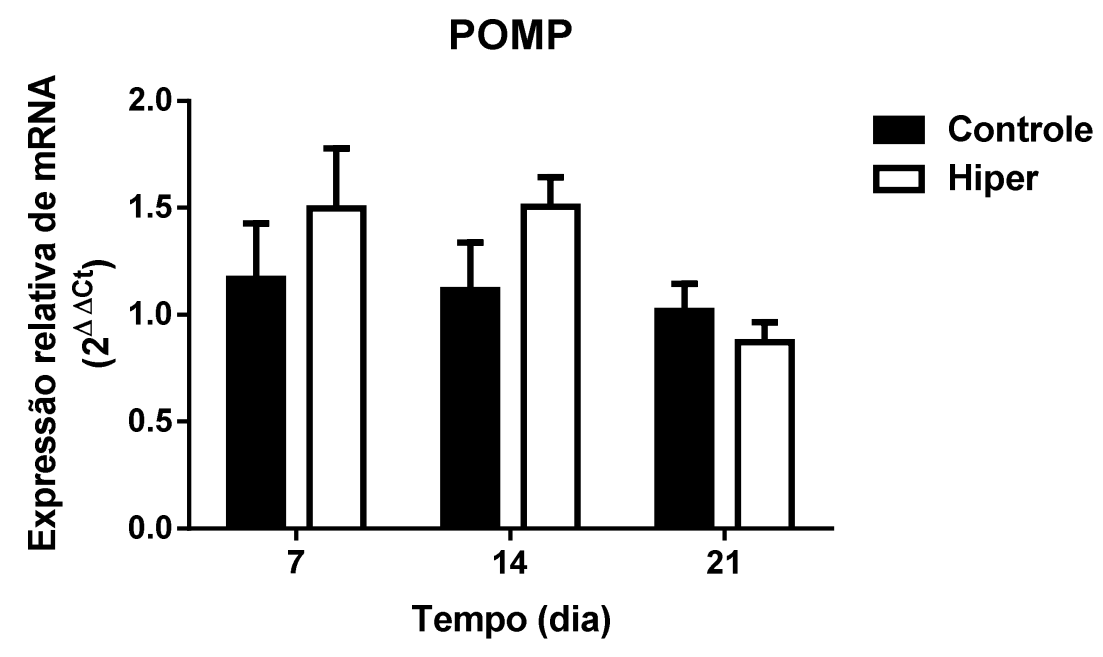

Análise dos níveis de mRNA que codificam POMP no miocárdio normal e hipertrofiado de animais controles e tratados com hormônios tireoidianos por 7, 14 e 21 dias, respectivamente, por RT-PCR em tempo real. Os valores são representados como média \pm erro padrão e expressos em vezes de variação em relação ao Controle $\left(2^{\Delta \Delta C t}\right)$, ( $n=5$ para os grupos Controle e Hiper tratados por 7 e 14 dias e $\mathrm{n}=3$ para os grupos Controle e Hiper tratados por 21 dias). As amostras foram avaliadas em duplicata, na presença de um controle negativo. A expressão de GAPDH foi utilizada como controle interno. *vs. Controle, sendo $p<0,05$.

\subsubsection{Atividade do PT20S e PT26S no tecido cardíaco}

O proteassoma, como explanado previamente, apresenta três atividades proteolíticas (tipo quimiotripsina, tipo tripsina e tipo caspase). O sítio catalítico semelhante à quimiotripsina, conferido à subunidade $\beta 5$, corresponde ao mais expressivo em termos de atividade. A seguir, encontram-se descritos os resultados referentes à análise da atividade do tipo quimiotripsina do PT20S (Figura 14A), realizado na ausência de ATP, e do PT26S (Figura 14B), realizado na presença de ATP. Conforme demonstrado, a atividade catalítica do PT20S apresentou-se significativamente diminuída no miocárdio hipertrofiado dos animais

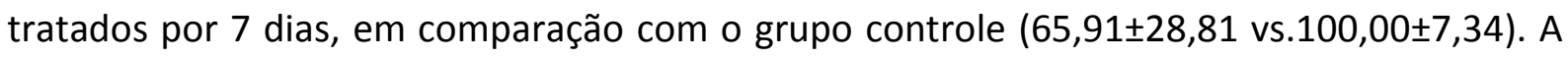
atividade proteolítica correspondente ao UPS foi distinguida dos demais através do uso de um inibidor farmacológico específico para as subunidades $\beta 1$ e $\beta 5$ (Bortezomibe), em ensaios realizados em paralelo. Com relação ao ensaio realizado na presença de ATP, foi observado aumento significativo no grupo Hiper tratado por 7 dias $(116,70 \pm 5,38$ vs. $100,00 \pm 4,04)$. 
Figura 14 - Análise da atividade do tipo quimiotripsina do proteassoma

A)

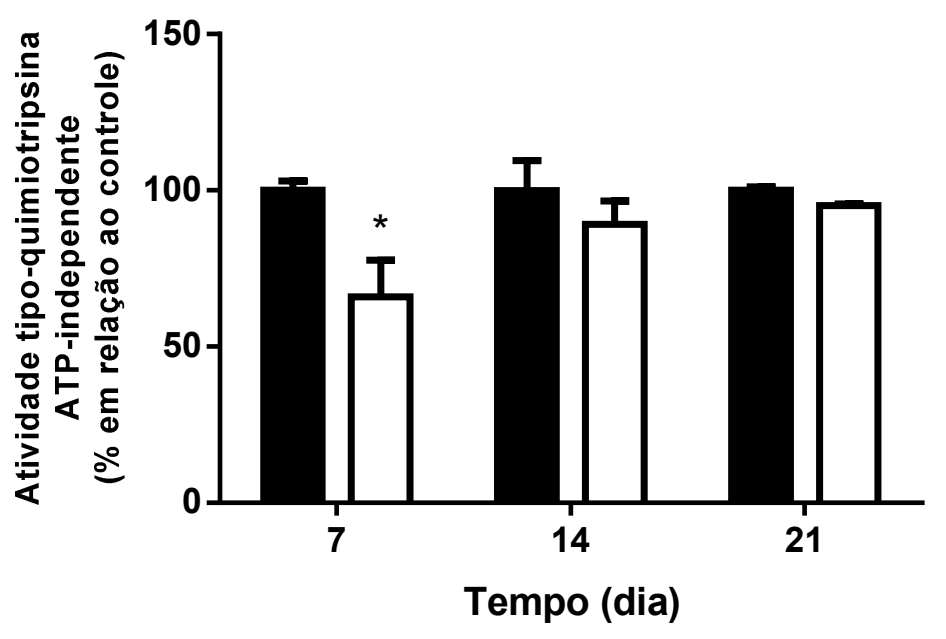

B)

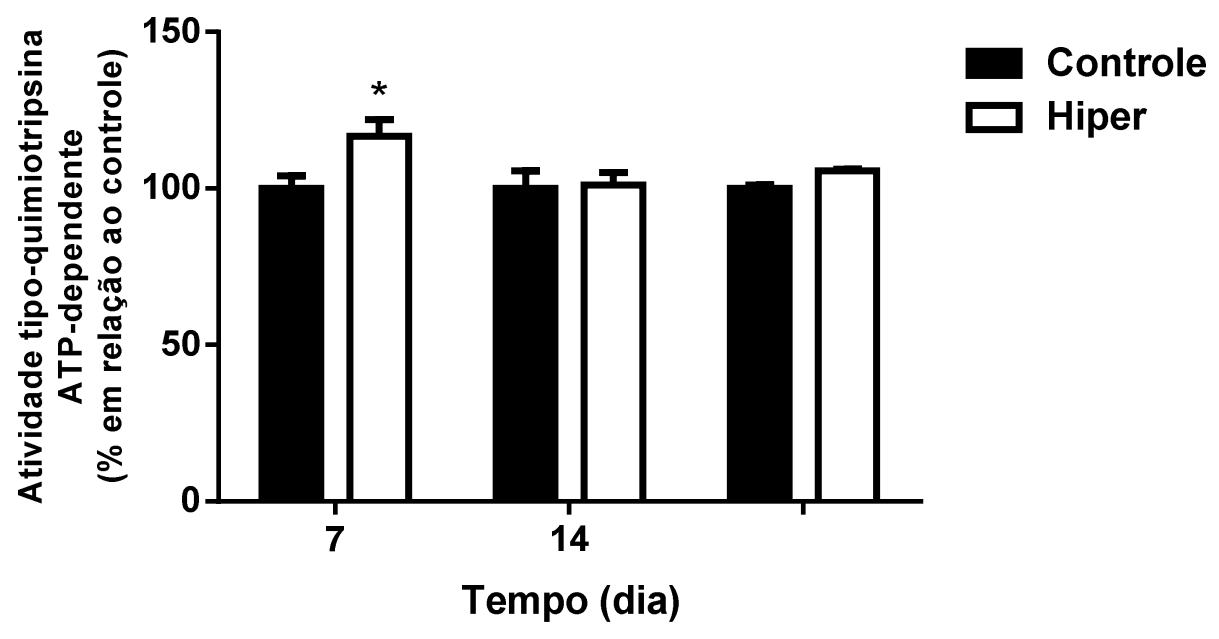

Análise da atividade do tipo quiomiotripsina do proteassoma no miocárdio normal e hipertrofiado de animais controles e tratados com hormônio tireoidiano por 7, 14 e 21 dias. A) Análise da atividade do proteassoma 20S, realizado na ausência de ATP. B) Análise do proteassoma 26S, realizado na presença de ATP. Os valores são representados como média \pm erro padrão e expressos em porcentagem em relação ao Controle ( $n=6$ para os grupos Controle e Hiper tratados por 7 e 14 dias e $\mathrm{n}=3$ para os grupos Controle e Hiper tratados por 21 dias). As amostras foram avaliadas em duplicata. *vs. Controle, sendo $p<0,05$. 
5.2.5 Efeitos do hipertireoidismo sobre a expressão de proteínas poliubiquitinadas no tecido cardíaco

A análise da expressão tecidual de proteínas poliubiquitinadas consiste em um dos principais ensaios como indicador da atividade proteassomal. Isto porque a ubiquitinação, necessária para que ocorra a degradação mediada pelo proteassoma $26 \mathrm{~S}$, consiste em uma etapa independente da degradação. Neste sentido, o acúmulo de proteínas poliubiquitinadas sugere o comprometimento da proteólise mediada pelo PT. Os resultados obtidos demonstram que a hipertrofia cardíaca promovida pelos HT não é acompanhada de alteração da expressão de proteínas poliubiquitinadas no tecido cardíaco (Figura 15). 
Figura 15 - Expressão de proteínas poliubiquitinadas

A)

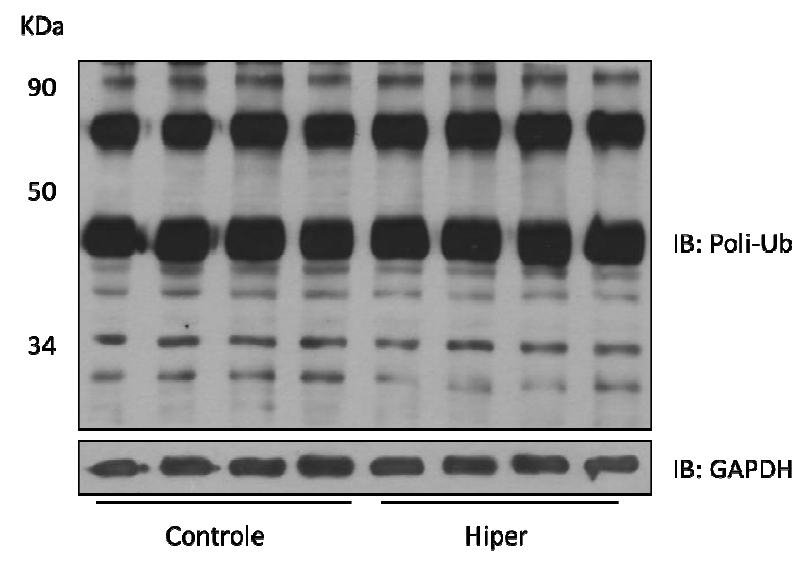

B)

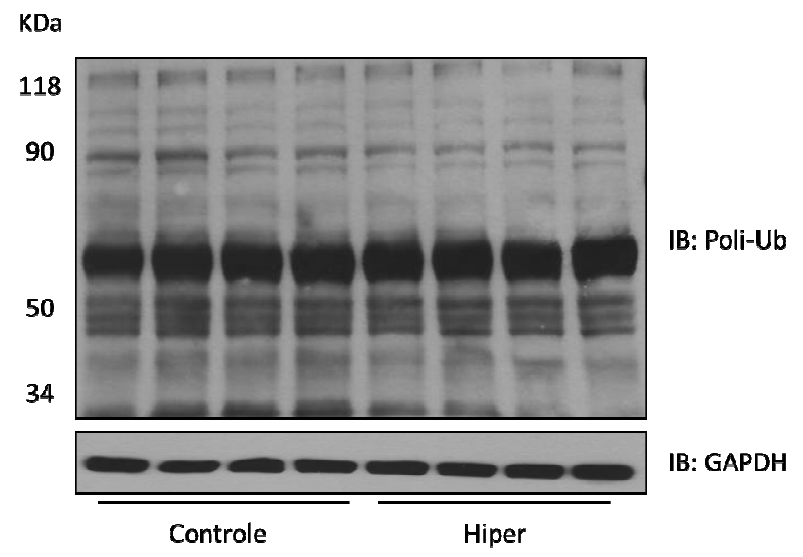

C)

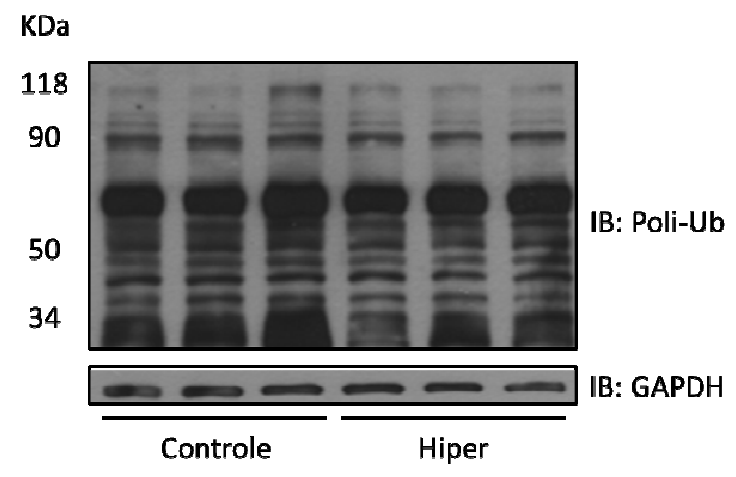

Imagem representativa da expressão de proteínas poliubiquitinadas no miocárdio normal e hipertrofiado de animais controles e tratados com hormônios tireoidianos, respectivamente, por Western Blotting. A) Proteínas poliubiquitinadas de animais tratados por 7 dias; B) Proteínas poliubiquitinadas de animais tratados por 14 dias; C) Proteínas poliubiquitinadas de animais tratados por 21 dias, ( $n=5$ para os grupos Controle e Hiper tratados por 7 e 14 dias e $n=3$ para os grupos Controle e Hiper tratados por 21 dias). A expressão de GAPDH foi utilizada como controle interno. *vs. Controle, sendo $p<0,05$. 


\subsubsection{Efeitos do hipertireoidismo sobre o estado oxidativo do tecido cardíaco - proteínas carboniladas.}

A carbonilação de proteínas consiste em um dano oxidativo irreversível, comumente associado à perda de função proteica. Embora as proteínas, moderadamente carboniladas, sejam degradadas por via proteassomal, as altamente carboniladas tendem a formar agregados proteicos de alto peso molecular, os quais são resistentes à degradação e se acumulam no meio intracelular. Esses agregados proteicos podem inibir a atividade do PT20S (DALLE-DONNE et al., 2006). O estado hipertireoideo, por sua vez, caracteriza-se pelo aumento do metabolismo energético (VENDITTI; DI MEO, 2006) e estudos sugerem que esteja envolvido com o aumento da produção de espécies reativas de oxigênio (ARAUJO et al., 2011; GREDILLA; BARJA; LOPEZ-TORRES, 2001; GUERRERO et al., 1999). No hipotireoidismo, ao contrário, observa-se a diminuição na produção de radicais livres e, consequentemente, menor dano aos lipídeos, proteínas e DNA (LOPEZ-TORRES; ROMERO; BARJA, 2000). Assim, considerando a diminuição observada na atividade referente ao PT20S, foi avaliada a expressão de proteínas carboniladas no miocárdio normal e hipertrofiado (Figura 16). 
Figura 16 - Expressão de proteínas carboniladas

A)

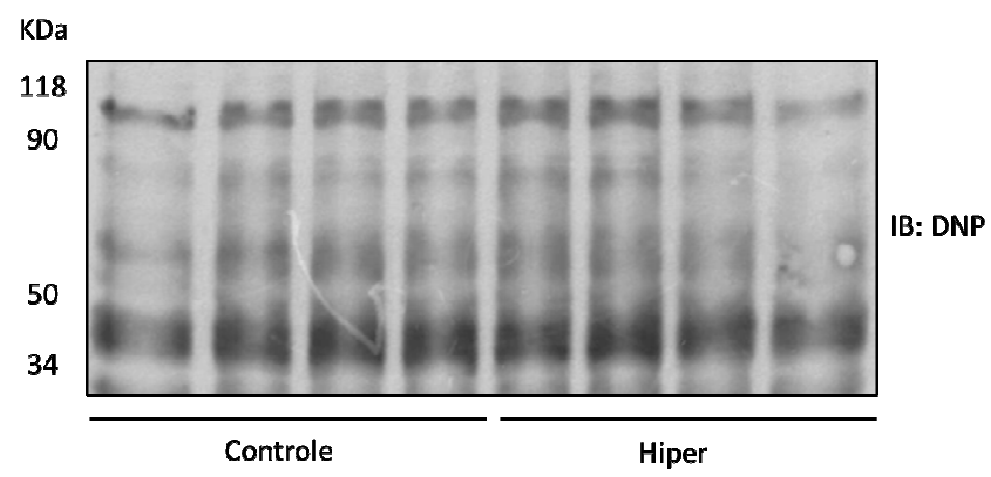

B)

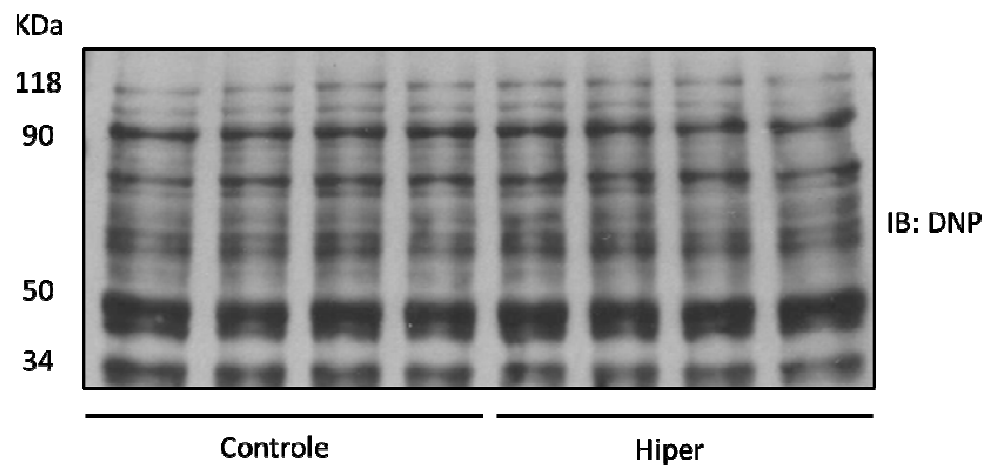

Imagem representativa da expressão de proteínas carboniladas no miocárdio normal e hipertrofiado de animais controles e tratados com hormônios tireoidianos, respectivamente, por Western Blotting. A) Expressão de DNP no coração de animais tratados por 7 dias; B) Expressão de DNP no coração de animais tratados por 14 dias; ( $n=4$ para os grupos Controle e Hiper tratados por 7 e 14 dias). A expressão de GAPDH (37KDa) foi utilizada como controle interno. *vs. Controle, sendo $p<0,05$.

Conforme demostrado, não foi observado aumento da expressão de proteínas carboniladas no miocárdio dos animais Hiper, tratados por 7 e 14 dias. Esses resultados sugerem, portanto, que a diminuição da atividade do proteassoma 20 S não seja devida ao aumento do estresse oxidativo e dano à estrutura do proteassoma. 


\subsection{Efeitos do hipertireoidismo sobre a expressão de E3 ligases no tecido cardíaco}

\subsubsection{Efeitos do hipertireoidismo sobre a expressão de MuRF1 no tecido cardíaco}

Os resultados referentes à análise da expressão gênica de MuRF1 no tecido cardíaco de animais tratados com HT por 7, 14 e 21 dias encontram-se a seguir (Figura 17). Conforme pode ser observado, o tratamento com HT promoveu a diminuição significativa na expressão gênica de MuRF1 nos períodos de $7(0,56 \pm 0,11$ vs. $1,07 \pm 0,44)$ e $14(0,45 \pm 0,28$ vs. $1,02 \pm 0,24)$ dias de tratamento.

Figura 17 - Análise dos níveis de mRNA que codificam MuRF1

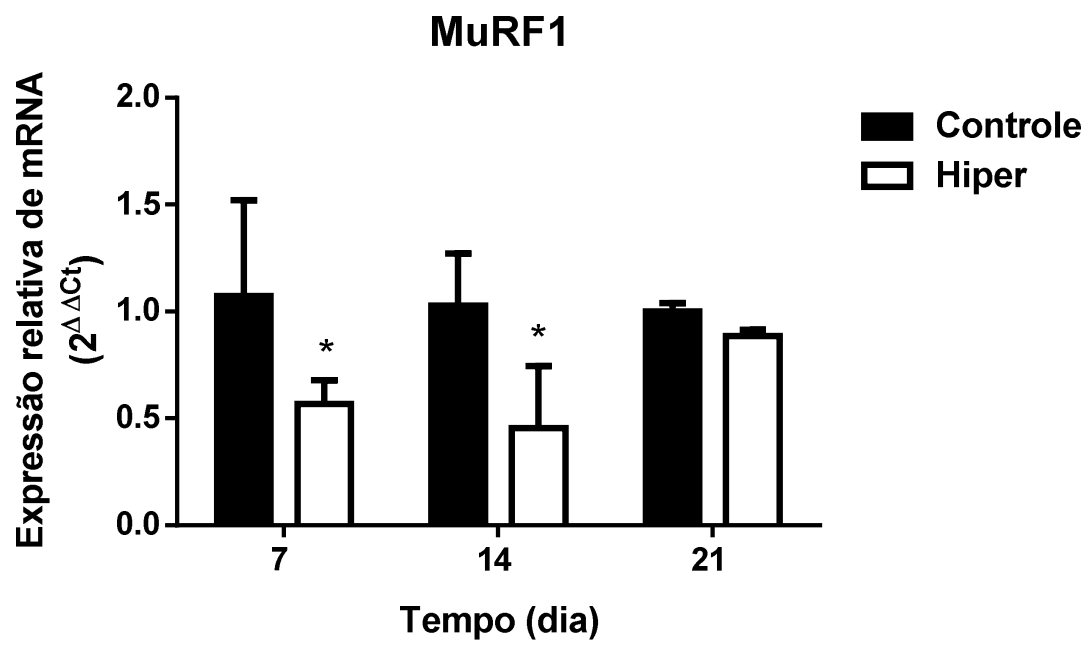

Análise dos níveis de mRNA que codificam MuRF1 no miocárdio normal e hipertrofiado de animais controles e tratados com hormônios tireoidianos por 7, 14 e 21 dias, respectivamente, por RT-PCR em tempo real. Os valores são representados como média \pm erro padrão e expressos em vezes de variação em relação ao Controle $\left(2^{\Delta \Delta c t}\right),(n=5$ para os grupos Controle e Hiper tratados por 7 e 14 dias e $n=3$ para os grupos Controle e Hiper tratados por 21 dias). As amostras foram avaliadas em duplicata, na presença de um controle negativo. A expressão de GAPDH foi utilizada como controle interno. *vs. Controle, sendo $p<0,05$. 
Embora o hipertireoidismo tenha promovido diminuição da expressão gênica de MuRF1, os resultados referentes à expressão proteica mostraram-se inalterados nos três períodos de tratamento, conforme observado a seguir (Figura 18).

Figura 18 - Expressão proteica de MuRF1

A)

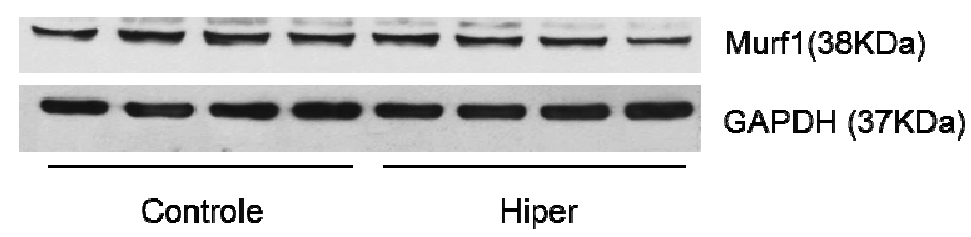

B)

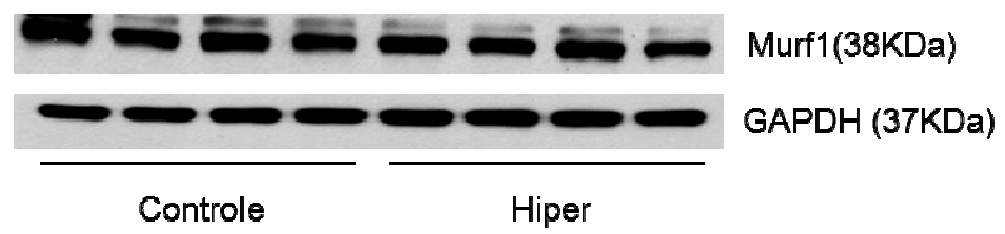

C)

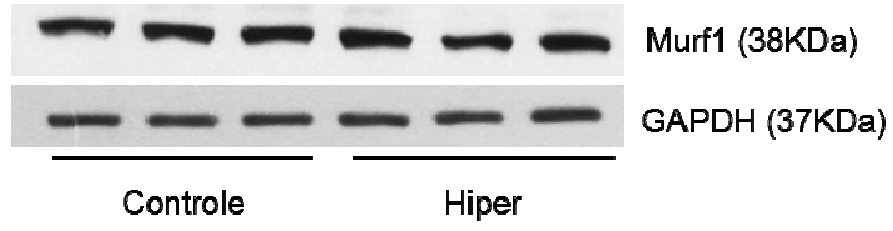

Imagem representativa da expressão proteica de MuRF1 (38KDa) no miocárdio normal e hipertrofiado de animais controles e tratados com hormônios tireoidianos, respectivamente, por Western Blotting. A) Expressão de MuRF1 no coração de animais tratados por 7 dias; B) Expressão de MuRF1 no coração de animais tratados por 14 dias; C) Expressão de MuRF1 no coração de animais tratados por 21 dias; ( $n=4$ para os grupos Controle e Hiper tratados por 7 e 14 dias e $n=3$ para os grupos tratados por 21 dias). A expressão de GAPDH (37KDa) foi utilizada como controle interno. *vs. Controle, sendo $p<0,05$. 


\subsubsection{Efeitos do hipertireoidismo sobre a expressão de Atrogin/MAFbx no tecido cardíaco}

Os níveis de mRNA para Atrogin/MAFbx parecem ser modulados ao longo do processo de hipertrofia cardíaca promovida pelo HT (Figura 19). Embora os resultados não sejam estatisticamente significativos, é possível observar uma tendência ao aumento aos 7 dias e diminuição ao 14 dias de tratamento.

Figura 19 - Análise dos níveis de mRNA que codificam Atrogin/MAFbx

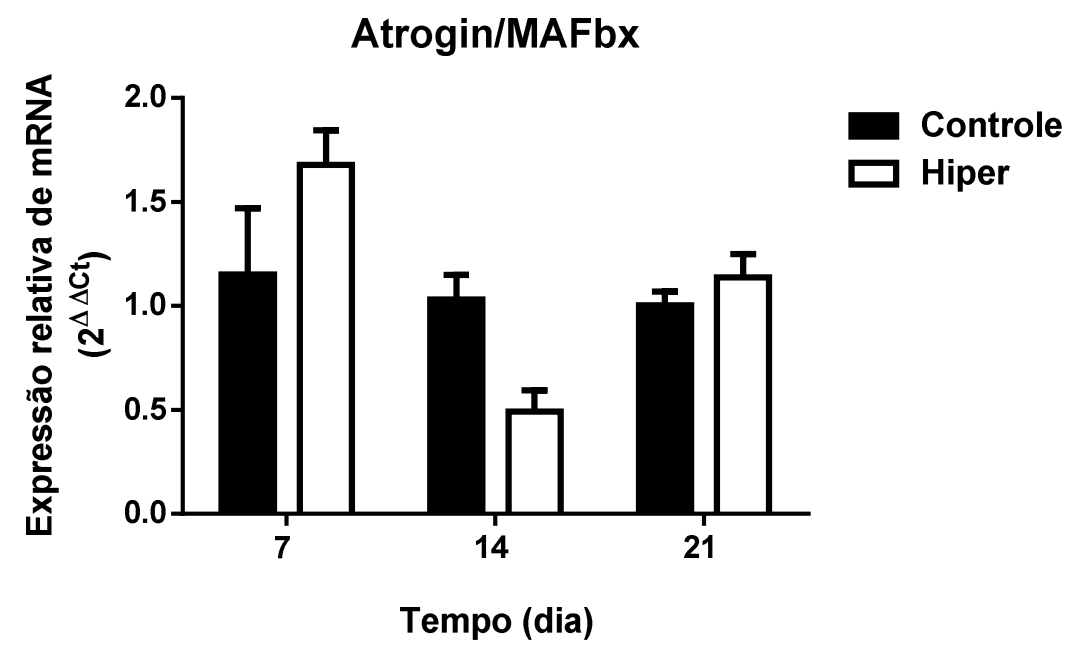

Análise dos níveis de mRNA que codificam Atrogin/MAFbx no miocárdio normal e hipertrofiado de animais controles e tratados com hormônios tireoidianos por 7, 14 e 21 dias, respectivamente, por RT-PCR em tempo real. Os valores são representados como média \pm erro padrão e expressos em vezes de variação em relação ao Controle $\left(2^{\Delta \Delta C t}\right),(n=5$ para os grupos Controle e Hiper tratados por 7 e 14 dias e $n=3$ para os grupos Controle e Hiper tratados por 21 dias). As amostras foram avaliadas em duplicata, na presença de um controle negativo. A expressão de GAPDH foi utilizada como controle interno. *vs. Controle, sendo $p<0,05$. 
Além da análise da expressão gênica, também foi avaliada a expressão proteica de Atrogin/MAFbx no tecido cardíaco. Conforme demonstrado (Figura 20), a modulação observada quanto à expressão gênica parece não ser acompanhada da proteica.

Figura 20 - Expressão proteica de Atrogin/MAFbx

A)

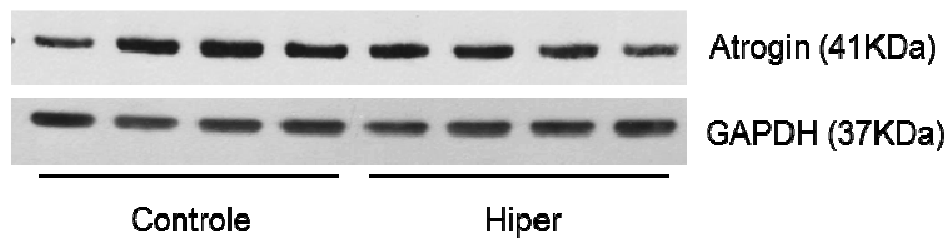

B)

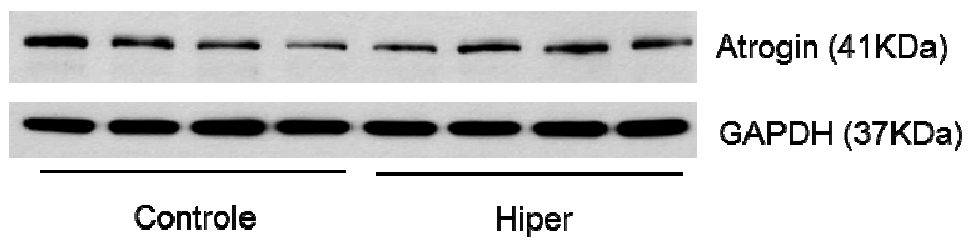

C)

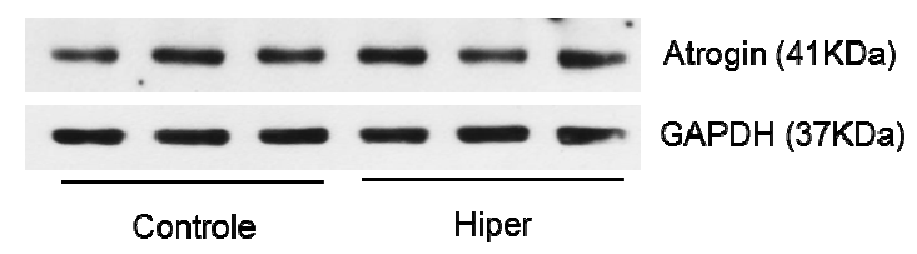

Imagem representativa da expressão proteica de Atrogin/MAFbx (41KDa) no miocárdio normal e hipertrofiado de animais controles e tratados com hormônios tireoidianos, respectivamente, por Western Blotting. A) Expressão de Atrogin/MAFbx no coração de animais tratados por 7 dias; B) Expressão de Atrogin/MAFbx no coração de animais tratados por 14 dias; C) Expressão de Atrogin/MAFbx no coração de animais tratados por 21 dias; ( $n=4$ para os grupos Controle e Hiper tratados por 7 e 14 dias e $n=3$ para os grupos tratados por 21 dias). A expressão de GAPDH (37KDa) foi utilizada como controle interno. *vs. Controle, sendo $p<0,05$. 


\subsubsection{Efeitos do hipertireoidismo sobre a expressão de E3- $\alpha / U B R 1$ no tecido cardíaco}

Não existem evidências na literatura da avaliação da expressão de E3- $\alpha$ /UBR1 no músculo cardíaco, apenas no esquelético. Considerando o compartilhamento das vias de sinalização intracelular entre músculo cardíaco e esquelético, além dos efeitos antihipertróficos observados para outras E3-ligases avaliadas (MuRF1 e Atrogin/MAFbx), foi contemplada a avaliação de E3- $\alpha$ /UBR1 no coração de animais controle e submetidos ao hipertireoidismo. Como pode ser observada (Figura 21), a expressão gênica de E3- $\alpha /$ UBR1 apresentou forte tendência à diminuição $(p=0,0908)$ nos corações de animais tratados com HT por 14 dias $(0,57 \pm 0,45$ vs. $1,13 \pm 0,50)$, enquanto que nos outros dois períodos sua expressão é semelhante ao respectivo controle.

Figura 21 - Análise dos níveis de mRNA que codificam E3- $\alpha$ /UBR1

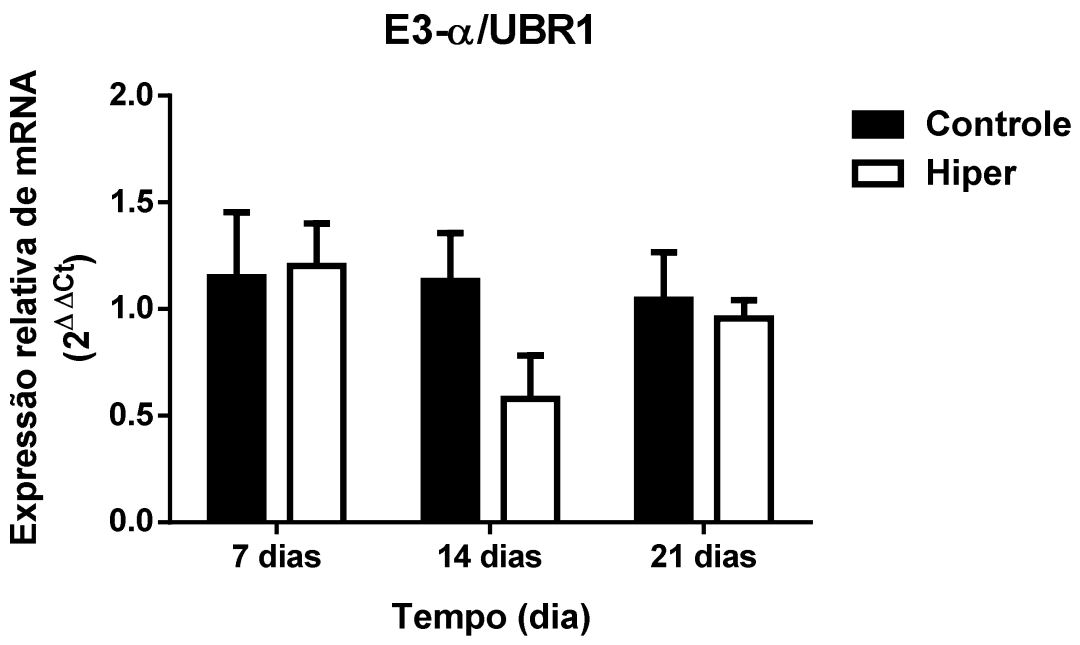

Análise dos níveis de mRNA que codificam E3- $\alpha$ /UBR1 no miocárdio normal e hipertrofiado de animais controles e tratados com hormônios tireoidianos por 7, 14 e 21 dias, respectivamente, por RT-PCR em tempo real. Os valores são representados como média \pm erro padrão e expressos em vezes de variação em relação ao Controle $\left(2^{\Delta \Delta c t}\right),(n=5$ para os grupos Controle e Hiper tratados por 7 e 14 dias e $n=3$ para os grupos Controle e Hiper tratados por 21 dias). As amostras foram avaliadas em duplicata, na presença de um controle negativo. A expressão de GAPDH foi utilizada como controle interno. ${ }^{*}$ vs. Controle, sendo $p<0,05$. 


\section{DISCUSSÃO}

O presente estudo teve como objetivo caracterizar o Sistema Ubiquitina Proteassoma na hipertrofia cardíaca induzida pelo hormônio tireoidiano Para isso, foram contemplados objetivos relacionados ao processo de ubiquitinação e ao complexo responsável pela degradação proteica, o proteassoma. A fim de nos certificarmos da eficiência do tratamento com T3 para indução do hipertireoidismo e desenvolvimento da hipertrofia cardíaca foram realizadas análises de caracterização do modelo experimental. A respeito do processo de ubiquitinação, foram avaliadas enzimas denominadas E3-Ligases, as quais conferem especificidade à degradação mediada pelo proteassoma 26S. Desta forma, foram selecionadas E3-Ligases conhecidamente relacionadas ao remodelamento cardíaco, MuRF1 e Atrogin1, relacionadas ao processo de atrofia muscular. Quanto ao proteassoma, foi avaliada a expressão de proteínas poliubiquitinadas, bem como a expressão gênica de subunidades constituintes da partícula regulatória e catalítica do proteassoma e atividade do tipo quimiotripsina do proteassoma $20 \mathrm{~S}$ e $26 \mathrm{~S}$.

\subsection{Modelo de hipertrofia cardíaca promovida pelo hormônio tireoidiano}

O estado hipertireoideo dos animais foi confirmado através da dosagem dos níveis séricos de T3 e T4 total por radioimunoensaio. Conforme demonstrado anteriormente, os animais tratados com T3 apresentaram redução significava da fração total de T4. Sabe-se que os hormônios tireoidianos são regulados por um mecanismo de feedback negativo, no qual os níveis circulantes de HT inibem ou estimulam o eixo hipotálamo-hipófise-tireóide para a síntese e secreção de hormônios pela glândula tireóide. Portanto, a diminuição significativa de T4 total observada sugere a eficiência dessa alça central de regulação em resposta ao tratamento. Estudos prévios do laboratório já haviam demostrado redução nos níveis de T4, tanto da fração livre quanto da fração total, em animais submetidos às mesmas condições experimentais (ANJOS-RAMOS et al., 2006; CARNEIRO-RAMOS et al. 2006). Os níveis de T3 total, por outro lado, apresentou-se significativamente aumentado apenas nos animais tratados por 7 dias. O tempo de meia-vida do T4 é consideravelmente maior que o T3. O do T4 é de aproximadamente de 6 dias, enquanto a do T3 é de apenas 18 a 24 horas. Há de se considerar que o hormônio injetado nos animais corresponde a uma fração livre, 
não associada a proteínas carreadoras. Desta forma, a degradação do hormônio em excesso por desiodases deve ser rápida, o que justifica não observarmos diferenças quanto aos níveis séricos nos animais tratados por 14 e 21 dias. Os resultados apresentados pelo grupo tratado por 7 dias, no entanto, foram inesperados.

No intuito de melhor caracterizar o modelo experimental utilizado, os efeitos dos hormônios tireoidianos, comumente descritos na literatura, foram analisados. Os hormônios tireoidianos exercem significativa influência sobre o metabolismo basal através do aumento do consumo periférico de oxigênio e da hidrólise de ATP. Neste sentido, pacientes com hipertireoidismo apresentam significativa redução da massa corpórea (KIM, 2008). De fato, verificamos que os animais tratados com HT, por uma, duas e três semanas, apresentaram diminuição significativa da massa corporal observada ao término do tratamento. Além dos efeitos metabólicos, os HT também promovem efeitos significativos sobre o sistema cardiovascular. Desta forma, os efeitos do tratamento com T3 na modulação dos parâmetros hemodinâmicos, frequência cardíaca e pressão arterial sistólica, também foram avaliados.

A frequência cardíaca basal é determinada pela atividade intrínseca das células musculares cardíacas localizadas no nodo sino atrial e pelo sistema nervoso autônomo. Além do sistema nervoso simpático e parassimpático outros fatores, como hormônios, podem modular a atividade dessas células especializadas, através da regulação da expressão de proteínas que constituem canais iônicos (DILLMANN, 2002; MITTAG et al., 2010). O aumento da frequência cardíaca e aparente taquicardia observada em pacientes hipertireoideos são as principais manifestações dos efeitos eletrofisiológicos promovidos pelos HT. A partir da similaridade clínica observada entre os sintomas do hipertireoidismo e do excesso de catecolaminas, estudos demonstraram a existência de interação entre HT e inervação autonômica no coração (BURGGRAAF et al., 2001; CACCIATORI et al., 2000; CHEN et al., 2006; LEVEY; KLEIN, 1990). Embora os mecanismos moleculares a respeito desta interação não sejam completamente compreendidos, sabe-se que TR $\alpha 1$, um dos receptores dos HT, está envolvido com a modulação autonômica da frequência cardíaca em determinadas condições (MITTAG, 2010). Além disso, os HT promovem aumento da expressão de receptores adrenérgicos no coração, aumentando a sensibilidade do tecido cardíaco às catecolaminas (DILLMANN; GLOSS, 2002; FOX et al., 1985). Conforme observado no presente estudo, os animais tratados com T3 apresentaram aumento progressivo da frequência cardíaca, acompanhado do aumento da pressão arterial. Esses resultados corroboram com 
outros já obtidos pelo nosso grupo, mostrando que após a administração diária de T4 por uma semana, a pressão arterial sistólica (PAS) ainda não é alterada, mas acompanhada do aumento significativo da frequência cardíaca (ANJOS-RAMOS et al., 2006). Talvez a necessidade de períodos de tratamento mais longos para que alterações na PAS possam ser evidenciadas ocorram em função do efeito dos HT sobre a redução da resistência vascular sistêmica (RVS), a qual é classicamente descrita (KAHALY e DILLMANN, 2005; OJAMAA; BALKMAN; KLEIN, 1993; OJAMAA; KLEMPERER; KLEIN, 1996).

Paralelamente aos efeitos dos HT sobre os parâmetros hemodinâmicos, os quais, por si só, já podem promover aumento da massa muscular cardíaca, os HT agem sobre a transcrição e tradução de proteínas diretamente relacionadas à maquinaria estrutural e contrátil dos miócitos cardíacos. Conforme descrito por OJAMAA (2010), a caracterização dos efeitos exercidos pelos HT sobre a regulação da expressão gênica não é totalmente compreendida. No entanto, há evidências consistentes na literatura de que, além da regulação do mecanismo de transcrição mediada pelos receptores nucleares, os HT também participam de processos cuja sinalização é iniciada ainda no citoplasma (DAVIS; LEONARD; DAVIS, 2008). Assim, seja através de seus receptores nucleares ou, ainda, por meio de ações não-genômicas, os HT modulam vias intracelulares que sinalizam para o crescimento dos cardiomiócitos. A hipertrofia cardíaca resultante do tratamento com hormônio tireoidiano, aparentemente, encontra-se estabilizada ao término de 7 dias de tratamento. Isto, porque o grau de hipertrofia encontrado não difere entre os tempos de tratamento avaliados, em termos percentuais, e sugerem um tipo de hipertrofia cardíaca estabelecida.

No tecido cardíaco normal, a expressão de $\alpha-\mathrm{MHC}$ é predominante em comparação à de $\beta-M H C$, sendo que alterações no padrão de predominância dessas proteínas miofibrilares podem ser induzidas por variações na concentração de HT (MORKIN, 1993). A administração de T3 estimula a expressão do gene da $\alpha-M H C$, mas diminui a expressão do gene da $\beta-M H C$ (DILLMANN, 2010). Desta forma, a expressão gênica dessas proteínas tem sido utilizada como marcador molecular de hipertrofia cardíaca. No presente estudo, embora não tenha sido observado aumento da expressão gênica de $\alpha-M H C$, foi verificada diminuição significativa da expressão de $\beta-\mathrm{MHC}$ em todos os períodos. 


\subsection{Efeitos do hormônio tireoidiano sobre modulação do proteassoma cardíaco}

De maneira geral, a análise dos níveis de mRNA que codificam as subunidades do centro catalítico e da partícula regulatória do proteassoma cardíaco parecem ser modulados em função da progressão da hipertrofia cardíaca. Assim, a regulação positiva da expressão dessas subunidades, observada no grupo tratado por 7 dias, tende à normalização nos períodos mais prolongados de tratamento. Corroborando com esses resultados, foi observado aumento da atividade do proteassoma 265 e diminuição do $20 S$ no miocárdio hipertrofiado.

De acordo com as evidências descritas na literatura, a ativação do proteassoma cardíaco parece ser requerida para o desenvolvimento de uma resposta adaptativa aos diferentes estímulos hipertróficos (DEPRE et al., 2006). A princípio, a ideia de ativação de sistemas proteolíticos em resposta a estímulos hipertróficos parece ser contra intuitiva. $\mathrm{Na}$ tentativa de se justificar esta evidência, duas hipóteses foram aventadas, inicialmente. A primeira refere-se à necessidade da manutenção do pool de aminoácidos requeridos para a síntese proteica (VABULAS; HARTL, 2005). A segunda é a de que atrogenes, genes relacionados à atrofia, sejam alvos do proteassoma. Neste sentido, a ativação do proteassoma cardíaco resultaria no favorecimento da degradação de atrogenes, promovendo a hipertrofia.

No intuito de se esclarecer se a ativação do proteassoma cardíaco é causa ou consequência do processo hipertrófico, um estudo concluiu que o aumento da expressão e atividade do proteassoma cardíaco é requerido para o estabelecimento do processo hipertrófico. Foi verificado que camundongos submetidos ao modelo de sobrecarga de pressão crônica e tratados previamente com Epoxomicina, um inibidor do proteassoma, apresentaram completa prevenção do desenvolvimento da hipertrofia. Nesse estudo é sugerido que o aumento da expressão dessa via proteolítica seja necessário para a eliminação eficiente de proteínas danificadas. Outra hipótese sugerida é que o aumento da expressão das subunidades do proteassoma ocorra como um mecanismo compensatório à diminuição de sua fosforilação (DEPRE et al., 2006).

O tratamento de células com inibidores do proteassoma induz ao aumento transitório da expressão gênica das subunidades que constituem o proteassoma 26S. Ainda, concomitantemente à upregulation dos níveis de mRNA, ocorre aumento da expressão de 
POMP, necessária para a maturação do proteassoma. Esses resultados consistem em evidências primárias de que, em mamíferos, a expressão do proteassoma é regulada em nível transcricional. Sugere-se, assim, a existência de um mecanismo de retroalimentação negativa que compense a diminuição da atividade do proteassoma através do aumento de sua expressão gênica (MEINERS et al., 2003).

A diminuição da atividade do proteassoma tem sido demonstrada durante a progressão da disfunção cardíaca, enquanto que o aumento de sua atividade tem sido observado em modelos de hipertrofia cardíaca compensada (DREWS et al., 2007; DREWS et al., 2010). Recentemente, a caracterização do Sistema Ubiquitina Proteassoma em modelo de hipertrofia cardíaca gestacional demonstrou que, ao término do período gestacional, a atividade do proteassoma 265 apresenta-se diminuída, bem como o nível de proteínas poliubiquitinadas (IORGA, 2012). Esses resultados parecem contradizer as evidências descritas na literatura sobre a ativação do proteassoma na hipertrofia cardíaca compensada. No entanto, faz-se necessário esclarecer que a hipertrofia cardíaca do estudo referido foi avaliada tardiamente, ou seja, quando não existem perspectivas de progressão do quadro hipertrófico. Sabe-se que a hipertrofia cardíaca decorrente da sobrecarga de volume, imposta durante a gestação, não progride para insuficiência. Caracteriza-se pelo retorno do coração à sua morfologia normal quando no período pós-natal e, por isso, é considerada fisiológica. Conforme demostrado pelos autores, esses animais apresentaram aumento da massa cardíaca, comparado às ratas não gestantes. No entanto, a análise da razão entre a massa cardíaca e a massa corpórea, ao invés de aumento, se apresentou significativamente diminuída, sendo justificada pelo aumento pronunciado da massa corporal observado nessas fêmeas (DAY, 2013).

A análise da expressão, atividade e distribuição subcelular do proteassoma cardíaco em modelo de hipertrofia induzida pela overexpression de HSP22 evidenciou a ocorrência da redistribuição das subunidades localizadas no citosol para a periferia nuclear, acompanhada do aumento da atividade do proteassoma 20S. Segundo os autores, essa redistribuição perinuclear facilitaria a degradação das proteínas que transitam entre o núcleo e o citoplasma da célula (fatores de transcrição), além de promover a degradação de proteínas mal-enoveladas e denaturadas localizadas no retículo endoplasmático. Ainda, foi demostrado pela primeira vez que a inibição do proteassoma com Epoxomicina e Lactacistina foi capaz de reverter a hipertrofia cardíaca pré-estabelecida. Assim, foi 
concluído que o proteassoma cardíaco, certamente, desempenha importante papel no crescimento cardíaco em resposta a diferentes estímulos hipertróficos (HEDHLI et al., 2008).

Em modelo de hipertrofia cardíaca induzida pela administração de Isoproterenol, um simpatomimético, foi observado aumento das três atividades catalíticas conferidas ao proteassoma $26 \mathrm{~S}$ e diminuição da atividade do tipo tripsina e caspase conferidas ao proteassoma 20S. Neste sentido, dentre as conclusões sugeridas está que a modulação das diferentes subpopulações de proteassoma consiste em eventos independentes (DREWS et al., 2010).

A ausência de modulação observada no conteúdo de proteínas marcadas com ubiquitina sugere que o clearence de proteínas no tecido cardíaco não foi alterado em função do tratamento com hormônio tireoidiano. Conforme esperado, ensaios complementares quanto à marcação de agregados proteicos também não apresentaram diferença entre os grupos experimentais. Conforme demostrado, a hipertrofia cardíaca desenvolvida neste modelo consiste em uma hipertrofia caracteristicamente modesta, que apresenta aumento de massa próximo a 30\%. Como descrito previamente por outros grupos, secções de miócitos cardíacos de pacientes com cardiomiopatia severa apresentam acúmulo de intermediários tóxicos solúveis para a formação de agregados (HEIN et al., 2003).

\subsection{Efeitos do hormônio tireoidiano sobre a expressão de E3-ligases no tecido cardíaco}

Os efeitos promovidos pelos HT no músculo cardíaco diferem daqueles observados no músculo esquelético, uma vez que no estado de hipertireoidismo o coração hipertrofia, enquanto o músculo esquelético é acompanhado de fraqueza e perda de massa muscular, caracterizando atrofia (HASSELGREN et al., 1984). Embora a diminuição da síntese proteica contribua para o processo de atrofia do músculo esquelético na condição de hipertireoidismo, estudos sugerem que a degradação proteica, principalmente de miofibrilas, seja o principal mecanismo responsável pela atrofia observada (FLAIM; LI; JEFFERSON, 1978; MORRISON et al., 1988). O aumento da expressão dos componentes do UPS no músculo esquelético tem sido descrito em inúmeros modelos de catabolismo (GLASS, 2003; HASSELGREN et al., 2005). A expressão e atividade de E3-ligases, tais como MuRF1, Atrogin/MAFbx e E3- $\alpha$ /UBR1, encontram-se substancialmente elevadas (BODINE et al., 2001; 
GOMES et al., 2001). No entanto, de acordo com O'Neal e colaboradores (2009), ainda não se sabe se a modulação da expressão dessas enzimas resulta da ação direta ou indireta dos HT.

A hipertrofia cardíaca caracteriza-se, primariamente, pelo aumento de síntese proteica. Neste sentido, inúmeros estudos foram desenvolvidos no sentido de identificar e descrever as vias intracelulares envolvidas com a regulação do tamanho celular. No entanto, relativamente pouco se sabe a respeito dos mecanismos relacionados à degradação proteica. Recentemente, Willis e colaboradores (2007) demonstraram que na ausência de MuRF1 a resposta hipertrófica é exacerbada, ou seja, a expressão de MuRF1 é necessária para que a resposta hipertrófica seja adequada ao estímulo. Por outro lado, estudos de ganho de função demostraram que o aumento da expressão de MuRF1 previne o desenvolvimento da hipertrofia cardiomiocítica (ARYA; KEDAR; HWANG, 2004; WILLIS et al., 2007). Esses resultados, portanto, sugerem que, assim como o observado no músculo esquelético, MuRF1 regula negativamente o tamanho celular no músculo cardíaco.

No presente estudo foi demostrado que o tratamento com HT promoveu significativa diminuição dos níveis de mRNA que codificam MuRF1 nos animais tratados por 7 e 14 dias. Neste sentido, o estabelecimento da hipertrofia cardíaca induzida por HT pode ser decorrente da regulação negativa ou inibição de atrogenes, tais como MuRF1. O remodelamento cardíaco pós-infarto compreende o crescimento hipertrófico do coração, o qual apresenta características bem semelhantes aos observados em modelos de hipertrofia cardíaca fisiológica e promovida pelos HT. Assim, pacientes infartados também apresentam diminuição da expressão gênica de MuRF1, além do aumento da expressão de TNF- $\alpha$ e da fosforilação de Akt/PKB (CONRAADS et al., 2010). O TNF- $\alpha$ (tumor necrosis factor) corresponde a uma citocina pró-inflamatória cujo envolvimento com as doenças cardiovasculares tem se mostrado extremamente complexa. As respostas adaptativas ao TNF- $\alpha$ podem variar desde fisiológicas às patológicas (SATOH et al., 2006; SCHULZ; HEUSCH, 2009). Estudos demostraram que a expressão de TNF- $\alpha$ induz à ativação da Akt e contribui para o desenvolvimento do processo hipertrófico (CONDORELLI et al., 2002; DEPRE, 2006). Essas evidências corroboram com os resultados descritos no presente estudo.

Estudos tem demonstrado que, no tecido cardíaco, MuRF1 e Atrogin/MAFbx promovem seus efeitos anti-hipertróficos através da interação com vias de sinalização associadas ao crescimento celular. Em células musculares cardíacas e esqueléticas, a 
expressão de MuRF1 e Atrogin/MAFbx é regulada, em nível transcricional, por fatores de transcrição da família Forkead box O (FoxO) (NI et al., 2006; SANDRI et al., 2004). Os fatores de transcrição FoxO são alvos downstream da Akt/PKB. A Akt/PKB consiste em uma proteína quinase envolvida com a regulação da proliferação, crescimento e sobrevivência celular (MATSUI; NAGOSHI; ROSENZWEIG, 2003). A fosforilação de FoxO, mediada pela Akt, inibe sua translocação para o núcleo e, consequentemente, reprime a transcrição de atrogenes, ou seja, genes que promovem atrofia, como é o caso de MuRF1 e Atrogin/MAFbx. Assim, estudos sugerem que Akt/PKB promove o aumento de síntese proteica inibindo os efeitos anti-hipertróficos de MuRF1 e Atrogin/MAFbx via Foxo3a (CONRAADS et al., 2010; SKURK et al., 2005). Neste sentido, a diminuição da expressão gênica de MuRF1, observada no coração dos animais tratados com $\mathrm{HT}$, vai ao encontro dos resultados previamente obtidos pelo nosso grupo, nos quais foi demostrado que a ativação da Akt/PKB é altamente responsiva ao tratamento com HT e uma das vias responsáveis pela hipertrofia cardiomiocítica (DINIZ; CARNEIRO-RAMOS; BARRETO-CHAVES, 2009).

Por outro lado, estudos demostraram que Atrogin/MAFbx parece contrabalancear a ativação de vias pró-hipertróficas através da regulação negativa de proteínas-chave como é o caso da calcineurina. A calcineurina ou PP2B (protein phosphatase $2 B$ ) é uma fosfatase responsiva às concentrações intracelulares de cálcio/calmodulina. Desempenha importante função na resposta ao estresse cardíaco, sendo o fator de transcrição NFAT (nuclear factor of activated $T$ cells), o seu principal alvo. Em cardiomiócitos, a defosforilação do NFAT resulta em sua translocação para o núcleo e transcrição de genes fetais e crescimento hipertrófico (WILKINS, 2004). Atrogin/MAFbx promove a degradação da calcineurina mediada pelo UPS. A degradação de calcineurina, por sua vez, favorece a ação de proteínas quinases que ao promoverem a fosforilação do NFAT, impedem sua translocação para o núcleo e bloqueiam a sinalização que resultaria em hipertrofia (LI et al., 2004). Desta forma, Atrogin/MAFbx inibe a hipertrofia cardíaca em resposta a um estímulo patológico in vivo e in vitro (LI et al., 2004). Estudos do nosso grupo demostraram que animais submetidos ao hipertireoidismo experimental, por sua vez, modulam a via da calcineurina, promovendo o aumento de sua expressão gênica e proteica no coração de ratos. O níveis de mRNA que codificam a calcineurina apresentam-se significativamente aumentados após 24 horas de tratamento com T3, sendo este aumento não mais observado aos 7 dias de tratamento, embora sua expressão proteica ainda se encontre elevada neste período. Desta forma, parece que 
quando a hipertrofia cardíaca é estabelecida, ocorre a modulação negativa de vias próhipertróficas importantes para o estabelecimento da mesma. Além disso, foi demostrado que o bloqueio farmacológico da calcineurina foi capaz de prevenir o desenvolvimento da hipertrofia cardiomiocítica em cultura de células primárias tratadas com T3, inibindo o aumento da expressão gênica de ANF (dados não publicados).

Por outro lado, embora tenha sido demonstrado que muitas das proteínas sinalizadoras, relacionadas ao crescimento hipertrófico, podem inibir a transcrição de atrogenes, também foi demonstrado que atrogenes são capazes de modular vias de sinalização. Um dos mecanismos através dos quais Atrogin-1 inibe a hipertrofia cardíaca é através do bloqueio da via da Akt. Por meio de sua atividade de E3-ligase, Atrogin-1 promove a poliubiquitinação do resíduo Lys63 de proteínas da família Forkhead, Foxo 1 e Foxo3a, aumentando a transcrição dos seus genes-alvo (LI et al., 2007). No presente estudo, Atrogin1 parece não ser modulada para o desenvolvimento do fenótipo hipertrófico. 


\section{CONCLUSÃO}

A partir das evidências descritas na literatura, verificamos que o fenótipo hipertrófico é determinado por um complexo de vias intracelulares, cuja ativação e desativação dependem, a princípio, da disponibilidade de proteínas-chave no meio intracelular. Atualmente, outros mecanismos de controle da expressão de proteínas, além de sua regulação transcricional, têm sido explorados. Neste sentido, o Sistema UbiquitinaProteassoma, em se tratando do principal mecanismo de proteólise intracelular, desempenha importância crítica na regulação negativa da expressão dessas proteínas, exercendo controle sobre eventos celulares e respostas adaptativas às condições adversas. Demonstrou-se, no presente estudo, que a hipertrofia cardíaca induzida por HT é acompanhada da modulação de enzimas ubiquitinas-ligases que, efetivamente, interferem na sinalização dos HT para o estabelecimento da hipertrofia. Os resultados referentes à expressão de MuRF1, particularmente, parecem ser mais consistentes e de grande importância para o estabelecimento do fenótipo hipertrófico. Desta forma, a investigação dos mecanismos moleculares e interação de MuRF1 com as vias intracelulares, que sabidamente são alvo dos HT, necessitam ser mais bem explorados. O entendimento da regulação do UPS frente a diferentes estímulos hipertróficos tem se mostrado de grande complexidade e, por vezes, incoerente na literatura. A princípio, a upregulation do proteassoma cardíaco, observado na hipertrofia compensada, parece estar diretamente relacionado ao aumento da síntese proteica. Estudos sugerem que este aumento seja uma tentativa de manter a qualidade das proteínas sintetizadas ou, ainda, manter o pool de aminoácidos necessários para síntese. A avaliação do proteassoma cardíaco ao longo de 3 semanas de tratamento com HT permite sugerir que esse sistema é ativado em fases agudas, verificado através do aumento da atividade do proteassoma $26 \mathrm{~S}$ e da expressão de suas subunidades estruturais. Quando a hipertrofia cardíaca encontra-se estabelecida, essa regulação positiva parece tender à normalização.

Por fim, através da abordagem de diferentes aspectos do UPS, contemplando enzimas relacionadas ao processo de ubiquitinação e proteólise, o presente estudo pôde contribuir para o melhor entendimento da relação entre UPS e hipertrofia cardíaca. 


\section{REFERÊNCIAS*}

ANJOS-RAMOS, L.; CARNEIRO-RAMOS, M. S.; DINIZ, G. P.; MARTINS-SILVA, J.; BARRETOCHAVES, M. L. Early cardiac hypertrophy induced by thyroxin is accompanied by an increase in VEGF-A expression but not by an increase in capillary density. Virchows Archiv, v. 448, $n$. 4, p. 472-479, 2006.

ARAUJO, A. S.; DINIZ, G. P.; SEIBEL, F. E.; BRANCHINI, G.; RIBEIRO, M. F.; BRUM, I. S.; KHAPER, N.; BARRETO-CHAVES, M. L.; BELLÓ-KLEIN, A. Reactive oxygen and nitrogen species balance in the determination of thyroid hormones-induced cardiac hypertrophy mediated by reninangiotensin system. Molecular and Cellular Endocrinology, v. 333, n. 1, p. 78-84, 2011.

ARYA, R.; KEDAR, V.; HWANG, J. R.; MCDONOUGH, H.; LI, H. H.; TAYLOR, J.; PATTERSON, C. Muscle ring finger protein-1 inhibits PKC\{epsilon\} activation and prevents cardiomyocyte hypertrophy. The Journal of Cell Biology, v. 167, p. 1147-1159, 2004.

BERGH, J. J.; LIN, H. Y.; LANSING, L.; MOHAMED, S. N.; DAVIS, F. B.; MOUSA, S.; DAVIS, P. J. Integrin alphaVbeta3 contains a cell surface receptor site for thyroid hormone that is linked to activation of mitogen-activated protein kinase and induction of angiogenesis. Endocrinology, v. 146, n. 7, p. 2864-2871, 2005.

BERNARDO, B. C.; WEEKS, K. L.; PRETORIUS, L.; MCMULLEN, J. R. Molecular distinction between physiological and pathological cardiac hypertrophy: experimental findings and therapeutic strategies. Pharmacololy and Therapeutics, v. 128, n. 1, p. 191-227, 2010.

BRADFORD, M. M. A rapid and sensitive method for the quantitation of microgram quantities of protein utilizing the principle of protein-dye binding. Analytical Biochemistry, v. 72, p. $248-254,1976$.

BOCCALANDRO, C.; BOCCALANDRO, F.; ORLANDER, P.; WEI, C. F. Severe reversible dilated cardiomyopathy and hyperthyroidism: case report and review of the literature. Endocrine Practice, v. 9, n. 2, p. 140-146, 2003.

BODINE, S. C.; LATRES, E.; BAUMHUETER, S.; LAI, V. K.; NUNEZ, L.; CLARKE, B. A.; POUEYMIROU, W. T.; PANARO, F. J.; NA, E.; DHARMARAJAN, K.; PAN, Z. Q.; VALENZUELA, D. M.; DECHIARA, T. M.; STITT, T. N.; YANCOPOULOS, G. D.; GLASS, D. J. Identification of ubiquitin ligases required for skeletal muscle atrophy. Science, v. 294, p. 1704-1708, 2001.

BOHELER, K. R.; SCHWARTZ, K. Gene expression in cardiac hypertrophy. Trends in Cardiovascular Medicine, v. 2, p. 176-182, 1992.

\footnotetext{
* De acordo com:

ASSOCIAÇÃO BRASILEIRA DE NORMAS TÉCNICAS. NBR 6023: informação e documentação: referências: elaboração. Rio de Janeiro, 2002.
} 
BURGGRAAF, J.; TULEN, J. H.; LALEZARI, S.; SCHOEMAKER, R. C.; DE MEYER, P. H.; MEINDERS, A. E.; COHEN, A. F.; PIJL, H. Sympathovagal imbalance in hyperthyroidism. American Journal of Physiology. Endocrinology and Metabolism, v. 281, p. 190-195, 2001.

BURRI, L.; HÖCKENDORFF, J.; BOEHM, U.; KLAMP, T.; DOHMEN, R. J.; LÉVY, F. Identification and characterization of a mammalian protein interacting with $20 \mathrm{~S}$ proteasome precursors. Procedings of the National Academy of Sciences, v. 97 n. 19, p. 10348-10353, 2000.

BYERS, S. O; ROSENMAN, R. H.; FRIEDMAN, M.; BIGGS, M. W. Rate of cholesterol synthesis in hypo and hyperthyroidism rats. The Journal of Experimental Medicine, v. 96, n. 5, p. 513516, 1952.

CACCIATORI, V.; GEMMA, M. L.; BELLAVERE, F.; CASTELLO, R.; DE GREGORI, M. E.; ZOPPINI, G.; THOMASETH, K.; MOGHETTI, P.; MUGGEO, M. Power spectral analysis of heart rate in hypothyroidism. European Journal of Endocrinology, v. 143, p. 327-333, 2000.

CANARIS, G. J.; MANOWITZ, N. R.; MAYOR, G.; RIDGWAY, E. C. The Colorado thyroid disease prevalence study. Archives of International Medicine, v. 160, n. 4, p. 526-534, 2000.

CARNEIRO-RAMOS, M. S.; DINIZ, G. P.; NADU, A. P.; ALMEIDA, J.; VIEIRA, R. L. P.; SANTOS, R. A. S.; BARRETO-CHAVES, M. L. M. Blockage of Angiotensin II type 2 receptor prevents thyroxine-mediated cardiac hypertrophy by blocking Akt activation. Basic Research in. Cardiology, v. 105, n. 3, p. 325-335, 2010.

CARNEIRO-RAMOS, M. S.; SILVA, V. B.; SANTOS, R. A.; BARRETO-CHAVES, M. L. Tissuespecific modulation of angiotensin-converting enzyme (ACE) in hyperthyroidism. Peptides, v. 27, n. 11, p. 2942-2949, 2006.

CHEN, J. L.; CHIU, H. W.; TSENG, Y. J.; CHU, W. C. Hyperthyroidism is characterized by both increased sympathetic and decreased vagal modulation of heart rate: evidence from spectral analysis of heart rate variability. Clinical Endocrinology, v. 64, p. 611-616, 2006.

CLAVEL, S.; COLDEFY, A. S.; KURKDJIAN, E.; SALLES, J.; MARGARITIS, I.; DERIJARD, B. Atrophyrelated ubiquitin ligases, atrogin-1 and MuRF1 are up-regulated in aged rat tibia's anterior muscle. Mechanisms of Ageing and Development, v. 127, n. 10, p. 794-801, 2006.

CONDORELLI, G.; MORISCO, C.; LATRONICO, M. V.; CLAUDIO, P. P.; DENT, P.; TSICHLIS, P.; FRATI, G.; DRUSCO, A.; CROCE, C. M.; NAPOLI, C. TNF-alpha signal transduction in rat neonatal cardiac myocytes: definition of pathways generating from the TNF-alpha receptor. The FASEB Journal, v. 16, p. 1732-1737, 2002.

CONRAADS, V. M.; VRINTS, C. J.; RODRIGUS, I. E.; HOYMANS, V. Y.; VAN CRAENENBROECK, E. M.; BOSMANS, J.; CLAEYS, M. J.; VAN HERCK, P.; LINKE, A.; SCHULER, G.; ADAMS, V. Depressed expression of MuRF1 and MAFbx in areas remote of recent myocardial infarction: a mechanism contributing to myocardial remodeling? Basic Research in Cardiolology, v. 105, p. 219-226, 2010. 
COUX, O., TANAKA, K., GOLDBERG, A. L. Structure and functions of the $20 \mathrm{~S}$ and $26 \mathrm{~S}$ proteasomes. Annual Review in Biochemistry, v. 65, p. 801-47, 1996.

DALLE-DONNE, I.; ALDINI, G.; CARINI, M.; COLOMBO, R.; ROSSI, R.; MILZANI A. Protein carbonylation, cellular dysfunction, and disease progression. Journal of Cellular and Molecular Medicine, v. 10, n. 2, p. 389-406, 2006.

DALLE-DONNE, I.; ROSSI, R.; GIUSTARINI, D.; MILZANI, A.; COLOMBO, R. Protein carbonyl groups as biomarkers of oxidative stress. Clinica Chimica Acta, v. 329, n. 1-2, p. 23-38, 2003.

DAVIS, P. J.; LEONARD, J. L.; DAVIS, F. B. Mechanisms of nongenomic actions of thyroid hormone. Frontiers in Neuroendocrinology, v. 29, n. 2, p. 211-218, 2008.

DAVIS, P. J.; DAVIS, F. B. Nongenomic actions of thyroid hormone on the heart. Thyroid, v. 12, n. 6, p. 459-66, 2002.

DAY, S. M. The ubiquitin proteasome system in human cardiomyopathies and heart failure. Heart and Circulatory Physiology: American Journal of Physiology, 2013

DEPRE, C.; WANG, Q.; YAN, L.; HEDHLI, N.; PETER, P.; CHEN, L.; HONG, C.; HITTINGER, L.; GHALEH, B.; SADOSHIMA, J.; VATNER, D. E.; VATNER, S. F.; MADURA, K. Activation of the cardiac proteasome during pressure overload promotes ventricular hypertrophy. Circulation, v. 114, n. 17, p. 1821-1828, 2006.

DIEKMAN, M. J.; HARMS, M. P.; ENDERT, E.; WIELING, W.; WIERSINGA, W. M. Endocrine factors related to changes in total peripheral vascular resistance after treatment of thyrotoxic and hypothyroid patients. European Journal of Endocrinology, v. 144, p. 339-346, 2001.

DILLMANN, W. H. Cardiac hypertrophy and thyroid hormone signaling. Heart Failure Reviews, v. 15, n. 2, p. 125-132, 2010.

DILLMANN, W. H. Cellular action of thyroid hormone on the heart. Thyroid, v. 12, n. 6, p. 447-452, 2002.

DILLMANN, W. H.; GLOSS, B. R. The role of thyroid hormone receptors in the heart. Methods in Molecular Biology, v. 202, p. 55-70, 2002.

DINIZ, G. P.; CARNEIRO-RAMOS, M. S.; BARRETO-CHAVES, M. L. M. Angiotensin type 1 receptor mediates thyroid hormone-induced cardiomyocyte hypertrophy through the Akt/GSK-3b/mTOR signaling pathway. Basic Research in Cardiology, v. 104, n. 6, p. 653-667, 2009.

DORN, G. W. The fuzzy logic of physiological cardiac hypertrophy. Hypertension, v. 49, n. 5, p. 962-970, 2007. 
DREWS, O.; WILDGRUBER, R.; ZONG, C.; SUKOP, U.; NISSUM, M.; WEBER, G.; GOMES, A.V.; PING, P. Mammalian proteasome subpopulations with distinct molecular compositions and proteolytic activities. Molecular and Cellular Proteomics, v. 6, n. 11, p. 2021-2031, 2007.

DREWS, O.; TSUKAMOTO, O.; LIEM, D.; STREICHER, J.; WANG, Y.; PING, P. Differential regulation of proteasome function in isoproterenol-induced cardiac hypertrophy. Circulation Research, v. 107, n. 9, p. 1094-1101, 2010.

ETLINGER, J. D.; GOLDBERG, A. L. A soluble ATP-dependent proteolytic system responsible for the degradation of abnormal proteins in reticulocytes. Proceedings of the National Academy of Sciences, v. 74, p. 54-58, 1977.

FLAIM, K. E.; LI, J. B.; JEFFERSON, L. S. Effects of thyroxine on protein turnover in rat skeletal muscle. American Journal of Physiology, v. 235, p. 231-236, 1978.

FOLETTA, V.; WHITE, L.; LARSEN, A.; LÉGER, B.; RUSSELL, A. The role and regulation of MAFbx/atrogin-1 and MuRF1 in skeletal muscle atrophy. Pflügers Archiv - European Journal of Physiology, v. 461, p. 325-335, 2011.

FOX, A. W.; JUBERG, E. N.; MAY, J. M.; JOHNSON, R. D.; ABEL, P. W.; MINNEMAN, K. P. Thyroid Status and Adrenergic Receptor Subtypes in the Rat: Comparison of Receptor Density and Responsiveness. The Journal of Pharmacology and Experimental Therapeutics, v. 235, n. 3, p. 715-723, 1985.

GLASS, D. J. Molecular mechanisms modulating muscle mass. Trends in Molecular Medicine, v. 9, p. 344-350, 2003.

GLASS, D. J. Signalling pathways that mediates skeletal muscle atrophy and hypertrophy. Nature Cell Biology, v. 5, p. 87-90, 2003.

GLICKMAN, M. H.; CIECHANOVER, A. The ubiquitin-proteasome proteolytic pathway: destruction for the sake of construction. Physiological Review, v. 82, p. 373-428, 2002.

GOMES, M. D.; LECKER, S. H.; JAGOE, R. T.; NAVON, A.; GOLDBERG, A. L. Atrogin-1, a musclespecific F-box protein highly expressed during muscle atrophy. Proceedings of the Natural. Academy of Sciences, v. 98, n. 25, p. 14440-14445, 2001.

GREDILLA, R.; BARJA, G.; LOPEZ-TORRES, M. Thyroid hormone-induced oxidative damage on lipids, glutathione and DNA in mouse hearts. Free Radical Research, v. 35, p. 417-425, 2001.

GUERRERO, A.; PAMPLONA, R.; PORTERO-OTIN, M.; BARJA, G.; LOPEZ-TORRES, M. Effect of thyroid status on lipid composition and peroxidation in the mouse liver. Free Radical Biology and Medicine, v. 26, p. 73-80, 1999. 
HASSELGREN, P. O.; ADLERBERTH, A.; ANGERAS, U.; STENSTROM, G. Protein metabolism in skeletal muscle tissue from hyperthyroid patients after preoperative treatment with antithyroid drug or selective $\beta$-blocking agent. Results from a prospective, randomized study. The Journal of Clinical Endocrinology and Metabolism, v. 59, p. 835-839, 1984.

HASSELGREN, P. O.; MENCONI, M. J.; FAREED, M. U.; YANG, H.; WEI, W.; EVENSON, A. R. Novel aspects on the regulation of muscle wasting in sepsis. The International Journal of Biochemistry.and Cell Biology, v. 37, p. 2156-2168, 2005.

HEDHLI, N.; DEPRE, C. Proteasome inhibitors and cardiac cell growth. Cardiovascular Research, v. 85, p. 321-329, 2010.

HEDHLI, N.; PELAT, M.; DEPRE, C. Protein turnover in cardiac cell growth and survival. Cardiovascular Research, v. 68, p. 186-196, 2005.

HEDHLI, N.; WANG, L.; WANG, Q.; RASHED, E.; TIAN, Y.; SUI, X.; MADURA, K.; DEPRE, C. Proteasome activation during cardiac hypertrophy by the chaperone H11 Kinase/Hsp22. Cardiovascuar Research, v. 7, n. 3, p. 497-505, 2008.

HEIN, S.; ARNON, E.; KOSTIN, S.; SCHÖNBURG, M.; ELSÄSSER, A.; POLYAKOVA, V.; BAUER, E.P.; KLÖVEKORN, W. P.; SCHAPER, J. Progression from compensated hypertrophy to failure in the pressure-overloaded human heart: structural deterioration and compensatory mechanisms. Circulation, v. 107, n.7, p. 984-991, 2003.

HERSHKO, A. Lessons from the discovery of the ubiquitin system. Trends in Biochemical Sciences, v. 21, p. 445-449, 1996.

HIROI, Y.; KIM, H. H.; YING, H.; FURUYA, F.; HUANG, Z.; SIMONCINI, T.; NOMA, K.; UEKI, K.; NGUYEN, N. H.; SCANLAN, T. S.; MOSKOWITZ, M. A.; CHENG, S. Y.; LIAO, J. K. Rapid nongenomic actions of thyroid hormone. Proceedings of the National Academy Sciences, $\mathrm{v}$. 103, n. 38, p. 14104-14109, 2006.

HU, L. W.; BENVENUTI, L. A.; LIBERTI, E. A.; CARNEIRO-RAMOS, M. S.; BARRETO-CHAVES, M. L. M. Thyroxine-induced cardiac hypertrophy: influence of adrenergic nervous system versus rennin-angiotensin system on myocyte remodeling. American Journal of Physiology Regulatory, Integrative and Comparative Physiology, v. 285, p. 1473-1480, 2003.

IORGA, A.; DEWEY, S.; PARTOW-NAVID, R.; GOMES, A. V.; EGHBALI, M. Pregnancy is associated with decreased cardiac proteasome activity and oxidative stress in mice. PloS One, v. 7, n. 11, 2012.

JENTSCH, S. The ubiquitin-conjugation system. Annual Review of Genetics, v. 26, p. 179-207, 1992.

KAHALY, G. J.; DILLMANN, W. H. Thyroid hormone action in the heart. Endocrine Reviews, v. 26, n. 5, p. 704-728, 2005. 
KENESSEY, A.; OJAMAA, K. Thyroid hormone stimulates protein synthesis in the cardiomyocyte by activating the Akt-mTOR and p70S6K pathways. The Journal of Biological Chemistry, v. 281, n. 30, p. 20666-20672, 2006.

$\mathrm{KIM}, \mathrm{B}$. Thyroid hormone as a determinant of energy expenditure and the basal metabolic rate. Thyroid, v. 18, n. 2, p. 141-144, 2008.

KLEIN, I.; OJAMAA, K. Thyroid hormone and the cardiovascular system. The New England Journal of Medicine, v. 344, n. 7, p. 501-509, 2001.

LECKER, S. H.; JAGOE, R. T.; GILBERT, A.; GOMES, M.; BARACOS, V.; BAILEY, J.; PRICE, S. R.; MITCH, W. E.; GOLDBERG, A. L. Multiple types of skeletal muscle atrophy involve a common program of changes in gene expression. FASEB Journal, v. 18, n. 1, p. 39-51, 2004.

LEVEY, G. S.; KLEIN, I. Catecholamine-thyroid hormone interactions and the cardiovascular manifestations of hyperthyroidism. American Journal of Medicine, v. 88, p. 642-646, 1990.

LEVINE, J. A.; NYGREN, J.; SHORT, K. R.; NAIR, K. S. Effect of hyperthyroidism on spontaneous physical activity and energy expenditure in rats. Journal of Applied Physiology, v. 94, n. 1, p. 165-170, 2003.

LI, H. H.; KEDAR, V.; ZHANG, C.; MCDONOUGH, H.; ARYA, R.; WANG, D. Z.; PATTERSON, C. Atrogin-1/muscle atrophy F-box inhibits calcineurin-dependent cardiac hypertrophy by participating in an SCF ubiquitin ligase complex. The Journal of Clinical Investigation, v. 114, n. 8, p. 1058-1071, 2004.

LI, H. H.; WILLIS, M. S.; LOCKYER, P.; MILLER, N.; MCDONOUGH, H.; GLASS,D. J.; PATTERSON, C. Atrogin-1 inhibits Akt-dependent cardiac hypertrophy in mice via ubiquitin-dependent coactivation of Forkhead proteins. The Journal of Clinical Investigation, v. 117, n. 11, p. 3211-3223, 2007.

LOPEZ-TORRES, M.; ROMERO, M.; BARJA, G. Effect of thyroid hormones on mitochondria oxygen free radical production and DNA oxidative damage in the rat heart. Molecular and Cellular Endocrinology, v. 168, p. 127-134, 2000.

MATSUI, T.; NAGOSHI, T.; ROSENZWEIG, A. Akt and PI3-kinase signaling in cardiomyocyte hypertrophy and survival. Cell Cycle, v. 2, p. 220-223, 2003.

MEARINI, G.; SCHLOSSAREK, S.; WILLIS, M. S.; CARRIER, L. The ubiquitin-proteasome system in cardiac dysfunction. Biochimica et Biophysica Acta, v. 1782, p. 749-763, 2008.

MEINERS, S.; HEYKEN, D.; WELLER, A.; LUDWIG, A.; STANGL, K.; KLOETZEL, P. M.; KRÜGER, E. Inhibition of proteasome activity induces concerted expression of proteasome genes and de novo formation of Mammalian proteasomes. The Journal of Biological Chemistry, v. 278, n.24, p. 21517-21525, 2003. 
MILL, J. G.; VASSALO, D. V. Hipertrofia cardíaca. Revista Brasileira de Hipertensão, v. 8, p. 63-75, 2001.

MITTAG, J.; DAVIS, B.; VUJOVIC, M.; ARNER, A.; VENNSTROM, B. Adaptations of the autonomous nervous system controlling heart rate are impaired by a mutant thyroid hormone receptor-alpha1. Endocrinology, v. 151, p. 2388-2395, 2010.

MORGAN, H. E.; BAKER, K. M. Cardiac hypertrophy. Mechanical, neural, and endocrine dependence. Circulation, v. 83, n. 1, p. 13-25, 1991.

MORKIN E. Regulation of myosin heavy chain genes in the heart. Circulation, v. 87, n. 5, p. 1451-1460, 1993.

MORRISON, W. L.; GIBSON, J. N.; JUNG, R. T.; RENNIE. M. J. Skeletal muscle and whole body protein turnover in thyroid disease. European Journal of Clinical Investigation, v. 18, p. 6268, 1988.

NI, Y. G.; BERENJI, K.; WANG, N.; OH, M.; SACHAN, N.; DEY, A.; CHENG, J.; LU, G.; MORRIS, D. J.; CASTRILLON, D. H.; GERARD, R. D.; ROTHERMEL, B. A.; HILL, J. A. Foxo transcription factors blunt cardiac hypertrophy by inhibiting calcineurin signaling. Circulation, v. 114, n. 11, p. 1159-1168, 2006.

OJAMAA, K. Signaling mechanisms in thyroid hormone-induced cardiac hypertrophy. Vascular Pharmacology, v. 52, p. 113-119, 2010.

OJAMAA, K.; KLEIN, I. In vivo regulation of recombinant cardiac myosin heavy chain gene expression by thyroid hormone. Endocrinology, v. 132, p. 1002-1006, 1993.

OJAMAA, K.; KLEMPERER, J.; KLEIN, I. Acute effects of thyroid hormone on vascular smooth muscle. Thyroid, v. 6, p. 505-512, 1996.

OJAMAA, K.; BALKMAN, C.; KLEIN, I. L. Acute effects of triiodothyronine on arterial smooth muscle cells. The Annals of Thoracic Surgery, v. 56, p. 61-67, 1993.

O'NEAL, P.; ALAMDARI, N.; SMITH, I.; POYLIN, V.; MENCONI, M.; HASSELGREN, P. O. Experimental hyperthyroidism in rats increases the expression of the Ubiquitin Ligases Atrogin-1 and MuRF1 and stimulates multiple proteolytic pathways in skeletal muscle. Journal of Cellular and Biochemistry, v. 108, n. 4, p. 963-973, 2009.

POPESCU, L. M.; GHERGHICEANU, M.; HINESCU, M. E.; CRETOIU, D.; CEAFALAN, L.; REGALIA, T.; POPESCU, A. C.; ARDELEANU, C.; MANDACHE, E. Insights into the interstitium of ventricular myocardium: interstitial Cajal-like cells (ICLC). Journal of Cellular and Molecular Medicine, v. 10, n. 2, p. 429-458, 2006.

RAMOS, P. C.; HÖCKENDORFF, J.; JOHNSON, E. S.; VARSHAVSKY, A.; DOHMEN, R. J. Ump1p is required for proper maturation of the $20 \mathrm{~S}$ proteasome and becomes its substrate upon completion of the assembly. Cell, v. 92, n. 4, p. 489-499, 1998. 
RUSSELL, B.; MOTLAGH, D.; ASHLEY, W. W. Form follows function: how muscle shape is regulated by work. Journal of Applied Physiology, v. 88, p. 1127-1132, 2000.

SANDRI, M.; SANDRI, C.; GILBERT, A.; SKURK, C.; CALABRIA, E.; PICARD, A.; WALSH, K.; SCHIAFFINO, S.; LECKER, S. H.; GOLDBERG, A. L. Foxo transcription factors induce the atrophy-related ubiquitin ligase atrogin-1 and cause skeletal muscle atrophy. Cell, v. 117, n. 3, p. 399-412, 2004.

SATOH, M.; NAKAMURA, M.; AKATSU, T.; SHIMODA, Y.; SEGAWA, I.; HIRAMORI, K. C-reactive protein co-expresses with tumor necrosis factor-alpha in the myocardium in human dilated cardiomyopathy. European Journal of Heart Failure, v. 7, p. 748-754, 2006.

SCHUBERT, U.; ANTON, L. C.; GIBBS, J.; NORBURY, C. C.; YEWDELL, J. W.; BENNINK, J. R. Rapid degradation of a large fraction of newly synthesized proteins by proteasomes. Nature, $v$. 404, p. 770-774, 2000.

SCHULZ, R.; HEUSCH, G. Tumor necrosis factor-alpha and its receptors 1 and 2: Yin and Yang in myocardial infarction? Circulation, v. 119, p. 1355-1357, 2009.

SIU, C. W.; YEUNG, C. Y.; LAU, C. P.; KUNG, A. W.; TSE, H. F. Incidence, clinical characteristics and outcome of congestive heart failure as the initial presentation in patients with primary hyperthyroidism. Heart (British Cardiac Society), v. 3, n. 4, p.483-487, 2007.

SKURK, C.; IZUMIYA, Y.; MAATZ, H.; RAZEGHI, P.; SHIOJIMA, I.; SANDRI, M.; SATO, K.; ZENG, L.; SCHIEKOFER, S.; PIMENTEL, D.; LECKER, S.; TAEGTMEYER, H.; GOLDBERG, A. L.; WALSH, K. The FOXO3a transcription factor regulates cardiac myocyte size downstream of AKT signaling. The Journal of Biological Chemistry, v. 280, n. 21, p. 20814-20823, 2005.

SOROKIN, A. V.; KIM, E. R.; OVCHINNIKOV, L. P. Proteasome System of Protein Degradation and Processing. Biochemistry, v. 74, p. 1411-1442, 2009.

SPONITZ, H. M.; SONNENBLICK, E. H. Structural conditions in the hypertrophied and failing heart. International Journal of Cardiology, v. 32, p. 398-406, 1973.

SUGDEN, P. H.; CLERK, A. Cellular mechanisms of cardiac hypertrophy. Journal of Molecular Medicine, v. 76, p. 725-746, 1998.

TSUKAMOTO, O.; MINAMINO, T.; KITAKAZE, M. Functional alterations of cardiac proteasomes under physiological and pathological conditions. Cardiovascular Research, v. 85, p. 339-346, 2010.

VABULAS, R.; HARTL, F. Protein synthesis upon acute nutrient restriction relies on proteasome function. Science, v. 310, p. 1960-1963, 2005.

VAKILI, B. A.; OKIN, P. M.; DEVEREUX, R. B. Prognostic implications of left ventricular hypertrophy. American Heart Journal, v. 141, n. 3, p. 334-341, 2001. 
VENDITTI, P.; DI MEO, S. Thyroid hormone-induces oxidative stress. Cellular and Molecular Life Sciences, v. 63, p. 414-434, 2006.

WANG, X.; LI, J.; ZHENG, H.; SU, H.; POWELL, S. Proteasome functional insufficiency in cardiac pathogenesis. American and Circulatory Physiology: American Journal of Physiology, v. 301, n. 6, p. 2207-2219, 2011.

WEBER, K. T.; BRILLA, C. G. Pathological hypertrophy and cardiac interstitium. Fibrosis and renin-angiotensin-aldosterone system. Circulation, v. 83, n. 6, p. 1849-1865, 1991.

WILKINS, B. J. Calcineurin/NFAT coupling participates in pathological, but not physiological, cardiac hypertrophy. Circulation Research, v. 94, p. 110-118, 2004.

WILKINSON, K. D. Ubiquitination and deubiquitination: targeting of proteins for degradation by the proteasome. Seminars in Cell and Developmental Biology, v. 11, n. 3, p. 141-148, 2000.

WILLIS, M. S.; ZUNGU, M.; PATTERSON, C. Cardiac Muscle Ring Finger-1 - Friend or Foe? Trends in Cardiovascular Medicine, v. 20, n. 1, p. 12-16, 2010.

WILLIS, M. S.; IKE, C.; LI, L.; WANG, D. Z.; GLASS, D. J.; PATTERSON, C. Muscle Ring Finger 1, but not Muscle Ringer Finger 2, regulates cardiac hypertrophy in vivo. Circulation Research, v. 100, n. 4, p. 456-459, 2007.

WITT, E.; ZANTOPF, D.; SCHMIDT, M.; KRAFT, R.; KLOETZEL, P. M.; KRÜGER, E. Characterization of the newly identified human Ump1 homologue POMP and analysis of LMP7 (beta $5 \mathrm{i}$ ) incorporation into $20 \mathrm{~S}$ proteasomes. Journal of Molecular Biology, v. 301, n. 1, p. 1-9, 2000.

YU, X.; PATTERSON, E.; KEM, D. C. Targeting proteasomes for cardioprotection. Current Opinion in Pharmacology, v. 9, p. 167-172, 2009.

ZENG, Y.; WANG, H. X.; GUO, S. B.; YANG, H.; ZENG, X. J.; FANG, Q.; TANG, C. S.; DU, J.; LI, H. $H$. Transcriptional effects of E3 ligase atrogin-1/MAFbx on apoptosis, hypertrophy and inflammation in neonatal rat cardiomyocytes. PLoS One, v. 8, n. 1, 2013.

ZHANG, J.; LAZAR, M. A. The mechanism of action of thyroid hormones. Annual Review of Physiology, v. 62, p. 439-466, 2000. 